\begin{tabular}{|c|c|c|c|}
\hline Report Title: & \multicolumn{3}{|c|}{$\begin{array}{c}\text { Application of Reservoir Characterization and Advanced Technology } \\
\text { to Improve Recovery and Economics in a Lower Quality Shallow Shelf } \\
\text { San Andres Reservoir }\end{array}$} \\
\hline Report Type: & ANNUAL & Reporting Period Start Date: 08/03/1 & 998 End Date: 08/02/2000 \\
\hline Principal Author(s): & \multicolumn{3}{|c|}{$\begin{array}{l}\text { T. Scott Hickman } \\
\text { James J. Justice }\end{array}$} \\
\hline Report Issue Date: & $01 / 09 / 2002$ & DOE Award No:: DE- FC22 & $-94 B C 14990$ \\
\hline \multirow[t]{3}{*}{$\begin{array}{l}\text { Submitting } \\
\text { Organization(s) } \\
\text { Name \& Address }\end{array}$} & \multicolumn{2}{|c|}{$\begin{array}{l}\text { OXY USA Inc. } \\
\text { P. O. Box } 50250 \\
\text { Midland, TX } 79710-0250\end{array}$} & (1) \\
\hline & \multicolumn{2}{|c|}{$\begin{array}{l}\text { T. Scott Hickman \& Associates, Inc. } \\
505 \text { N. Big Spring, Ste } 105 \\
\text { Midland, TX } 79701\end{array}$} & (2) \\
\hline & \multicolumn{2}{|c|}{$\begin{array}{l}\text { Advanced Reservoir Technologies } \\
\text { P. O. Box } 985 \\
\text { Addison, TX 75001-0985 }\end{array}$} & (3) \\
\hline
\end{tabular}

(4) 


\title{
APPLICATION OF RESERVOIR CHARACTERIZATION AND ADVANCED TECHNOLOGY TO IMPROVE RECOVERY AND ECONOMICS \\ IN A LOWER QUALITY SHALLOW SHELF CARBONATE RESERVOIR
}

Cooperative Agreement No. DE-FC22-94BC14990

\author{
Prepared by \\ OXY USA, Inc. \\ Midland, Texas
}

January 9, 2002

\author{
Award Date: August 3, 1994 \\ Anticipated Completion Date: September 30, 2001 \\ Government Award for Current Fiscal Year: 1999 - \$753,163 \\ $2000-\$ 1,754,320$ \\ Principal Investigator: Rebecca Egg (OXY) \\ Project Manager: Gary Walker, Bartlesville Project Office
}

Reporting Period: August 3, 1998 - August 2, 2000 


\section{TABLE OF CONTENTS}

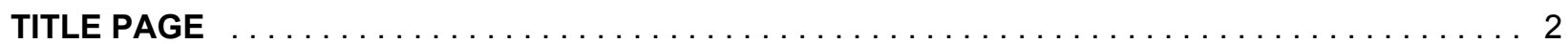

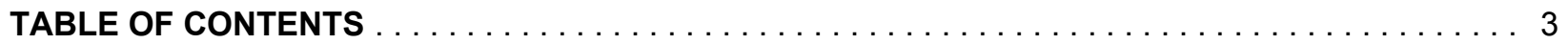

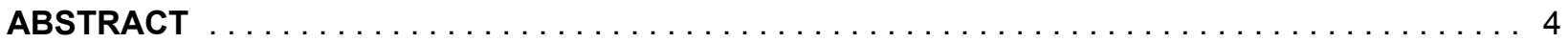

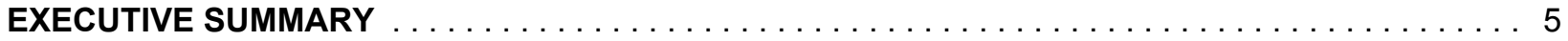

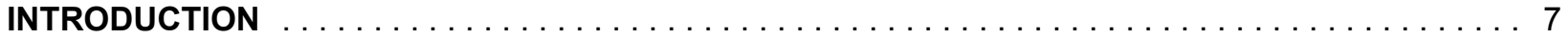

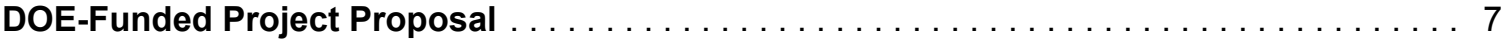

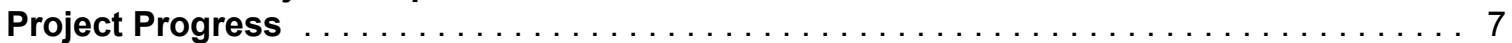

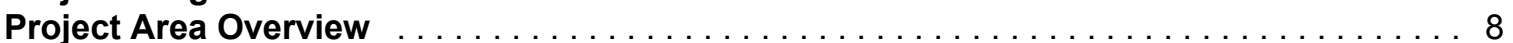

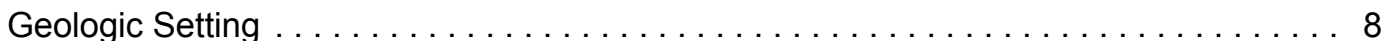

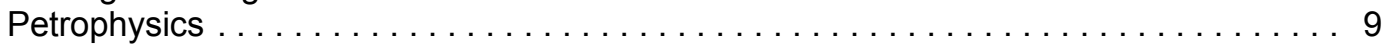

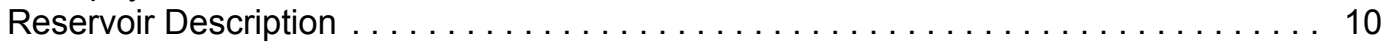

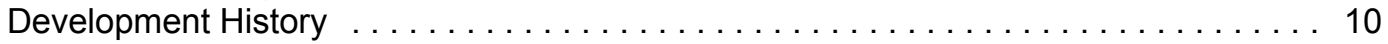

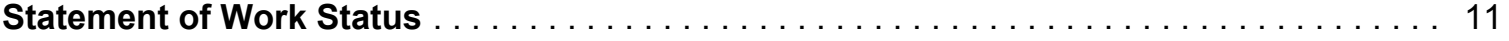

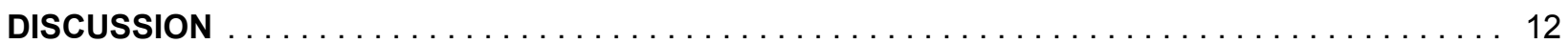

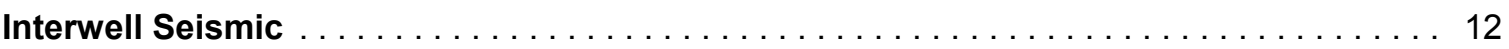

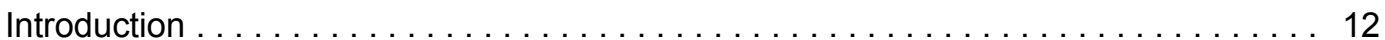

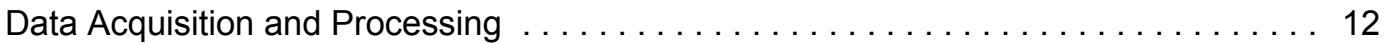

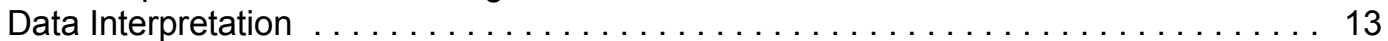

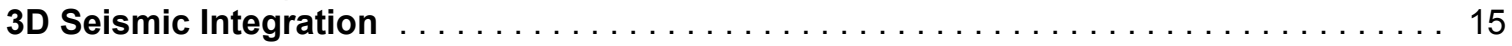

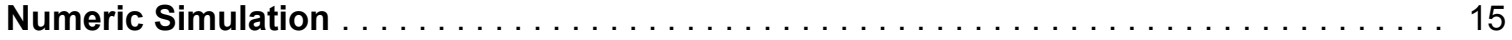

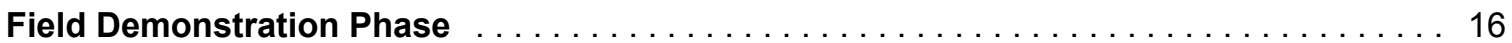

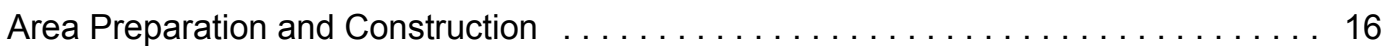

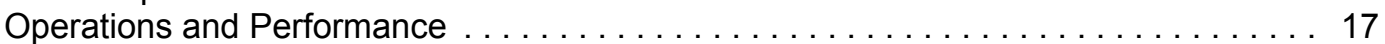

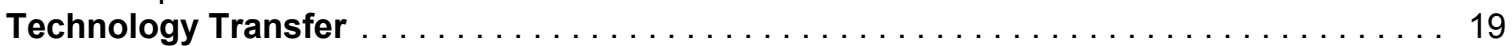

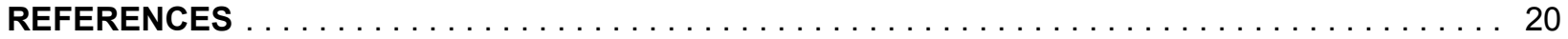

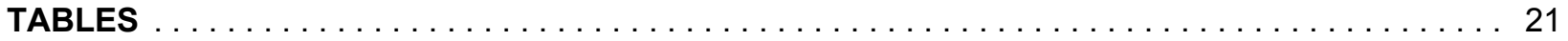

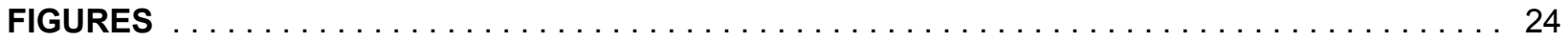

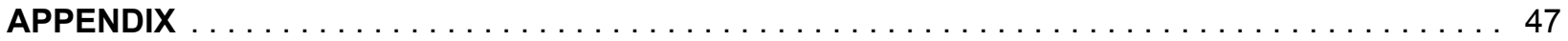




\begin{abstract}
The OXY-operated Class 2 Project at West Welch is designed to demonstrate how the use of advanced technology can improve the economics of miscible $\mathrm{CO}_{2}$ injection projects in lower quality Shallow Shelf Carbonate reservoirs. The research and design phase (Budget Period 1) primarily involved advanced reservoir characterization. The current demonstration phase (Budget Period 2) is the implementation of the reservoir management plan for an optimum miscible $\mathrm{CO}_{2}$ flood design based on the reservoir characterization. Although Budget Period 1 for the Project officially ended 12/31/96, reservoir characterization and simulation work continued during the Budget Period 2.

During the fifth and sixth annual reporting periods (8/3/98-8/2/00) covered by this report, work continued on interpretation of the cross well seismic data to create porosity and permeability profiles which were distributed into the reservoir geostatistically. The initial interwell seismic $\mathrm{CO}_{2}$ monitor survey was conducted, the acquired data processed and interpretation started. Only limited well work and facility construction was conducted in the project area. The $\mathrm{CO}_{2}$ injection initiated in October 1997 was continued, although the operator had to modify the operating plan in response to low injection rates, well performance and changes in $\mathrm{CO}_{2}$ supply. $\mathrm{CO}_{2}$ injection was focused in a smaller area to increase the reservoir processing rate. By the end of the reporting period three producers had shown sustained oil rate increases and ten wells had experienced gas $\left(\mathrm{CO}_{2}\right)$ breakthrough.
\end{abstract}




\section{EXECUTIVE SUMMARY}

The West Welch Unit is one of the four large waterflood units in the Welch Field located in the northwestern portion of Dawson County, Texas. The Welch Field was discovered in the early 1940's, and oil production is from the San Andres formation at approximately 4800 feet. The primary production mechanism is solution gas drive. The field has been under waterflood for 35 years and mostly infill drilled on 10-acre spacing. $\mathrm{A} \mathrm{CO}_{2}$ Injection Pilot on the offsetting South Welch Unit done during 1982-86 provided encouraging results. The availability of $\mathrm{CO}_{2}$ from a new pipeline near the field allowed a phased development of a miscible $\mathrm{CO}_{2}$ injection project in the South Welch Unit.

The reservoir quality is poorer in the West Welch Unit due to relatively shallow sea level during deposition. Because of the close proximity to a $\mathrm{CO}_{2}$ source and the $\mathrm{CO}_{2}$ operational experience gained in the South Welch Unit, the West Welch is ideally located for demonstrating methods that can enhance economics of improved oil recovery for lower quality shallow shelf carbonate reservoirs.

The West Welch DOE Class 2 Project is divided into Budget Periods 1 and 2. Budget Period 1, which ended $12 / 31 / 96$, involved a detailed reservoir characterization effort based primarily on advanced petrophysics. The resulting "geologic" model was used to design a $\mathrm{CO}_{2}$ flood. An economic analysis, based on the model predictions, resulted in the project's continuation into Budget Period 2, which comprises the completion of project installations and field demonstration of the project.

Much of the reservoir characterization effort was carried over into Budget Period 2. A methodology had been developed to extract porosity estimates from the 3D seismic data set. The seismic-derived porosity was used to constrain the interwell estimates of porosity from the geologic model. This "seismic-enhanced" model gave better total-fluid history match over the geologic model. Other changes to the model included altering the mix of rock types and the relative permeability relationships for specific rock types for an improved water-oil ratio match. This enhanced model was used as the basis for the final optimization of the $\mathrm{CO}_{2}$ flood.

The bulk of the interwell seismic activity prior to the current reporting period (8/3/98-8/2/00) involved the reprocessing and interpretation of the cross well seismic data. The high frequency $(600-700 \mathrm{~Hz})$ at which the data is recorded offers an opportunity for a much finer vertical resolution and therefore more detailed interwell characterization than has ever been possible. Still, the conditions under which the cross well seismic surveys are conducted create serious challenges in the acquisition, processing and interpretation of the data. A number of obstacles had to be overcome before any useful interpretations of the reflection data could be obtained.

Work that was started in the prior annual reporting period to develop methods to identify rock types using the relationship between shear and compressional wave velocities from the cross well seismic data was completed in the current reporting period. The ability to identify rock types allows porosity and permeability profiles to be created along the interwell survey lines. Variograms were created from the profiles and used to distribute porosity and permeability geostatistically into the 3D reservoir model. Data was successfully acquired on the first interwell seismic $\mathrm{CO}_{2}$ monitoring survey. The data was processed and preliminary representations of the $\mathrm{CO}_{2}$ saturation along the survey lines constructed using the difference in apparent porosity between the baseline and first monitor survey.

Before this reporting period, most of the work associated with the wells, surface facilities for distributing $\mathrm{CO}_{2}$ for injection and gathering produced $\mathrm{CO}_{2}$, was completed. Per the optimization plan, water injection rates were reduced in the project area to reduce the injection pressure below the formation parting pressure. This resulted in significant drop in the oil-producing rate. $\mathrm{CO}_{2}$ injection was initiated October 1997 and a total of $3.7 \mathrm{BCF}$ of $\mathrm{CO}_{2}$ had been injected through 6/30/00.

The project was scaled down due to several factors, including reservoir quality, wellbore integrity, associated cost, anomalous performance and $\mathrm{CO}_{2}$ supply. The operating plan has changed to the extent the reservoir model's forecasts are not representative of the current operating plan and are to be updated. To help insure 
that sufficient hydrocarbon pore volume (HCPV) would be processed by the $\mathrm{CO}_{2}$ to give an adequate evaluation, the $\mathrm{CO}_{2}$ injection was limited to six injectors in a 400 -acre "focus" area. By $6 / 30 / 00$, only $9.4 \%$ of the focus area HCPV had been processed, while experience indicates that at least $15 \%$ is required for significant response. A request has been made to extend the project termination date from 10/31/00 to $10 / 31 / 01$. During the reporting period three wells have shown sustained oil response and ten wells have shown gas $\left(\mathrm{CO}_{2}\right)$ breakthrough. Two of the injectors were WAG'd during the two-year reporting period. 


\section{INTRODUCTION}

\section{DOE-Funded Project Proposal}

In response to the DOE's 1992 solicitation for Class 2 Shallow Shelf Carbonates (SSC) Reservoir demonstration projects, OXY USA Inc. in Midland, Texas submitted a proposal titled "Application of Reservoir Characterization and Advanced Technology Improves Economics in a Lower Quality Shallow Shelf San Andres Reservoir." The proposal was aimed at proving lower quality San Andres reservoirs can be economically $\mathrm{CO}_{2}$ flooded by applying advanced reservoir characterization and a combination of EOR methods that are not widely utilized. The reservoir characterization efforts would demonstrate new technologies, using 3D and cross well seismic methods. The proposal generally focused on using commercially available resources. The EOR methods involved both miscible $\mathrm{CO}_{2}$ flooding and cyclic $\mathrm{CO}_{2}$ stimulation.

Because of the large area that West Welch Unit covers, it contains reservoir of varying quality and connectivity. The West Welch is therefore a good representative of lower quality shallow shelf carbonate reservoirs. Several factors favored the selection of West Welch Unit as a test site. As an operator of both South Welch Unit and West Welch Unit, OXY had a large working database for the field which included the logs from 770 wells, core data from 147 wells, and a 3D seismic survey. In addition, several PVT fluid analyses were also available. The infrastructure for $\mathrm{CO}_{2}$ supply and gas processing plant was available at the adjacent South Welch Unit. Due to the ongoing $\mathrm{CO}_{2}$ flood in South Welch, OXY personnel were experienced in the modeling and field implementation of $\mathrm{CO}_{2}$ flooding.

The proposed project was to have used six technologies to enhance the probability of success for the $\mathrm{CO}_{2}$ flood. These technologies included detection of directional fracture propagation with passive seismic measurements, using the fracture stimulation of injectors to enhance sweep and thus eliminate the need for drilling of infill injectors, using cross-well seismic data to refine the interwell geologic model and to monitor the $\mathrm{CO}_{2}$ flood front, integrating the 3D seismic and the cross well seismic interpretations to enhance the reservoir characterization, using an enhanced compositional reservoir simulator to improve the prediction of $\mathrm{CO}_{2}$ flood response, and investigate the use of mobility control agents with $\mathrm{CO}_{2}$ injection to improve vertical sweep. The investigation of the first five technologies is either complete or well underway.

\section{Project Progress}

The DOE selected the OXY proposal as one of the successful candidates for a mid-term Class 2 project. A contract was finalized during 1994, which provided for a 50-50 cost sharing arrangement of the $\$ 22.2 \mathrm{MM}$ estimated budget. The project officially started August 3, 1994 and was divided into 2 phases. Budget Period 1 was the design phase in which advanced reservoir characterization was used to build a geologic model for use in a reservoir simulator. This characterization included detailed petrophysical analysis leading to the identification of rock type from log response. This methodology permitted detailed estimates of permeability and saturations from log data. The MORE Compositional Simulator was used to optimize the miscible $\mathrm{CO}_{2}$ flood design and maximize the economics. Based on a favorable economic analysis, it was recommended that the project be continued into the demonstration phase in Budget Period 2, which officially began on January 1 , 1997.

To further support the reservoir characterization effort In Budget Period 1, a pre-existing 3D seismic data set was reprocessed and interpreted for the San Andres horizon. This reprocessing ultimately yielded a vertical resolution of $50 \mathrm{ft}$. This enhanced resolution enabled the geophysicist to describe the reservoir in 2 layers. Furthermore, by relating the seismic response to sonic log response, the average porosity and thickness for each layer could be estimated. In Budget Period 2, this detailed interpretation of the 3D seismic data set was used to constrain the porosity-thickness estimate of the grid blocks in the interwell regions. The seismicconstrained geologic model was the basis for the "seismic-enhanced" model that gave an improved history match over the Budget Period 1's "geologic" model and the current predictive run for the $\mathrm{CO}_{2}$ flood. 
The updated seismic interpretation indicated that additional oil could be recovered by drilling wells south of the DOE-funded project area. The maps indicated good porosity and pay thickness in that area. Since OXY had earlier success in extending the southward development in the West Welch Unit, the project area was expanded in October 1997 for drilling new wells to test the seismic interpretation. Seven wells were drilled in the fourth annual reporting period in the expanded area. Well logs confirmed the seismic-based estimates of porosity to within one- percent porosity unit and reservoir thickness. The top of the pay section was within the accepted error margin, however, it was 15 feet lower than predicted. Because of the low structural position, the predicted net pay in these wells was reduced. Most recent estimates indicate that these wells will recover a total of 180,000 bbls of incremental oil. These reserves are insufficient to provide an acceptable rate of return. During this period two pre-existing injectors had also been converted to $\mathrm{CO}_{2}$ injection in the expansion area, but have since been converted back to water injection service.

Another technology that was investigated in Budget Period 1 was cyclic $\mathrm{CO}_{2}$ stimulation. This process involves injecting $\mathrm{CO}_{2}$ into producing wells, allowing a time for soaking, and then producing tertiary oil from the nearproducer region. The cyclic $\mathrm{CO}_{2}$ process can provide an almost immediate production increase, and thus reduce the payout time, compared to a conventional $\mathrm{CO}_{2}$ flood. $\mathrm{CO}_{2}$ stimulations were conducted in Budget Period 1 to determine if performance could be predicted accurately using the enhanced compositional simulator or some other method. The results proved to be ambiguous, and the use of cyclic $\mathrm{CO}_{2}$ stimulation for project enhancement was not pursued into Budget Period 2. Any further testing of cyclic $\mathrm{CO}_{2}$ injection was precluded so long as sour $\mathrm{CO}_{2}$ was being injected.

During the Budget Period 1, the use of fracture stimulations to eliminate the need for infill drilling injection wells in a part of the project area was investigated. To test this technology, a foamed frac treatment was pumped in an existing injection well while seismic receivers placed in three offset wells monitored the fracture growth. The interpretation yielded a four dimensional map of fracture growth. This work was completed and reported in Budget Period 1. In Budget Period 2, this stimulated injector was converted to $\mathrm{CO}_{2}$ injection. Anomalous breakthrough of $\mathrm{CO}_{2}$ and nitrogen in September 1998 occurred in wells outside the injector's pattern, indicating a lack of control in the fracture growth.

The drilling of the expansion area wells to test the predictive capabilities of the 3D seismic interpretation offered the operator an opportunity to test a fracture simulation model. Refined by the actual results of seven fracture stimulations, this model predicts that the propped half-length of a fracture is limited to 80 to 100' before the fracture will grow dramatically out-of-zone. This technology was tested in the northwest part of the DOE area, where performance suggests the presence of permeability barriers between injectors and producers. After the fracture stimulation, the injector indicated that communication was successfully extended beyond lateral barriers in the pay interval. Should the $\mathrm{CO}_{2}$ flood prove successful in better parts of the project area, this technology may be useful in extending the flood to areas of the field with higher degrees of lateral heterogeneities.

At the beginning of Budget Period 2, well bores were prepared and facilities were upgraded for $\mathrm{CO}_{2}$ injection, which was initiated in October 1997. Flood monitoring, well injectivity, wellbore issues and acquisition of the initial interwell seismic monitor survey were the main field demonstration activities in the 1999/2000 annual reporting periods.

\section{Project Area Overview}

\section{Geologic Setting}

The Welch Field is located in the north part of the Midland Basin and in the northwestern portion of Dawson County, Texas. Production is from the Permian-Age dolomite of the San Andres Formation. The determination of the depositional environment and diagenetic history was established from detailed interpretations of core samples within and surrounding the project area. The cyclic pattern of alternating depositional environments has been documented throughout the Permian Basin. The depositional cycles were put into a sequence stratigraphic framework in order to insure that the correlation of individual reservoir layers remained consistent 
from well to well. The Bureau of Economic Geology was consulted to bring the Welch San Andres sequences into an established hierarchy.

The San Andres deposits were emplaced on a shallow shelf ramp near the paleoshoreline. Structural relief was very low; probably less than 3 degrees of slope per mile, hence minor fluctuations in sea level moved the shoreline several miles at a time. These depositional environments produced broad bands of sediments with variable textural characteristics depending on the sub-environments associated with each major environment. Tidal flat deposits are produced along the strand line as well as on islands within the lagoon. Higher energy tidal channels are seen dissecting the low energy tidal flats, producing coarse-grained sediments encased in lime muds. Small amounts of grainier rocks can also appear within the lagoonal settings.

The post-depositional history describes the diagenetic events that changed the physical properties of the reservoir rock. From the time of deposition, the sediments have been altered extensively in places to the point that the original fabric of the sediment is no longer recognizable. These processes are sometimes termed random, because the controlling factors are often not known. However, their effect is manifested at Welch in terms of dolomitization, pore-filling anhydrite, leaching and precipitation of quartz and calcite cements, and the presence of stress fields that produce directional trends in permeability.

\section{Petrophysics}

A common problem in discerning petrophysical relationships from log and core data is reconciling the differences in data acquisition methodologies through time. As the industry's knowledge of factors affecting the measurements of porosity and permeability has evolved, so have the methods and practices used for their measurements. The extensive data collected in Welch Field is useful for correlation and for pay quality comparisons, but it can not provide simple and direct correlation between porosity and permeability. For a single porosity value the porosity-permeability semi-log cross-plots produced a standard error estimate of several orders of magnitude.

In Sept/Oct 1994 two observation wells, WWU 4852 and WWU 7916, were drilled and cored in the West Welch Unit project area. An extensive suite of logs was run on these wells. The data from these wells was used to calibrate the logs and cores in the project area and is the basis for the detailed petrophysical data used in various project area models.

The mineralogy of the productive San Andres interval is simple, with dolomite comprising $77 \%$, anhydrite comprising $17 \%$, quartz comprising $4 \%$ and gypsum, calcite, and clay minerals each comprising less than $1 \%$ of the rock matrix. However, the pore structure is highly complex. David K. Davies and Associates described four different rock types for the section. Comparison of these rock types to the normally determined features of depositional environment and fabric found little in the way of correlation. This poor correlation demonstrates the importance of diagenetic processes to flow characteristics at Welch. Any rock type can occur in any depositional facies, and basing reservoir parameters on inferred depositional environments can result in erroneous interpretations.

A methodology was needed that would allow the geologist to recognize rock type from log response. Furthermore, the relationships between log response and the various reservoir parameters needed for complete reservoir characterization had to be derived for each rock type. Relative permeability tests indicated that the reservoir is of mixed wettability. The resulting uneven distribution of fluids in the pore system affected the resistivity log response. The resistivity logs therefore could not be used to identify rock type, and a nonstandard log interpretation approach was needed. The methodology that was developed was published in $1996^{1}$. 


\section{$\underline{\text { Reservoir Description }}$}

The reservoir interval at West Welch Unit occurs at an average depth of 4800 - $4900 \mathrm{ft}$ approximately $400 \mathrm{ft}$ below the top of the formation. The West Welch Unit covers 12,000 acres. The general structure of the field is a monocline, gently dipping to the south-southeast. The present structure is a result of pre-depositional movement of deeper fault blocks. No fault cuts the San Andres at West Welch and the appearance of actual fractures in core is rare. The average gross thickness of the producing interval is $100 \mathrm{ft}$ with a net pay thickness of $50 \mathrm{ft}$. The porosity in the reservoir interval ranges between 0 and $22 \%$, with an average value of $9 \%$ for the entire Unit and $12 \%$ for the project area. The average permeability for the project area is less than $5 \mathrm{md}$.

The reservoir is highly stratified as a result of depositional processes, with Dykstra-Parsons coefficient values in the 0.75 range. The producing interval is divided into two hydraulically separated intervals: the Main Pay and the Lower Pay. The oil/water contact (depth of $100 \%$ water production) for the Main Pay is at a subsea depth of $-1890 \mathrm{ft}$. Lower Pay is wet in this part of the field. The oil/water contact varies slightly across the field due to the capillarity of the reservoir rock. The underlying water provides little pressure support and the primary drive mechanism is solution gas. An anhydrite seal at the top of the reservoir section creates the trap. The productive limits of Welch Field are controlled by a combination of structure and permeability variations. The Main Pay loses permeability moving northward in the updip direction and it produces excess water in the downdip direction. At West Welch, production is from the Main Pay in the south and from the Lower Pay in the north. Production in the project area is from the Main Pay. Many of the original wells in the south and central part of the Unit have produced in excess of $300 \mathrm{MBO}$. Per well cumulative oil production tends to be less in the north.

From a comparison of permeability profiles and gamma ray logs, it was recognized that certain gamma ray spikes within the Main Pay correlate with the thin, low permeability intervals. These boundaries could be correlated from well to well through the entire project area, and form the basis of the layering for the model. Basically, the reservoir is described in nine layers separated by ancient flooding surfaces. Each layer is a continuous rock unit across the model area. Because of variability in the diagenetic processes, these layers do not have uniform properties throughout but should exhibit bounded flow character. Lateral discontinuities within a layer are expressed by rapid changes in porosity and permeability. This variability has an adverse affect on the sweep efficiency of any flooding mechanism.

In the original "geologic" model, reservoir parameters were simply contoured between the wells for each layer. This model was used to justify the continuation of the project into Budget Period 2, the demonstration phase. In Budget Period 2, the model was enhanced by using the 3D seismic data to constrain the total porositythickness in the interwell locations.

\section{Development History}

Welch Field was discovered in 1941 and was initially developed with 40-acre well spacing. West Welch Unit has been under waterflood since 1963. Unit production peaked at 9000 BOPD in 1971. Infill drilling from 1980 to 1991 stabilized the producing rate at 2000 to 3000 BOPD. Later, limited infill drilling and well maintenance work reduced the annual decline rate to $4 \%$, but the economic margin associated with this work has become increasingly narrow. We anticipate the Unit decline rate to increase 7 to $10 \%$ as such work can no longer be justified economically.

West Welch Unit consists of approximately 350 producers and 200 injectors in a line drive pattern of varying density. Currently the unit is producing around 2,500 BOPD and 23,000 BWPD. The average well produces 7 BOPD and 65 BWPD. All produced water is reinjected at West Welch Unit.

Most of the producers in West Welch Unit were completed openhole. Casing was set at the top of the pay interval, and then the producing zone was drilled out. All of the producers have been hydraulically fractured with fluid and sand. Attempts to stimulate production by a second fracture treatment have generally failed, 
leading to the conclusion that the initial fractures are still open and sufficiently clean to contribute to the well's flow rate. The combination of the openhole completions and the fracture treatments limits the determination of the layers which are contributing to the production. Profile modification in producers is difficult because of the open-hole completion.

The earlier injectors at West Welch Unit are also open hole completions. Many of these wells, which were producers prior to their conversion, were also fracture stimulated. Injectors drilled since 1980 are typically cased hole completions. These wells were rarely frac treated, though they may have been acidized several times. The problem in determining the injected water distribution into individual layers is complicated by the field-wide practice of injecting above the formation parting pressure in order to get a sufficient volume of water into the reservoir. In various areas of the Unit and in the project area, attempts have been made to reduce injection pressure below the parting pressure. In every case, some reduction of water and oil production was seen. This indicates that some water cycling was happening at higher injection pressures, while the oil reduction suggests that the high injection pressure probably results in the flooding of low permeability areas.

Common producing problems at West Welch Unit include corrosion, scale precipitation in producers, paraffin precipitation in well bores and flow lines, and casing leaks. We strive to control corrosion through the use of chemicals to protect steel from corrosive fluids. Scale formation rarely seems to adversely affect production. Scale most often accumulates in the lower part of the reservoir section, and communication with the wellbore can still be maintained through the propped fracture. Experience has shown that except for cases of extreme accumulation, scale cleanouts rarely improve producing rates and are not generally justified. Paraffin is removed by pumping heated fluids down well bores and flow lines. Casing leaks generally occur in the older wells and are most often repaired by the installation of steel liners. All the producers in the West Welch Unit are on beam pumping units. They are sized on the total fluid production of the individual wells. Installation of additional pump-off controllers has reduced the electricity usage and prolonged the life of the pumping components.

\section{Statement of Work Status}

Appendix A is the Statement of Work (SOW) that was included in the original proposal to the DOE and serves as the guideline for conducting the project. The activities were divided into Budget Period 1-project design and economic projection- and Budget Period 2- project execution and evaluation. Budget Period 1 ended December 31, 1996 after the projected economics justified initiating the actual $\mathrm{CO}_{2}$ field demonstration phase, i.e. Budget Period 2. All of the subtasks listed under Budget Period 1 in the SOW were successfully accomplished except for Subtask 1.4.3 Baseline Tomography Survey. While the interwell seismic was acquired and processed, much of the technology involved had to be developed by Advanced Reservoir Technologies (ART). Consequently, the interwell seismic contribution to the reservoir characterization was not available for enhancing the reservoir model used in the simulation at the end of Budget Period 1 that produced the performance projections and economics on which the demonstration phase was justified.

The interwell seismic interpretation and application to reservoir characterization has continued into Budget Period 2 and expanded to include Subtask 2.4.2 Tomograph Surveys for Front Tracking. Although the 3D seismic interpretations contributed to the reservoir characterization in Budget Period 1 (Subtask 1.4.5), some activity continued in the early part of Budget Period 2 as part of Subtask 2.3.1 Update Existing Reservoir Characteristics. Similarly reservoir computer simulation continued into the second budget period. If the interwell seismic interpretations are incorporated into the reservoir model then additional simulation will be required under Subtask 2.3.1 and possibly under Subtask 2.4.3 Project Evaluation. Two of the subtasks under Task 2.3 Project Area Preparation--2.3.3 Fracture Stimulation and 2.3.4 Facilities Upgrade -- have been completed by September 2, 2000. The remaining three subtasks are still active through this annual reporting period. Task 2.1 Project Management, Task 2.2 Technology Transfer and Subtasks 2.4.1 and 2.4.2 under Task 2.4 Reservoir Management Plan Initiation and Operations are ongoing through the demonstration phase. Subtask 2.4.3 Project Evaluation and Task 2.5 Final Data Set do not start until the demonstration phase has ended. 


\title{
DISCUSSION
}

\section{Interwell Seismic}

\author{
$\underline{\text { Introduction }}$
}

In the design of this project interwell seismic was included as one of the new technologies to be demonstrated. There are two components to interwell seismic - tomography (direct waves) and reflective waves. Both aspects had the potential to refine the interwell reservoir characterization beyond the resolution that could be accomplished with conventional 3D seismic interpretations. Also reshooting some of the baseline survey lines after $\mathrm{CO}_{2}$ injection began might allow imaging of the $\mathrm{CO}_{2}$ invaded areas with tomography. At the beginning of Budget Period 1 twenty lines of interwell seismic (baseline survey) were obtained using two source wells and thirteen receiver wells (Figure 1). The bulk of Budget Period 1 was spent developing the technology for processing both the tomography and reflective data.

In Budget Period 2 further improvements were made in the processing, particularly the reflective data, but the majority of the effort was spent on interpretation of the processed data. During the 1999/2000 annual reporting period this effort resulted in the construction of profiles that depict the distribution of rock type, porosity and permeability along survey lines that tied into well log and surface 3D seismic data. These realizations were used to derive spatial geostatistics that were combined with hard data to create reservoir parameter maps. Work was then initiated on developing a 3D geologic model.

Also during the reporting period the first interwell seismic monitoring survey was planned and successfully executed over five of the original Phase 1 survey lines and one new line in the southern pattern. The data was processed and interpreted, utilizing velocity differences between baseline and monitor data to image the $\mathrm{CO}_{2}$ invasion along two survey lines.

Overall, during the reporting period, progress was made in characterizing the reservoir and understanding $\mathrm{CO}_{2}$ performance through the use of interwell seismic. Because this is a new technology, particularly as it relates to the length of the survey lines, developing the techniques for processing and interpreting the data has extended over the project life to date. Hence, these results have not yet impacted the design of the project and the field demonstration phase. The availability of time and funds will determine if the reservoir characterization developed from the interwell seismic will be fully utilized by the project. Regardless, the database acquired and the techniques developed have advanced the technology and will be available to industry.

\section{Data Acquisition and Processing}

Interwell reflection imaging is a relatively new concept that had never been tested for survey lines of the length obtained at West Welch (700 to $2000 \mathrm{ft}$ ). Experimentation during the baseline acquisition period resulted in obtaining reflection data of useable quality on many of the survey lines. Due to the broad bandwidth of the data, the migration algorithms in the available VSP (vertical seismic profile) geometry seismic processing systems proved unsatisfactory. It was necessary to utilize a VSP to CDP (common data point) transform to obtain the initial interpretations. The interwell reflection data were reprocessed with new migration algorithms which has resulted in vertical resolution of 10-12 ft with one-foot lateral trace spacing. This type of vertical resolution is not achievable with surface seismic data.

ART, working with OXY personnel, planned and executed the first round of $\mathrm{CO}_{2}$ monitor surveys on six interwell seismic survey lines in the south pattern of the study area (Figure 2) The six lines were chosen to provide good radial coverage around the south observation (source) well, 4852, which is near the $4811 \mathrm{CO}_{2}$ injector. The receiver wells used in monitor survey were 4822, 4827, 4828, 4841, 4843, and 4844. Because of potential high pressures and presence of hydrogen sulfide gas $\left(\mathrm{H}_{2} \mathrm{~S}\right)$, it was necessary to build and deploy a special wellhead lubricator, approximately 120 feet in length. This is believed to be the tallest lubricator ever used in a well logging operation and was deployed from a 165 foot crane brought to the site. Because of the required use of this 
one-of-a-kind lubricator, only one survey line at a time could be acquired. The operations were successful, providing a very good set of data to be used to monitor the location of $\mathrm{CO}_{2}$ within the reservoir.

In the first quarter of 2000, ART completed the processing of the new data from the first six monitor survey lines. In addition, the baseline data on these lines was re-processed to bring them up to date with improvements in processing that has occurred since acquiring the surveys in 1994.

\section{Data Interpretation}

Significant progress was made in using the shear velocity $(V s)$ to compression velocity $(V p)$ relationships to identify not only rock types, but also to determine interwell porosity and permeability. Access by ART to the OXY Stacked Curve PC program greatly facilitated this progress. Interpretations were obtained from some of the survey lines, using the response of the $\mathrm{Vp} / \mathrm{Vs}$ relationship to variations in porosity to apparently defined individual flow units that are less than ten feet thick. ART made an initial attempt at scaling these profiles to porosity units utilizing the BiotGassman equation (Table 1) to combine core, log and interwell seismic data. Values for rock and fluid moduli were estimated from published data. It was possible to generate a reasonable range of porosity values along the length of the survey line by calibration with detailed core porosity values from observation Well No. 4852 that serves as the source well for the southern baseline survey pattern (Figure 3). The accuracy of this process could be further improved by obtaining a more representative value for the moduli, perhaps by direct measurement on core samples.

No counterpart to the Biot-Gassman equation is known which could relate core, log and seismic measurements directly to permeability. However, during the petrophysical phase of this project in Budget Period 1, four major rock types were identified within the reservoir and a porosity/permeability relationship established for each type. By matching these rock types to the rock types seen on the porosity profiles, it was possible to use these relationships to derive permeability profiles. As seen on Figure 4, the vertical permeability barriers are sharply defined, cleanly delineating thin flow units within the reservoir. Lateral permeability variations are also evident.

Neutron logs were used to add control for calibrating the porosity distribution profiles where core data were not available. Since the neutron logs were run by several different companies using a variety of radioactive logging sondes, it was not possible to normalize all of the logs so they may not be fully comparable. The neutron logcalibrated distributions were compared favorably to the core-calibrated distributions. The permeability profile sections were upgraded for the neutron-enhanced porosity profile sections. Examples of the upgraded porosity and permeability profile sections are shown by Figures 5 and 6 respectively. The neutron log enhancement of the porosity profiles survey was limited to use of the logs in the receiver and source well of each survey line.

While these interwell seismic data interpretations discussed above have demonstrated the potential for significantly advancing the ability to characterize highly heterogeneous carbonate reservoirs, acquiring interwell seismic data is relatively expensive which would greatly limited its coverage on most projects. Also the final results, although very detailed, are 2D presentations between wells and not comparable to the reservoir volumes derived from 3D surface seismic. Geostatistics were investigated as a means of converting the limited interwell seismic interpretations into 3D volumes.

Industry uses statistical procedures for combining "hard" and "soft" reservoir data to derive spatial geostatistics for the interwell distribution of rock properties in reservoir models. Variograms provide the basis for distributing petrophysical properties in a 3D volume by yielding a measure of the probability of the occurrence of any value of a reservoir property as a function of distance away from each point in the reservoir along a particular azimuthal direction. The interwell area can be sampled indirectly by pressure transient and performance analysis, but vertical resolution is low and results are nondirectional. Surface seismic data represent a direct sampling of the reservoir interwell area, but both the vertical and lateral resolution are often too low for use in numerical simulation. A preferred approach is to take closely spaced measurements of porosity and permeability on outcrops of the reservoir formation to create variograms. However, outcrops are weathered and may not be representative of the reservoir rock properties. Interwell seismic data offer the opportunity to derive spatial statistics from direct sampling of the interwell area with high resolution. Within the West Welch project area, the interwell survey lines radiated 
out from two central wells, giving a good variation in azimuthal direction which allows the reservoir anisotropy to be determined.

ART created spatial variograms for all of the porosity and permeability distribution profile sections that had been constructed from the interwell seismic data and enhanced by neutron logs and calibration to core data. Three difference mathematical approaches to distributing petrophysical properties three-dimensionally were investigated. Initially, the spatial dip was removed from the interwell data and an ordinary kriging techinque used to distribute porosity and permeability values between and beyond control points to generate a 3D model of the reservoir. The method honored all the core and log data points. This model was useful for examining variation in porosity and permeability within a single lithologic unit. Spatial dip was then restored, creating a full 3D reservoir model which reflects all of the "hard" data and interpolates between control points consistent with the data. Figures 7 and 8 show a 2500 -ft east-west cross section from the reservoir model for porosity and permeability distribution, respectively. The section starts $1000 \mathrm{ft}$ east and $500 \mathrm{ft}$ north of source well 4852.

Next, conditional simulation was investigated. This required extracting the appropriate spatial statistics from the variograms for use in generating a conditional simulation model for the 3D porosity distribution over the study area surrounding the north and south patterns. The same procedure was carried out for the conditional simulation of permeability. Figures 9 and 10 show a cross section of the reservoir realization developed for porosity and permeability, respectively, along the same east-west line as for the kriging exhibits.

The third method investigated was cokriging, which allows the statistics of two independent data sets (i.e. neutron porosity logs and enhanced interwell seismic results) to be used simultaneously to produce a map which honors both sets of statistics. One data set is chosen as the primary data set (largely honored) and the other data is secondary, acting as an additional constraint on the primary data set. Two separate porosity models were created for comparison. Figure 11 shows the results using the interwell data as primary and the neutron porosity data as secondary. Conversely, Figure 12 shows the results using neutron porosity data as primary and interwell seismic data as secondary. Both porosity sections are along the same east-west line used for the kriging and conditional simulation. Whereas the neutron log enhancement of porosity along a interwell seismic survey line involved only two wells (Fig. 5), the cokriging approach allows the use of all neutron logs in the model area.

Visually, the different approaches appear to give similar results. It would be necessary to test each of the reservoir models derived in a numeric simulator to determine which realization best represents actual reservoir conditions. This has not yet been done.

The displacement of pore fluids, i.e. oil and water, by $\mathrm{CO}_{2}$ causes a change in the bulk rock seismic velocity. Therefore, any changes in interwell seismic compressional wave velocities which might have occurred between the baseline and monitor surveys would be due to $\mathrm{CO}_{2}$ injection. While no rock physics analysis has been done with the cores from the Welch study area, experience in other carbonate $\mathrm{CO}_{2}$ projects in the Permian Basin has indicated that replacement of the original pore fluid by $\mathrm{CO}_{2}$ can result in changes in compressional wave seismic velocity on the order of $1,000 \mathrm{fps}$ (shear wave velocities are not affected). Preliminary investigations in this area indicate that replacement of original pore fluid by $\mathrm{CO}_{2}$ in the Welch reservoir results in a change in apparent porosity of between two and six percent. By producing detailed cross sections of interwell porosity distribution from the corresponding survey line for the baseline and first monitor surveys and taking the difference between the results, it was possible to identify zones where the change in apparent porosity exceeds the two percent threshold.

This seismic compressional wave velocity change approach is illustrated by Figure 13, which shows the interwell line from well 4852 (left) to well 4844 (right). By highlighting in darker grey the zones where apparent porosity has changed by two percent or more between baseline and monitor surveys, a very detailed interwell image of the presence of $\mathrm{CO}_{2}$ is obtained. The other line with significant indicated velocity changes was source well 4852 to receiver well 4843 . These results are qualified by the fact that there was not a baseline survey on either line and the baseline surveys on neighboring lines of similar length were substituted. Also the source well is located several hundred feet west of the 4811 injector. 
A comparison of the baseline and monitor surveys for the four survey lines radiating to the north, northeast, northwest and southwest from the 4852 source well did not indicate significant porosity changes. The orientation of the two lines with significant change suggests that the injected $\mathrm{CO}_{2}$ in the vicinity of the monitor lines exhibits a strong south-southeast directional preference. At the time of the monitor survey, $\mathrm{CO}_{2}$ breakthrough had already occurred on 4841 due north of the 4811. While directional permeability is not an uncommon occurrence in Permian age carbonates, the one-directional nature of the findings above are unusual, i.e. $\mathrm{CO}_{2}$ flowing only southeast from injector 4811 rather than northwest and southeast. This may be a function of the distribution of the permeability in this portion of the reservoir, but more likely it is a function of the data since $\mathrm{CO}_{2}$ breakthrough had already occurred on 4841 due north of the 4811 injector. The $\mathrm{CO}_{2}$ saturation can be studied further when the second monitor survey is conducted. An attempt will be made to construct a full $3 \mathrm{D}$ map of the estimated $\mathrm{CO}_{2}$ saturation in the vicinity of the survey lines.

A spin-off of the monitor survey investigation was some new developments related to calibration of interwell seismic shear and compressional wave velocities which created improved detailed interwell maps of porosity and permeability distribution.

\section{D Seismic Integration}

Structure and porosity maps generated from the 3D seismic data interpretations indicated that additional oil reserves were present in the area south of the original DOE project area. In October 1997 the DOE project area was expanded to include the 275 acres to the immediate south (Figure 14). The expansion area contained one row of water injection wells. By May 1998 a total of seven new producers had been drilled based on the 3D seismic interpretations with a total initial potential of 251 BOPD and 1239 BWPD. Ultimate recovery for the seven wells was initially estimated at $320 \mathrm{MBO}$. By September 1998 the combined test rates were down to 108 BOPD and 296 BWPD. The oil rate was down to 90 BOPD by the end of 1998 and the estimated total ultimate recovery reduced to $180 \mathrm{MBO}$. Table 2 shows initial potentials on seven wells drilled in the expansion area.

The log-derived porosity on the new wells agreed within one porosity unit of the 3D seismic prediction, but structurally the main pay ran about 15 feet low to the seismic guided mapping. While this was well within the vertical resolution error band for surface 3D seismic, the thinner-than-anticipated oil column reduced the ultimate recoveries below economic levels. Consequently, no more wells are planned.

While not commercial under existing conditions, it was thought that the expansion area performance might improve under tertiary recovery. Two of the four existing water injection wells were converted to $\mathrm{CO}_{2}$ injection. Well 4802 was converted May 1998 and a total of $74 \mathrm{MMCF}$ of $\mathrm{CO}_{2}$ have been injected. Well 4817 was also converted May 1998 and a total of $75 \mathrm{MMCF}$ of $\mathrm{CO}_{2}$ injected. $\mathrm{CO}_{2}$ injection in both wells was terminated in November 1999 when it became apparent that not enough of the area's HCPV would be processed by the project end date to give any meaningful results.

The expansion drilling provided a real life test under actual field conditions that further validated the seismic guided mapping that had been developed during Budget Period 1 . The new drilling also provided a test bed for the fracture stimulation treatments that have been designed by the fracture model developed for this project as discussed in detail in the 1998 annual report ${ }^{2}$.

\section{Numeric Simulation}

The main purpose of the extensive reservoir characterization activities that were conducted in the West Welch project was to construct a detailed geologic-based reservoir model that would improve the predictive capability of numeric simulation. A representative reservoir model would allow the optimization of the $\mathrm{CO}_{2}$ miscible flood design and realistic projections of the economics of tertiary recovery in a marginal shallow shelf carbonate reservoir. During Budget Period 1, the geologic-based reservoir model was constructed and used in the commercially available MORE compositional simulator to history-match the waterflood performance of the West Welch DOE Project area. One of the concepts included in the original project proposal was the evolution of the reservoir model from one based on basic geological description to incorporation of 3D surface seismic interpretation and finally 
inclusion of the interwell seismic interpretation. This staged evolution would allow the change in model performance to be isolated for each stage to determine if the improvement attained justified the extra cost.

The simulator's match of the waterflood history was improved when the geologic-based reservoir model was enhanced by incorporating the 3D seismic interpretation to constrain the porosity-thickness in the interwell areas. The enhanced model also came closer to predicting the actual injection rates. The enhanced reservoir model was used at the end of Budget Period 1 to predict the $\mathrm{CO}_{2}$ flood performance. The results obtained from this performance projection were the basis for the decision to move into the field demonstration phase of the project (Budget Period 2).

$\mathrm{CO}_{2}$ injection began in the project area during October 1997. The actual $\mathrm{CO}_{2}$ injection rates matched the seismicenhanced reservoir model's predictions for the first four months and then began to fall below these predictions although they were still greater than the basic geologic-based reservoir model's predictions. The total injection rate comparison has little meaning since the model assumed a total of $17 \mathrm{CO}_{2}$ injectors and the actual number never exceeded the 12 injectors that were active in July of 1998. On an individual well basis the enhanced reservoir model injection rate forecasts are reasonable compared to actual rates except on two wells where actual rates are much higher than predicted.

$\mathrm{CO}_{2}$ breakthrough occurred initially in June 1998 in Well 4843, which was earlier than predicted by the model. Within a short period of time $\mathrm{CO}_{2}$ breakthrough was detected in two other producers within the project area and two producers outside the project boundaries. This breakthrough occurred at a cumulative $\mathrm{CO}_{2}$ injection volume of $1.85 \mathrm{BCF}$ versus a predicted cumulative of $2.1 \mathrm{BCF}$. This may be related to the two injectors with rates considerably higher than forecasted. Comparisons between actual and predicted performance became even less meaningful after $\mathrm{CO}_{2}$ input rates were initially curtailed in the fourth quarter of 1998 for economic reasons. In 1999 a shortage in the $\mathrm{CO}_{2}$ supply caused a continuation of injection curtailments in the project area.

During the two year reporting period from $8 / 3 / 98$ to $8 / 2 / 00$ operational changes in the original tertiary recovery plans have made it difficult to evaluate the representativeness of the reservoir model as a function of the accuracy of the simulation predictions compared to actual performance. Certainly no meaningful comparison is possible in the short term and the project will be terminated before the $\mathrm{CO}_{2}$ flood is mature enough to make judgments about overall recoveries. It will be necessary to update the reservoir model for the operational changes if an evaluation is to be obtained. The performance has shown, however, that the 3D seismic-enhanced reservoir model is more accurate than the basic geologic-based model.

The interwell seismic representations of the porosity and permeability profiles along the survey lines were finalized near the end of the reporting period and the decision has not yet been made as to its incorporation into the reservoir model. The work under way to map the CO2-saturated portions of the reservoir as discussed in the Interwell Seismic Section could prove useful in helping calibrate the model after it has been updated.

\section{Field Demonstration Phase}

\section{Area Preparation and Construction}

Since $\mathrm{CO}_{2}$ injection had been initiated in October 1997, the majority of the well work and surface facility installation necessary for injection was completed prior to 1998. Consequently, work in this reporting period related mainly to the production facilities. New production and test separators were installed. Gas gathering lines along with a high pressure 10-in. line were installed in preparation for handling increasing volumes of produced $\mathrm{CO}_{2}$. The injection of recycled $\mathrm{CO}_{2}$ that had been separated but not sweetened at a gas plant was initiated in 1999, requiring the installation of $\mathrm{H}_{2} \mathrm{~S}$ monitors in accordance with industry safety standards.

In the second quarter of 2000 the $\mathrm{CO}_{2}$ supply source was switched back from the gas treating plant to the Estes pipeline. This gave an increased volume of $\mathrm{CO}_{2}$ at a higher pressure that is not contaminated with $\mathrm{H}_{2} \mathrm{~S}$. The creation of a $\mathrm{H}_{2} \mathrm{~S}$ free environment within the injection system facilitates any injection well intervention such as wireline surveys and future interwell seismic surveys. 
The only well work that has occurred was the stimulation of producer No. 4847 with 20,000 gallons of $65 \%$ quality $\mathrm{CO}_{2}$ and $15 \% \mathrm{HCL}$ foamed acid at a rate of $2 \mathrm{BPM}$. The pretreatment test was $6 \mathrm{BOPD}$ and $43 \mathrm{BWPD}$, and the post treatment test was $11 \mathrm{BOPD}$ and $103 \mathrm{BWPD}$. The treatment was judged to be unsuccessful.

\section{Operations and Performance}

The project field demonstration area as designated in OXY's original proposal to the DOE covered about one section in the south central portion of the West Welch Unit ( Fig. 14). One reason for choosing this area was that the top (northern) two east-west injection rows had been infilled to 20-acre density, while the bottom two rows of injectors remained on the original 40-acre density. As discussed in detail in the 1998 annual project report ${ }^{2}$, one objective of the proposal was to demonstrate if a fracture stimulation treatment could be designed that would maximize the horizontal extension of the induced fracture while staying in zone on 40 -acre spaced injectors. If the technique was successful it would increase the injection rate and sweep of the injectors without the cost of infill drilling.

Subsequently a model-designed frac stimulation treatment was applied to 4807 . Analysis of the passive seismic data and post-frac tracer survey indicated that the treatment had stayed in zone (1998 report). However once the well was placed on $\mathrm{CO}_{2}$ injection, $\mathrm{CO}_{2}$ broke through to producers 4965 and 4922 located $1476 \mathrm{ft}$ and $2081 \mathrm{ft}$ respectively northeast of 4807 outside the demonstration area. Also the annulus of injector 4816 , located two locations north, began to pressure up. It was found to be charged with nitrogen, the only possible source of which was the stimulation treatment on 4807 . In all three instances the path of communication with 4807 was apparently outside the pay zone, making the extended fracture length treatment unpredictable and hence too risky to be applied in an injection project.

The original field demonstration phase plan called for two rows of $\mathrm{CO}_{2}$ injectors that had been infilled to 20-acre density and two rows still on the original 40-acre density. Eliminating three abandoned wells, this scheme would result in a total of 21 injectors. $\mathrm{CO}_{2}$ injection was initiated in October of 1997 in a total of eleven converted water injection wells. Two other injectors, 4803 and 4838, were converted in February 1998. The original $\mathrm{CO}_{2}$ area is shown on Figure 15. The southern expansion area to the original demonstration area was added in October 1997, based on the 3D seismic-enhanced mapping techniques developed during Budget Period 1 showing undeveloped potential. Seven producers were drilled in the expansion area as discussed in the 3D Seismic Integration Section of this report. Two existing water injectors in the expansion area were converted to $\mathrm{CO}_{2}$ injection in May 1998. The other two wells on the row were not mechanically fit for injection service.

Three of the $\mathrm{CO}_{2}$ injectors in the second row had low input rates due to the poor quality of the reservoir in this area and were converted back to water injection by mid-1998. Another water injector in the row, 4813, had a thief zone above the pay and was never used for $\mathrm{CO}_{2}$ service. The top row of water injection wells were never converted to $\mathrm{CO}_{2}$ service because of the concerns about low injection rates related to the poor quality reservoir. Injector 4807 was converted back to water injection in October 1998 because it was communicating with other wells as discussed above. Due to its close proximity to a residence, injector 4803 was converted back to water injection January 1999 as a safety measure because of the switch to a plant source of $\mathrm{CO}_{2}$ that was contaminated with $\mathrm{H}_{2} \mathrm{~S}$. Injectors 4802 and 4817 were also converted back to water service in January 1999. These were isolated, low input rate injectors in an area where recent development drilling had proven disappointing. Given the limited amount of time left in the project life the chance of usable information being gained in this area was very low. The well status for the demonstration area shown on Figure 15 as of July 31, 2000 has remained unchanged since April 1999. The status and particulars on the $\mathrm{CO}_{2}$ injection wells as of August 1, 2000 are given on Table 3.

By the beginning of 1999, operational and safety considerations based on 15 months of actual experience injecting $\mathrm{CO}_{2}$ had reduced the number of $\mathrm{CO}_{2}$ injectors from the original proposed 21 to eight wells, six of which were concentrated in the southern half of the original project area where the injectors were still on 40-acre density. Although this area contained the better quality reservoir rock and higher $\mathrm{CO}_{2}$ injection rates, the lack of injectors and the failure of the fracture extension technique resulted in an extremely low hydrocarbon pore volume (HCPV) processing rate on the order of $3.5 \%$ per year. Industry experience with miscible $\mathrm{CO}_{2}$ floods in San Andres reservoirs indicated that very little response is seen until at least $15 \%$ of the HCPV has been processed. With a 
project termination date of September 30, 2000 there was a strong possibility that total injection would not be sufficient to evaluate the project.

In February 1999 the $\mathrm{CO}_{2}$ source switched from the Estes pipeline to recycled $\mathrm{CO}_{2}$ from a gas plant with a supply limited by plant capacity, daily gas input and $\mathrm{CO}_{2}$ content. Demand began to exceed supply and in the face of low oil prices, priority was given to projects already experiencing significant oil response. Although the other two active $\mathrm{CO}_{2}$ injectors located in the expansion area, 4814 and 4816, had good input rates and both of their north offset producers, 4833 and 4834 , were showing some response in the form of increased gas production, the decision was made to convert both back to water service. $\mathrm{A} \mathrm{CO}_{2}$ focus area (Figure 15) was created that concentrated the $\mathrm{CO}_{2}$ injection in a 400 acre area in an attempt to maximize the reservoir processing rate. The six remaining injectors created six inverted seven-spot patterns with a center point injector serving six producers. To gain more time to process the reservoir, application was made to the DOE for a one-year extension of the termination date to September 30, 2001. The official approval had not been received by August 3, 2000, but it was highly probable that the extension would be granted since no additional funds from the DOE was involved. The performance of the six individual injectors in the focus area is shown by Figures $16-21$.

The $\mathrm{CO}_{2}$ focus area with it closed patterns made possible the volumetric determination of the processing rate in terms of percent of HCPV. Table 4 shows the monthly processing rate for both $\mathrm{CO}_{2}$ and water from 8/1/99 to 7/31/00. Injector 4811 was switched (WAG'd) from $\mathrm{CO}_{2}$ to water injection in November 1999 to control gas breakthrough in producer 4843. In December 1999, injector 4805 was WAG'd to water injection to eliminate gas breakthrough in producer 4844 . Well 4811 was returned to $\mathrm{CO}_{2}$ injection in February 2000, but 4805 was still on water as of August 3, 2000. In June 2000 the $\mathrm{CO} 2$ source was switched back to the Estes pipeline which gave an ample supply at a higher pressure, creating the opportunity to increase $\mathrm{CO}_{2}$ injection. At the start of $\mathrm{CO}_{2}$ injection maximum surface injection pressure had been set for each well based on waterflood step-rate tests adjusted for the density difference between water and $\mathrm{CO}_{2}$. Bottom hole flowing pressure surveys were run to verify the surface pressures. All of the injectors were then operated at the calculated maximum surface injection pressure.

Having to WAG an injector to water lowers the $\mathrm{CO}_{2}$ processing rate. The volume of produced gas that can be handled is not only a function of gathering facilities and plant capacity, but the ability to effectively pump high ratio producers. The physical properties of $\mathrm{CO}_{2}$ create special problems as it changes from a liquid to a gas upon approaching the wellbore. As the field operators gain experience higher ratio wells can be kept on production without having to WAG the injectors to water to control gas breakthrough. Other approaches being considered to increase the processing rate include: 1) running new step rate test to determine if the injection pressure can be increased; 2) drill a horizontal lateral; and 3) perform remedial treatment on producers to remove any wellbore damage. More frequent monitoring of performance by both the field and reservoir personnel has been initiated to insure that $\mathrm{CO}_{2}$ input is maximized.

The classic response of a producer to an approaching miscible oil bank is a drop in water production, followed by an increase in gas (mainly $\mathrm{CO}_{2}$ ) production, then a prolonged increase in oil. At the West Welch demonstration project response has usually not followed a set pattern primarily due to the heterogenous nature of the reservoir rock that allows gas to break through to a producer without forming an miscible oil bank. Variation in the injection rates for both $\mathrm{CO}_{2}$ and water have an impact on saturation and pressure distributions in the reservoir, which affects response. These factors also make it difficult to separate actual response of a well to an approaching miscible oil bank from other variations in a wells performance. For example, a major reduction in the historical water injection rates in the demonstration area prior to initiation of $\mathrm{CO}_{2}$ injection lowered reservoir pressure and caused a significant decline in the producing rates of many wells. This can be seen on the individual performance curves for the 21 focus area producers (Figures 22 - 42). Some of the curves indicate an increase in oil production during the reporting period. It is necessary to make a judgment whether the increase is due to an approaching miscible oil bank or response to an increase in reservoir pressure.

The problem has been complicated by inaccurate data in the well test database that is used to allocate production to individual wells. The database has been corrected and the allocation methodology improved. It is also necessary to observe well performance over a period of several months. Some of the apparent "oil responses" to $\mathrm{CO}_{2}$ 
injection that were reported in the quarterly reports proved to be short-lived. This may have been a result of inaccurate test data or a change in $\mathrm{CO} 2$ input when an injector was restricted or switched to water. The identification of $\mathrm{CO}_{2}$ breakthrough is much easier since the only hydrocarbon gas left in the formation is the small volume still in solution in the oil and the $\mathrm{CO}_{2}$ content can be readily analyzed. The use of decreasing water production as a precursor to an approaching miscible oil bank has not been reliable since the established water input volumes and patterns changed dramatically with the initiation of $\mathrm{CO}_{2}$ injection.

As of August 2, 2000 within the focus area there have been three producers that were judged to have a sustained oil response to $\mathrm{CO}_{2}$ and ten wells with $\mathrm{CO}_{2}$ breakthrough (Figure 43 ). Overall an insufficient volume of the HCPV $(<10 \%)$ in the focus area has been processed to date by $\mathrm{CO}_{2}$ for significant response to occur. Hence it is premature to make any judgments about the success of the project. The steps now being taken or planned, including very detailed monitoring of performance, to maximize the $\mathrm{CO}_{2}$ processing rate in the focus area will allow a much more comprehensive evaluation of the project by the proposed termination date in September 2001.

\section{Technology Transfer}

All five of the technology transfer events listed below involved results from the ongoing interpretation and application of the interwell seismic data that have been acquired as part of the project. Nearly all of the new or advanced technologies to be demonstrated by the West Welch project were directed toward the reservoir characterization that took place during Budget Period 1. A large number of papers and presentations resulted from the petrophysical and 3D seismic investigations that were conducted in this phase. The interwell seismic processing and interpretation techniques were literally being developed from scratch. This investigation has continued into Budget Period 2 with results being reported periodically. The field demonstration phase has not yet advanced to evaluation phase so there is no technology transfer from this source yet.

1. Presentation by Jim Justice: Justice, Jim, J. C. Woerpel, G. W. Watts, W. Waddell, " Interwell Porosity and Permeability from Biot-Gassmann with Shear and Compressional Tomography and Cross-Plots," Annual SEG Meeting, Houston, TX 11/2/1999.

2. Presentation by Jim Justice: Justice, Jim, "Interwell Seismic Data For Reservoir Characterization," SPE Permian Basin Oil and Gas Recovery Conference, Midland, TX, 3/22/00. (Published in Proceedings).

3. Presentation by Jim Justice: Justice, Jim, "Reservoir Characterization Using Interwell Seismic in a Shallow Shelf Carbonate Reservoir," Petroleum Systems of Sedimentary Basins Southern Mid-Continent Workshop, Oklahoma City, OK, 3/29/00.

4. Presentation by Jim Justice: Justice, Jim, "Interwell Seismic for Reservoir Characterization and Monitoring," SPE/DOE Improved Oil Recovery Conference, Tulsa, Ok, 4/5/00.

5. Presentation by Jim Justice: Justice, Jim "Interwell Seismic for Reservoir Characterization and Monitoring," SPE/AAPG Western Regional Meeting in Long Beach, CA, 6/20/00. (Published in Proceedings) 


\section{REFERENCES}

1. Watts, G.P., Hinterlong, G.D. et al, "Seismic Estimate of Porosity in the Permian San Andres Carbonate Reservoir, Welch Field, Dawson County, Texas," March 1996 Proceedings: Oklahoma Geological Society Workshop on Platform Carbonated of the Southern Midcontinent.

2. Egg, Rebecca, Hickman, T.S., Justice, J.J., "Application of Reservoir Characterization and Advanced Technology to Improve Recovery and Economics in a Lower Quality Shallow Shelf Reservoir", DOE Contract No. DE-FC22-94BC14990, 1998 Annual Report, January 9, 2001. 
Table 1

BIOT-GASSMAN MODEL

EFFECTS OF PORE FLUID COMPRESSIBILITY ON SEISMIC VELOCITY

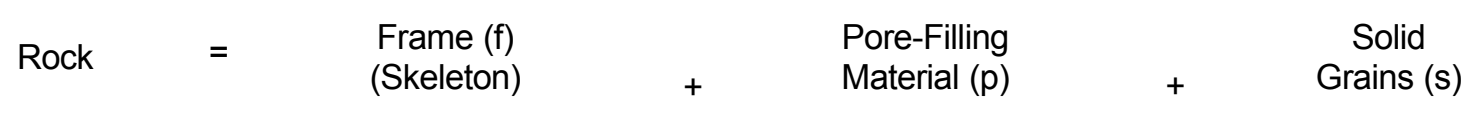

$$
\begin{array}{ll}
\mathrm{pV}_{\mathrm{s}}^{2}=\mathrm{G}_{\mathrm{f}} & \Phi=\text { porosity } \\
\mathrm{pV}_{\mathrm{p}}^{2}=\mathrm{K}_{\mathrm{f}}+\frac{4}{3} \mathrm{G}_{\mathrm{f}}+\frac{\left(1-\frac{\mathrm{K}_{\mathrm{f}}}{\mathrm{K}_{\mathrm{S}}}\right)^{2}}{\left(1-\Phi-\frac{\mathrm{K}_{\mathrm{f}}}{\mathrm{K}_{\mathrm{S}}}\right) \frac{1}{\mathrm{~K}_{\mathrm{S}}}+\frac{\Phi}{\mathrm{Kp}}} & \mathrm{K}=\text { rock density } \\
\text { "frame" } & \mathrm{G}=\text { shem modulus modulus } \\
\text { "pores" } &
\end{array}
$$


Table 2

\section{Initial Potential of Wells Drilled in Expansion Area}

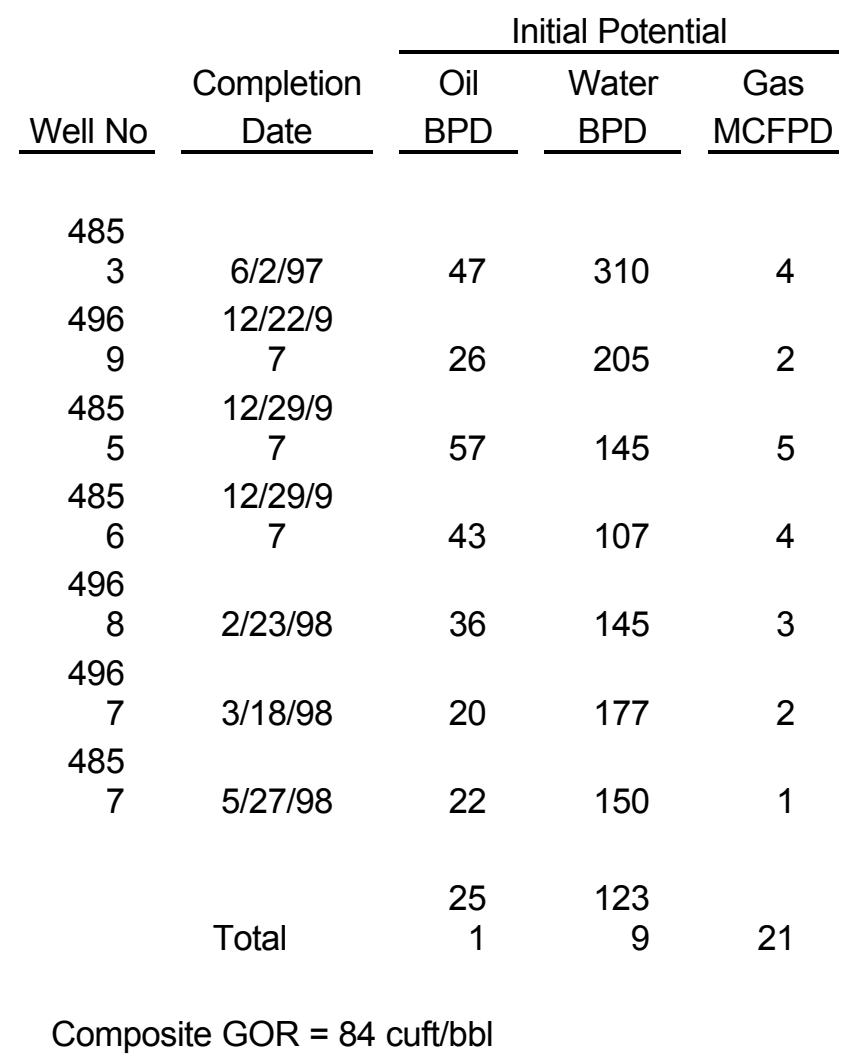

Table 3

CO2 Injector Status

As of July 31, 2000

West Welch Unit DOE Area

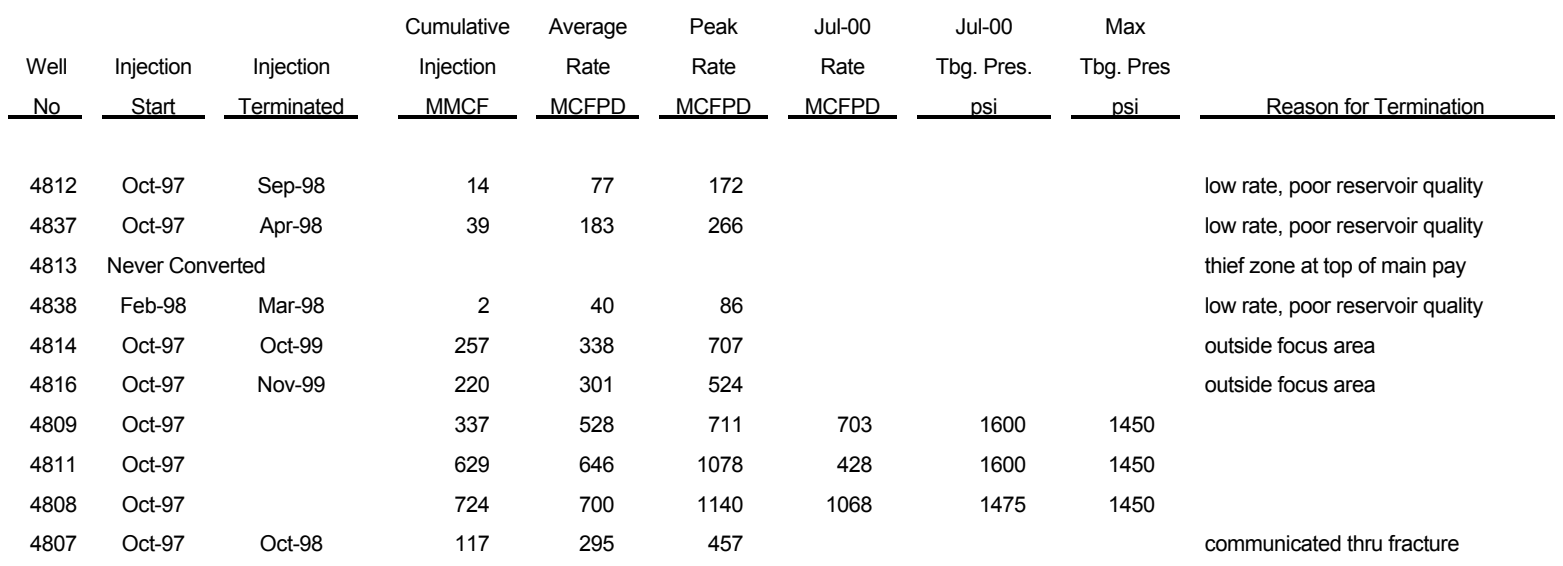




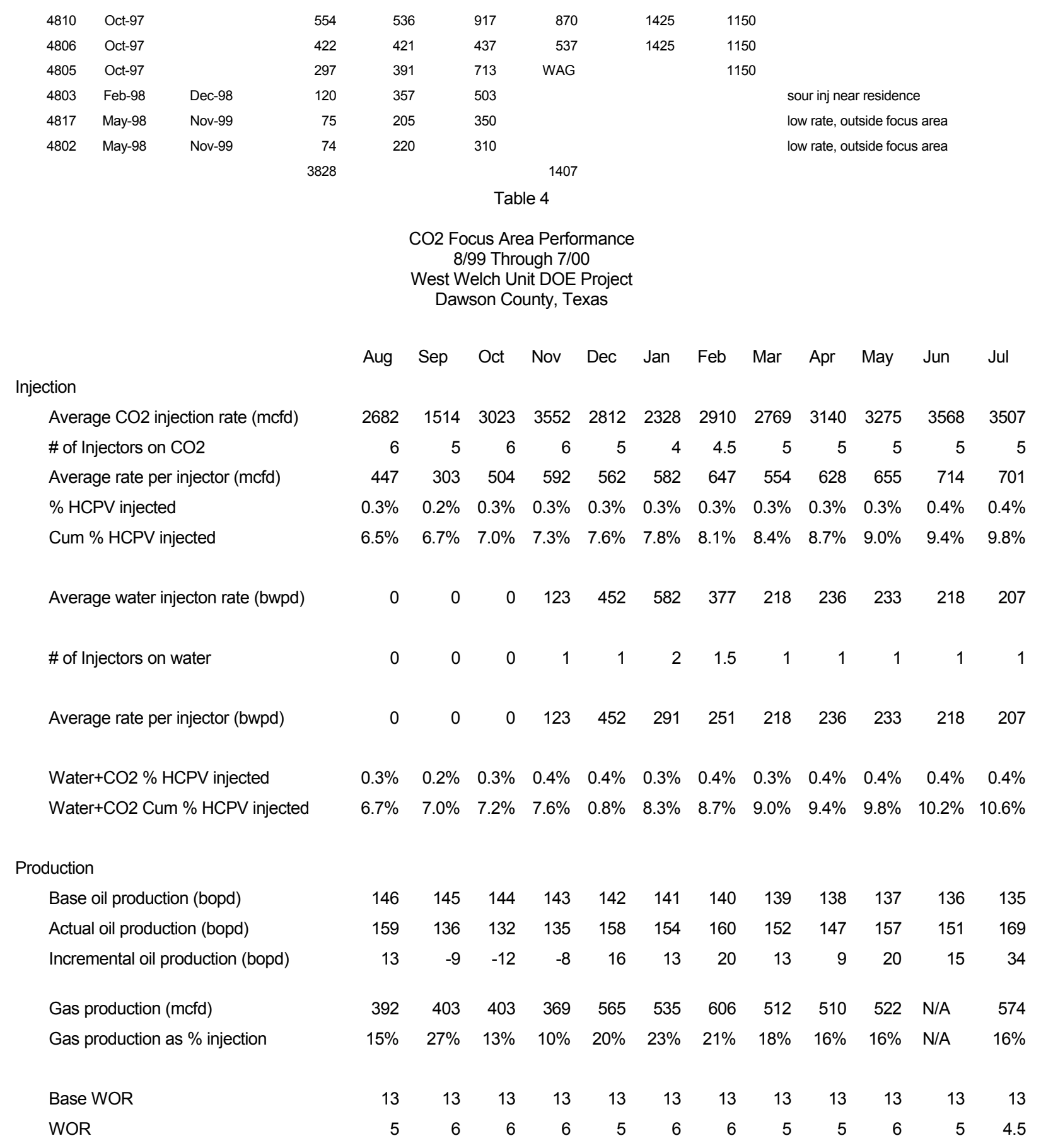




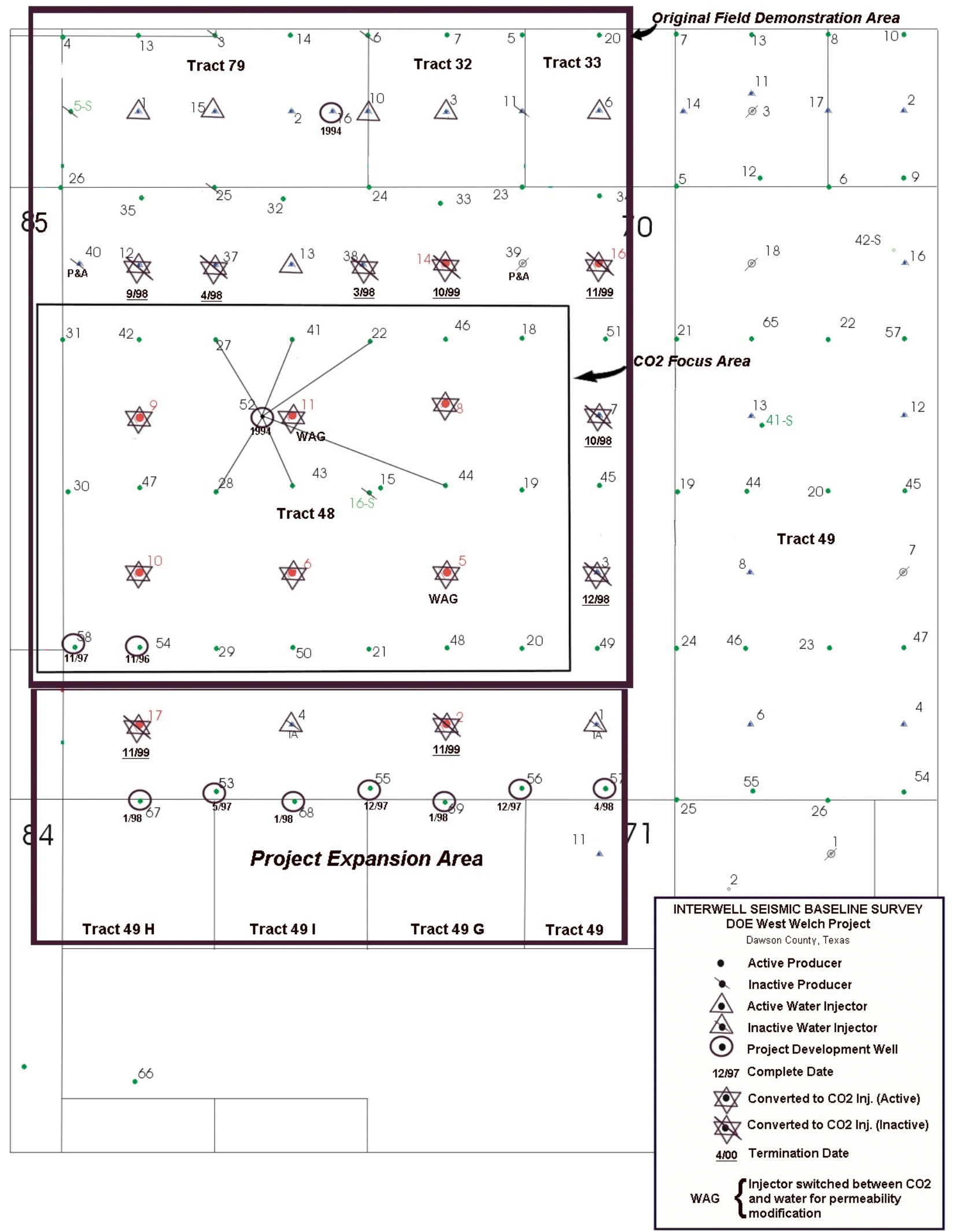

Fig. 1 - Interwell Seismic Acquisition Lines - Baseline Survey 


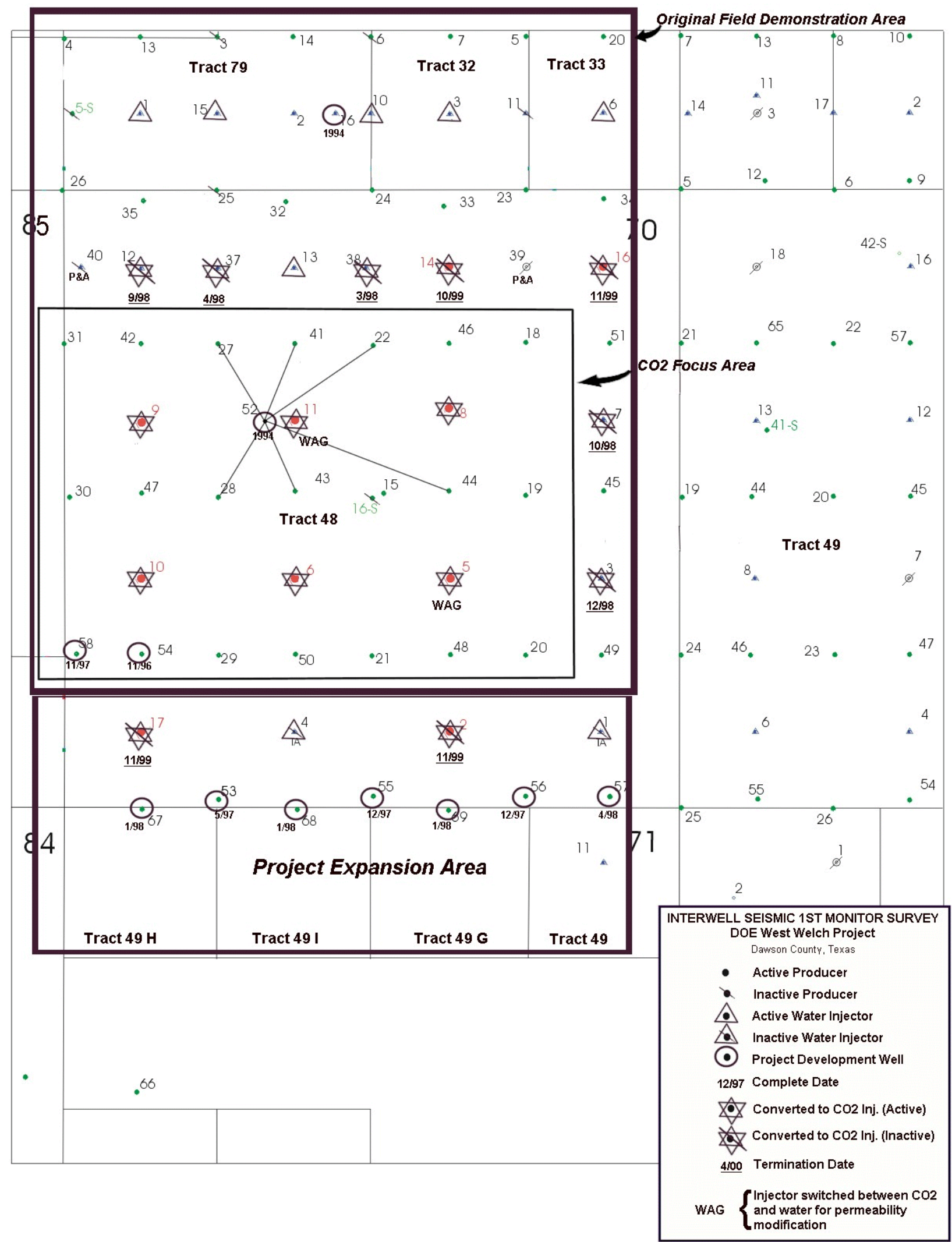

Fig. 2 - Monitor Survey (Phase 2) 


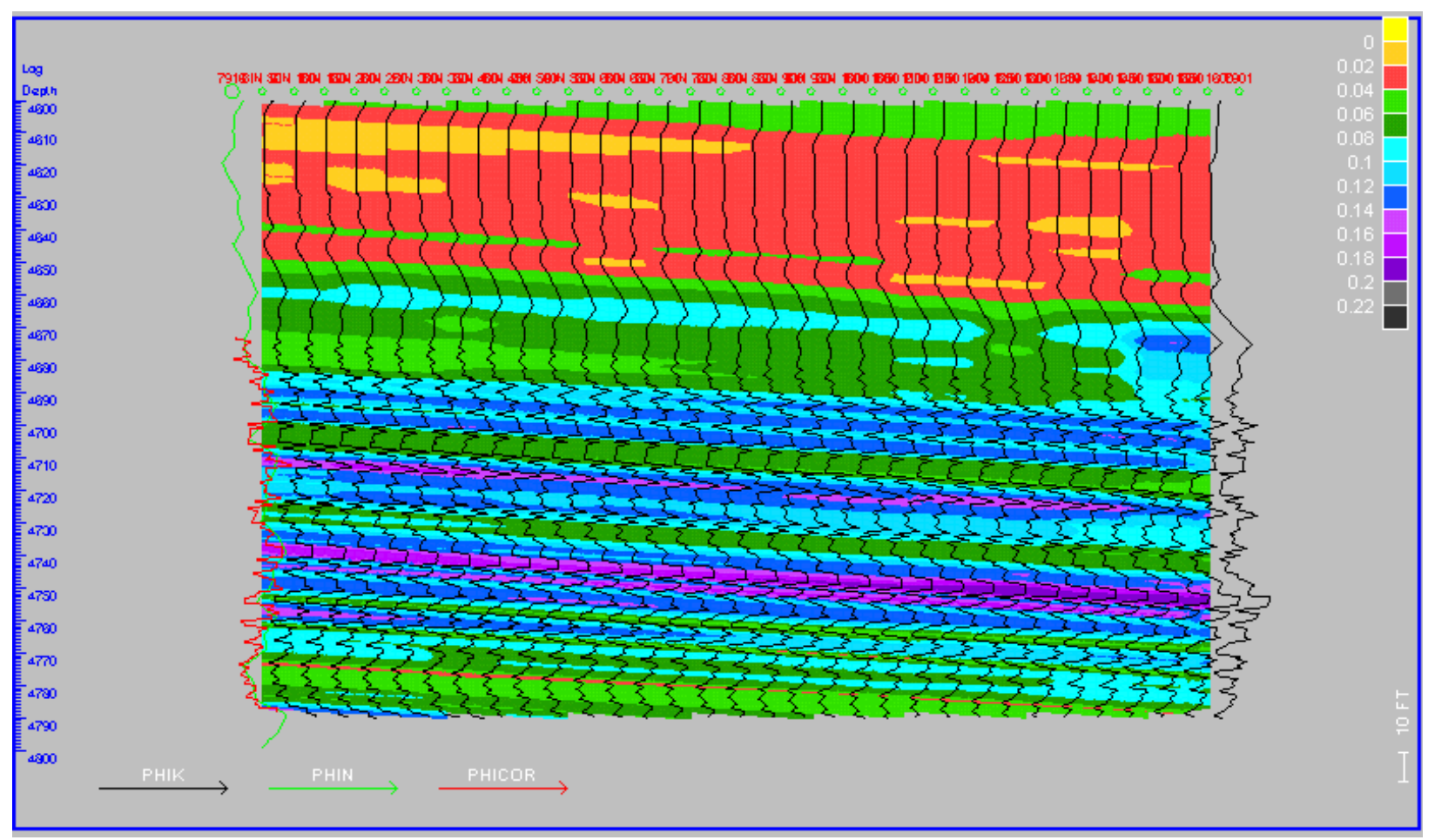

Fig. 3 - Interwell (Nos 7916-7910) Porosity Profile Developed with Biot-Gassman Equation

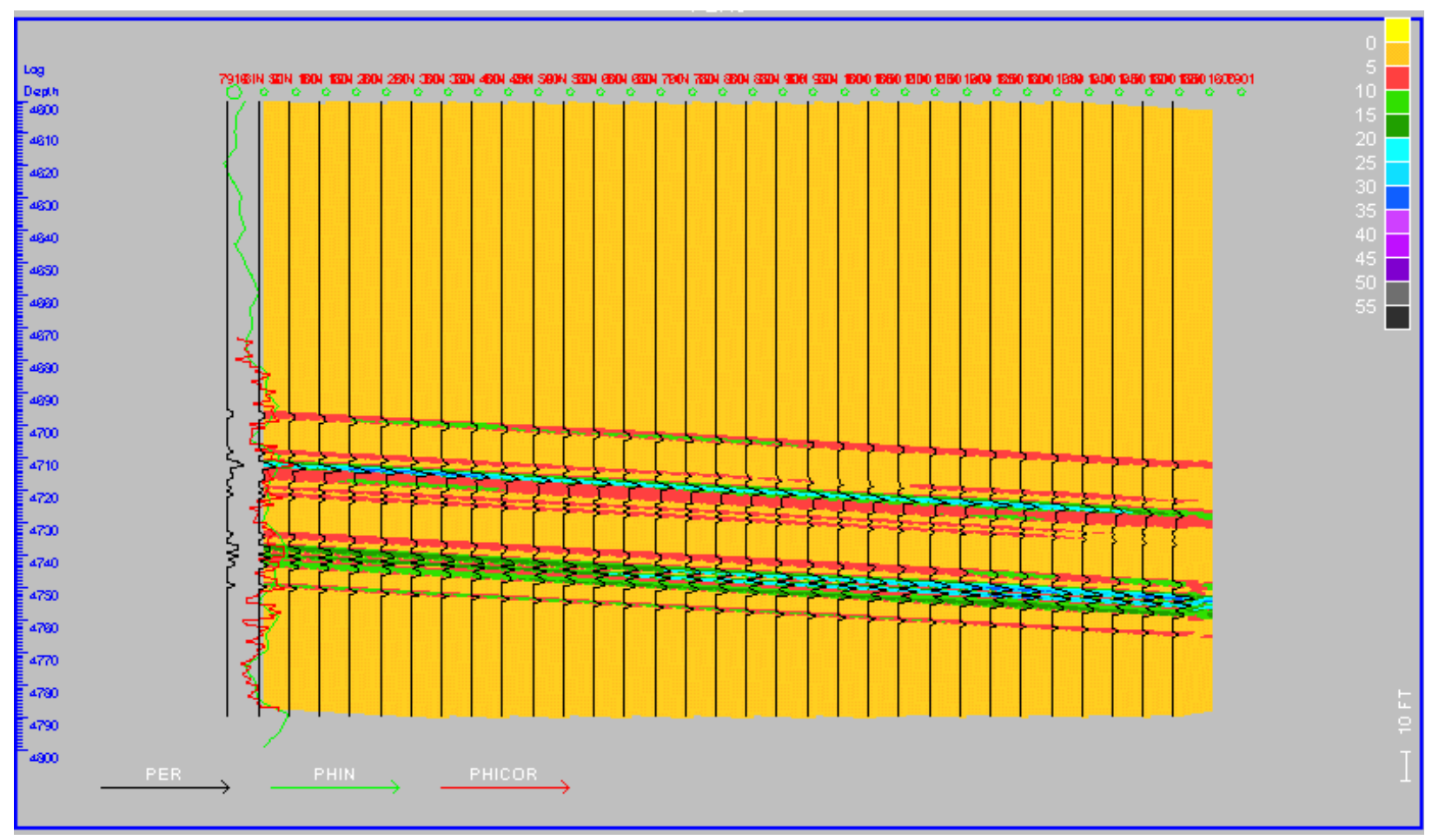

Fig. 4 -

Interwell (Nos 7916-7910) Permeability Profile Based on Porosity v. Permeability Relationship Developed for Four Major Rock Types 


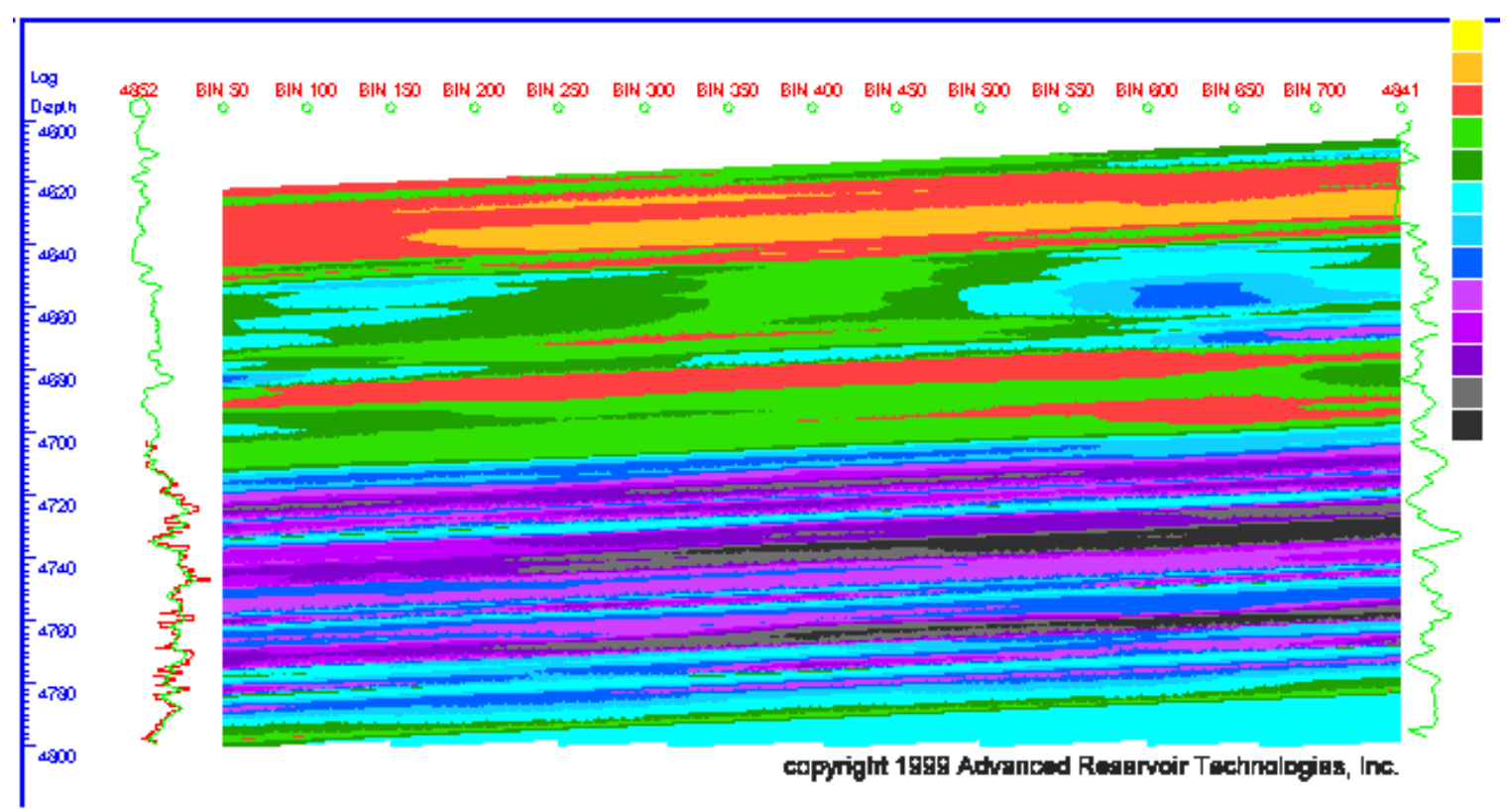

Fig. 5 - Interwell Seismic Porosity Section Enhanced by Neutron Log

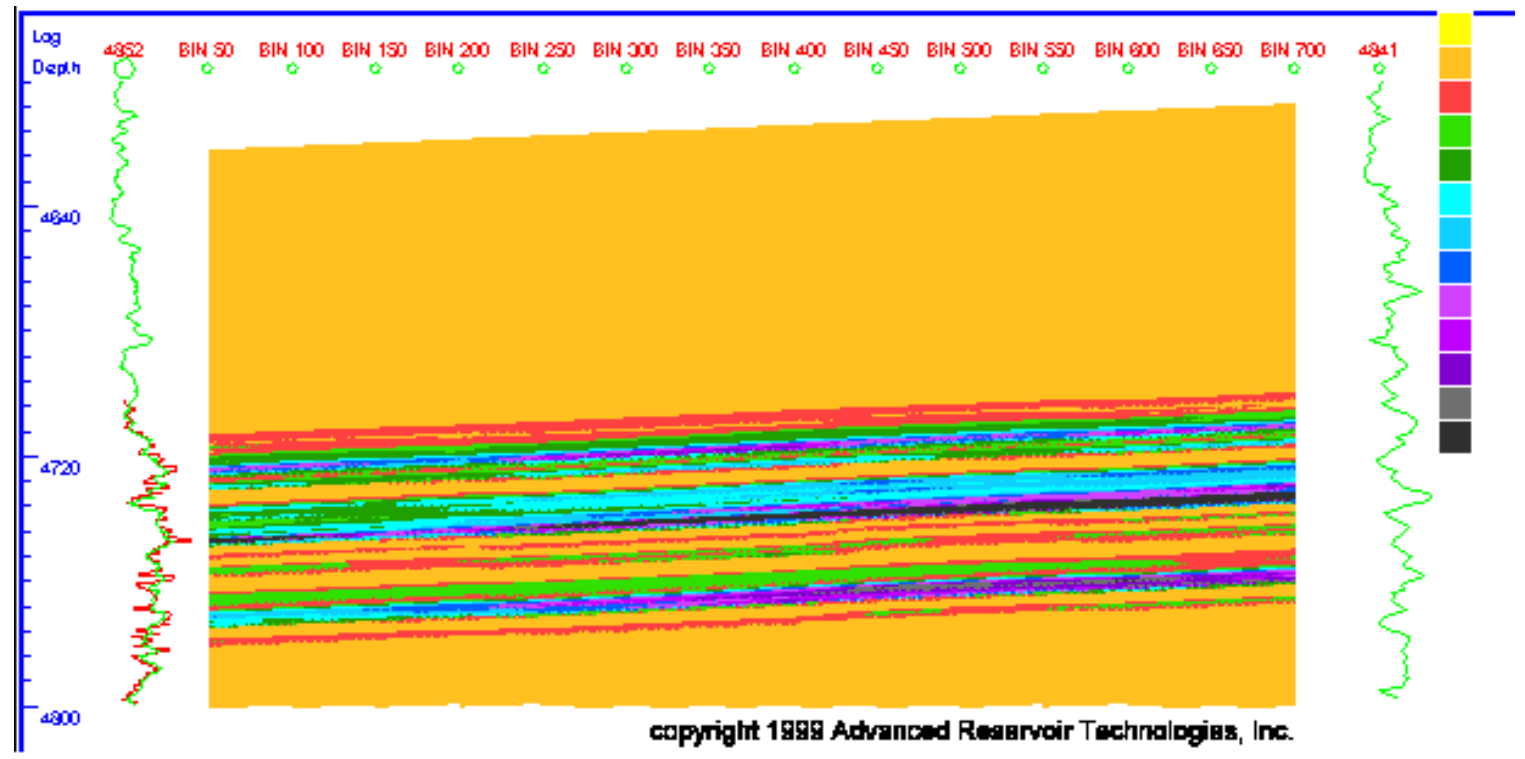

Fig. 6 - Interwell Permeability Section Based on Enhanced Porosity Interpretation 

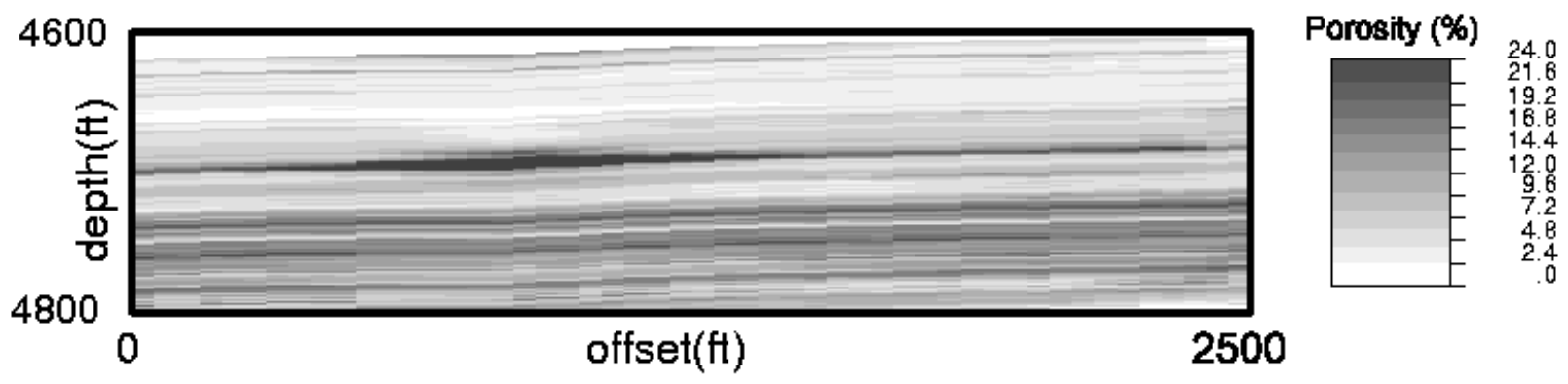

Fig. 7 - East-West Porosity Section from Reservoir Volume Model Created by Ordinary Kriging
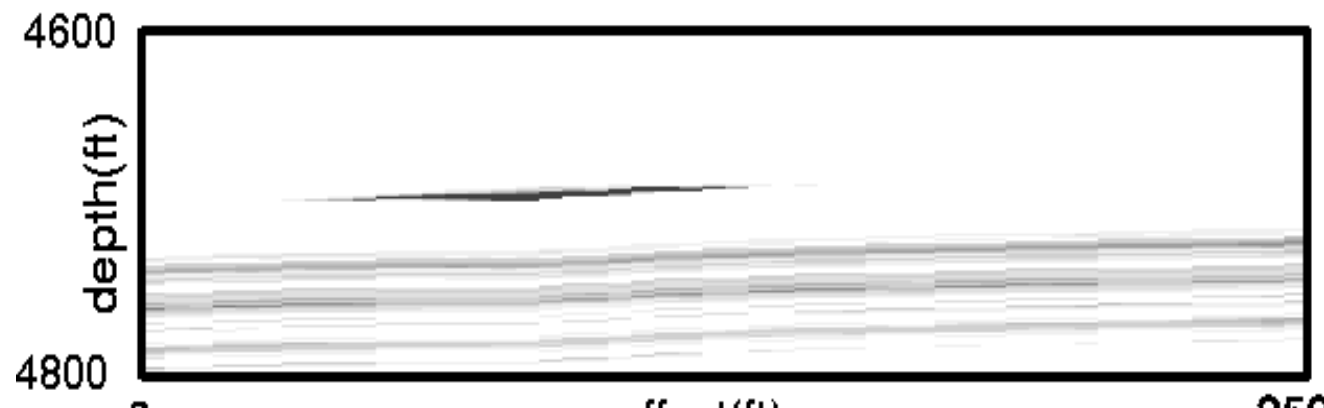

Permeability (mx)

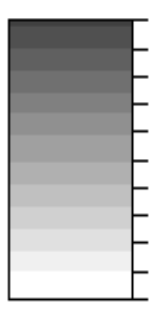

60.0

54.0

48.0

42.0

36.0

30.0

18.0

12.0

0

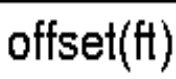

2500

Fig. 8 - East-West Permeability Section from Reservoir Model Created by Ordinary Kriging

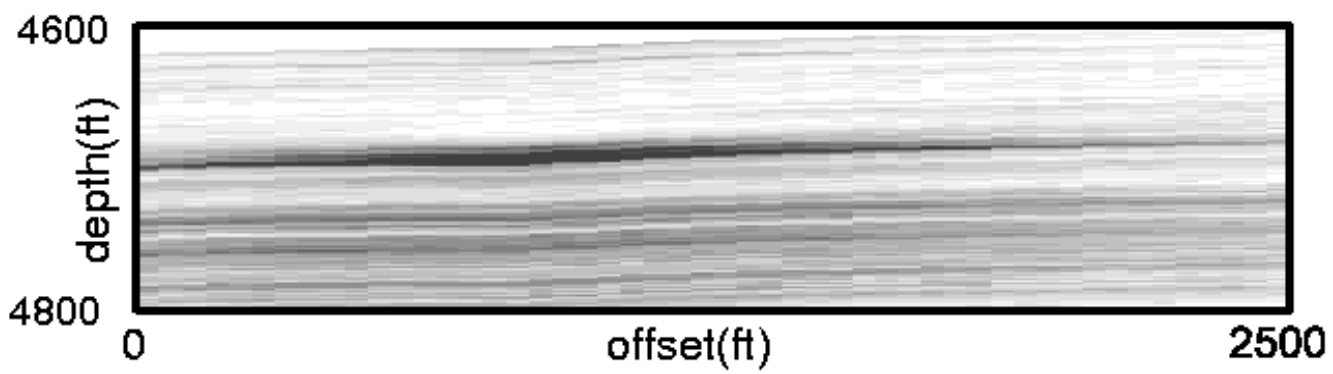

Porosity (\%)
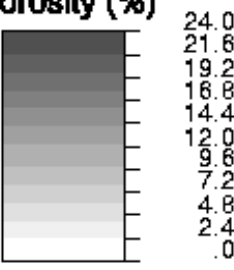

Fig. 9 - East-West Porosity Section from Reservoir Model Created by Conditional Simulation

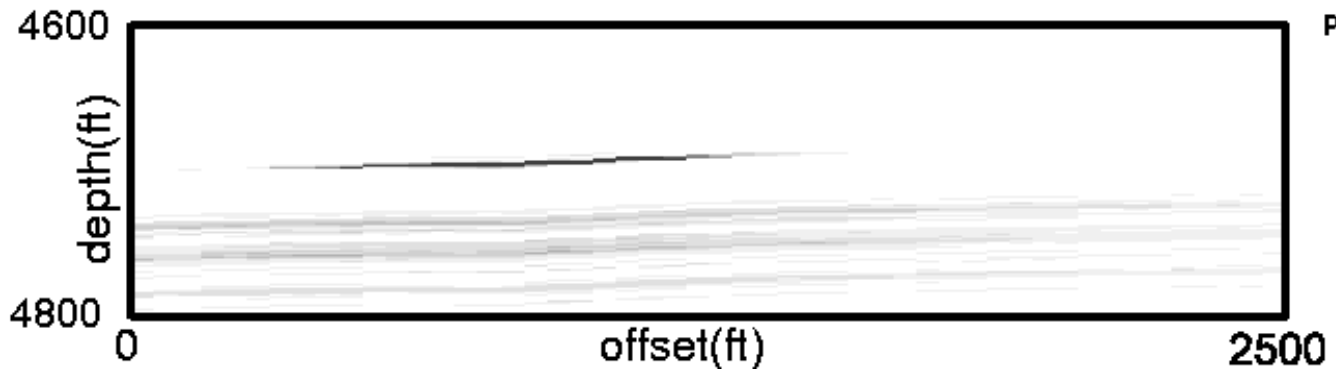

Permeability (md)

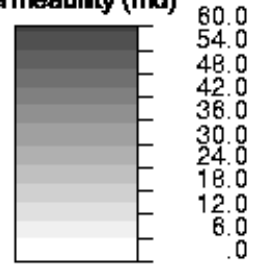

Fig. 10 - East-West Permeability Section from Reservoir Model Created by Conditional Simulation 


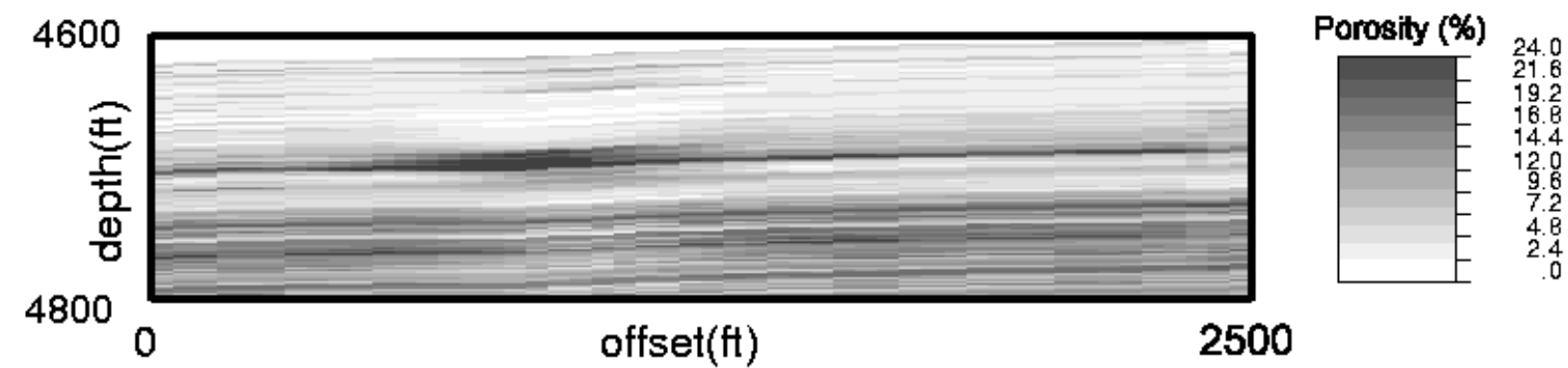

Fig. 11 - East-West Porosity Section from Reservoir Model Created by Cokriging (Neutron Logs Secondary)

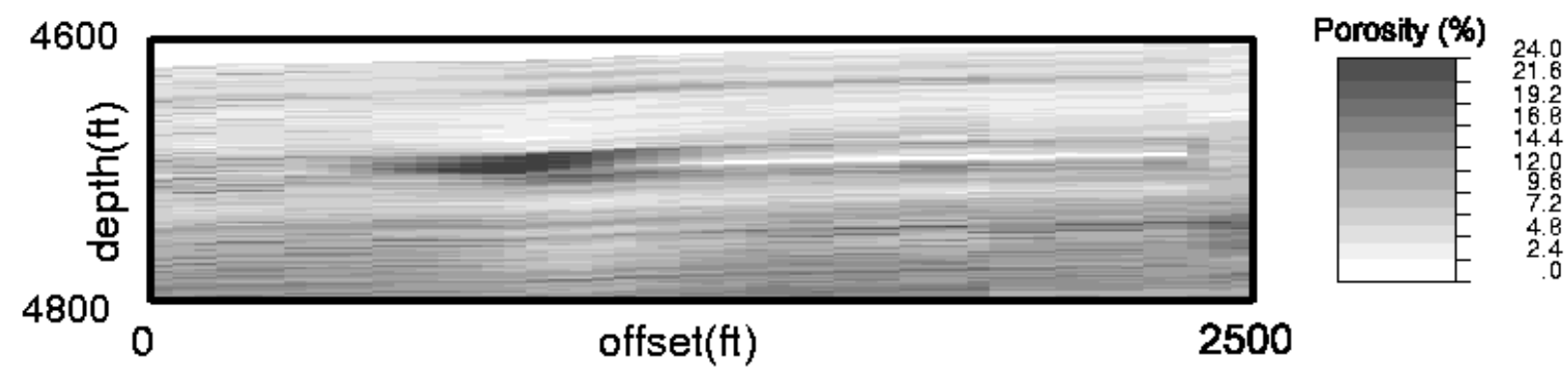

Fig. 12 - East-West Permeability Section from Reservoir Model Created by Cokriging (Neutron Logs Primary)

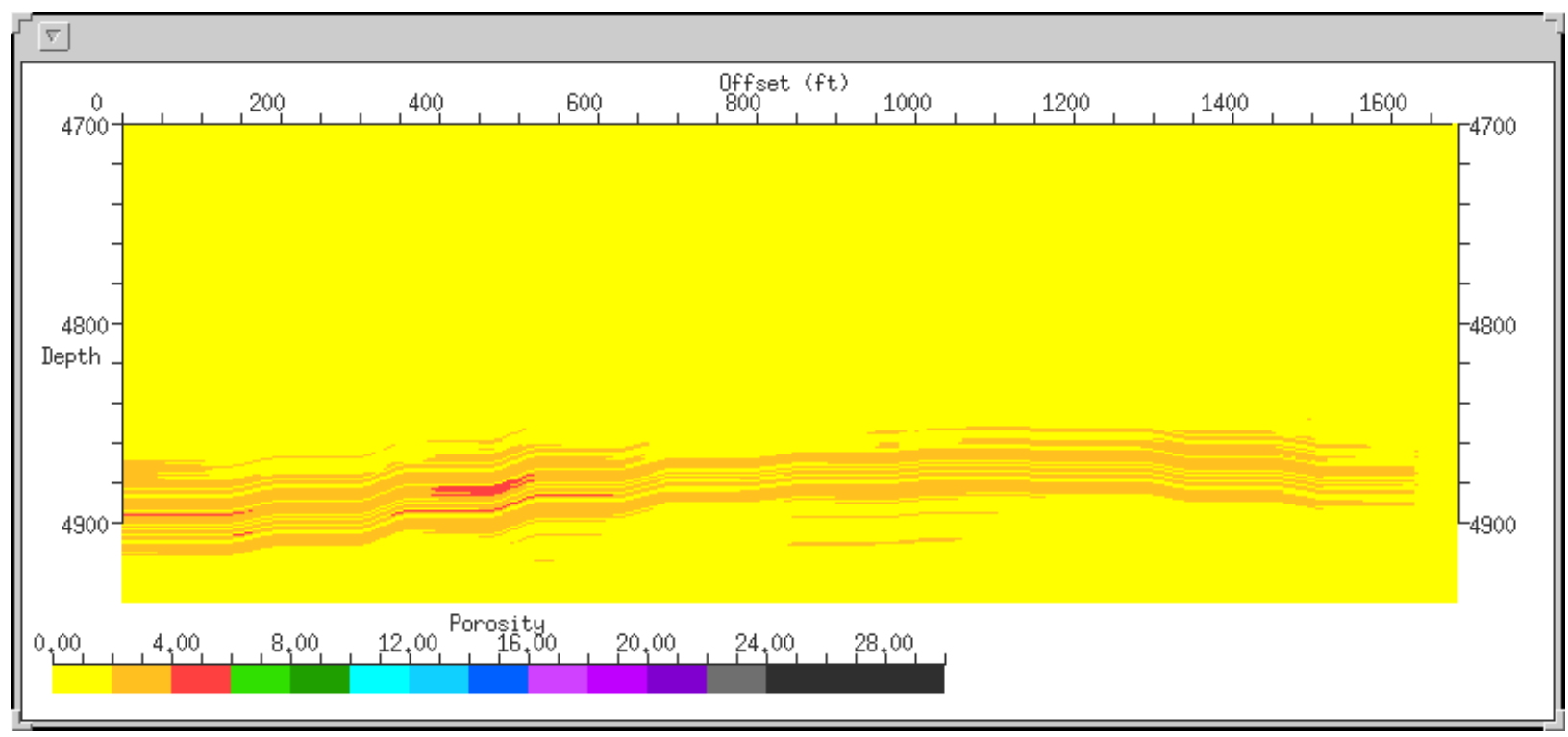

Fig. 13 - Apparent Porosity Change Greater than 2.0 Porosity Percent Along Survey Line 4852-4844 


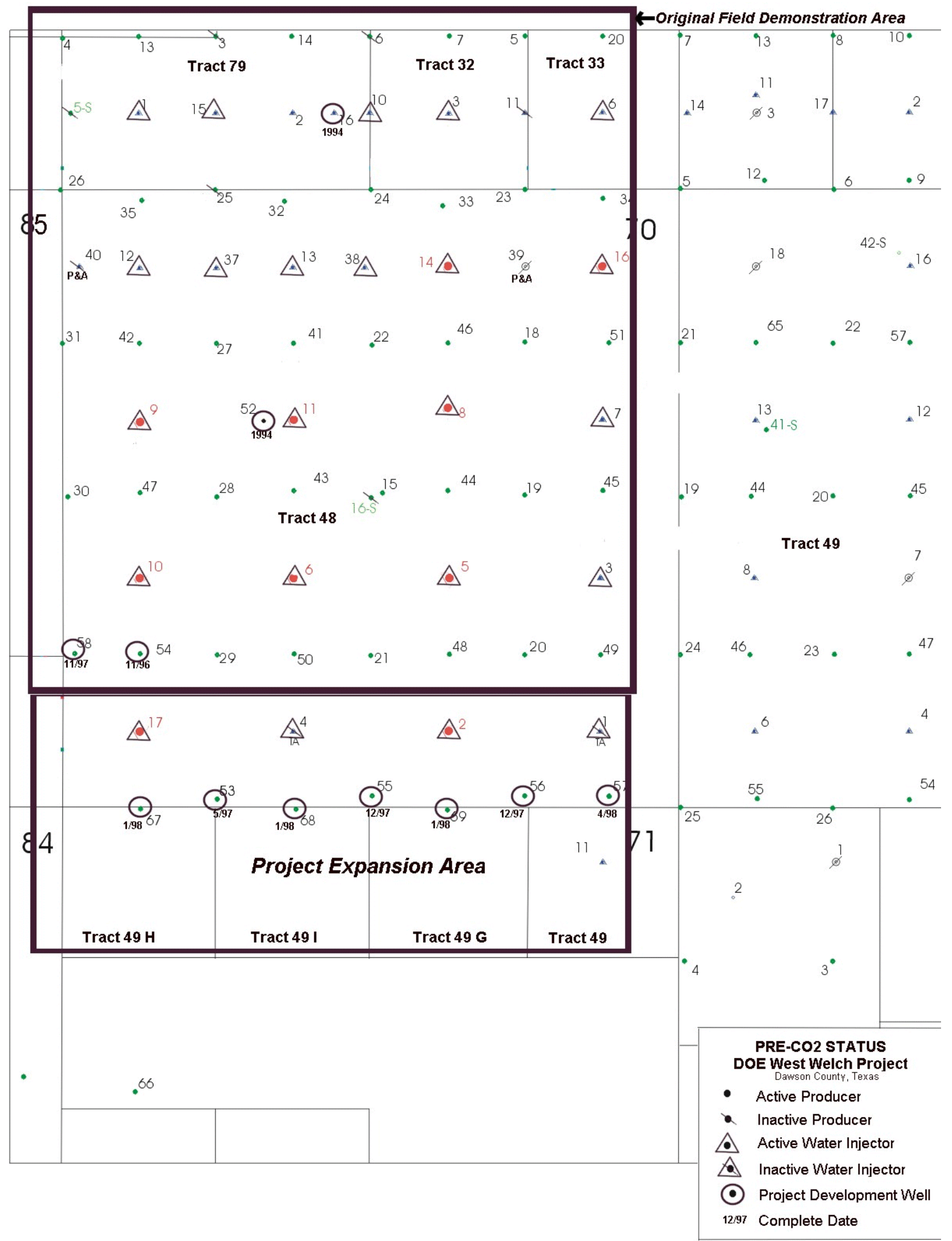

Fig. 14 


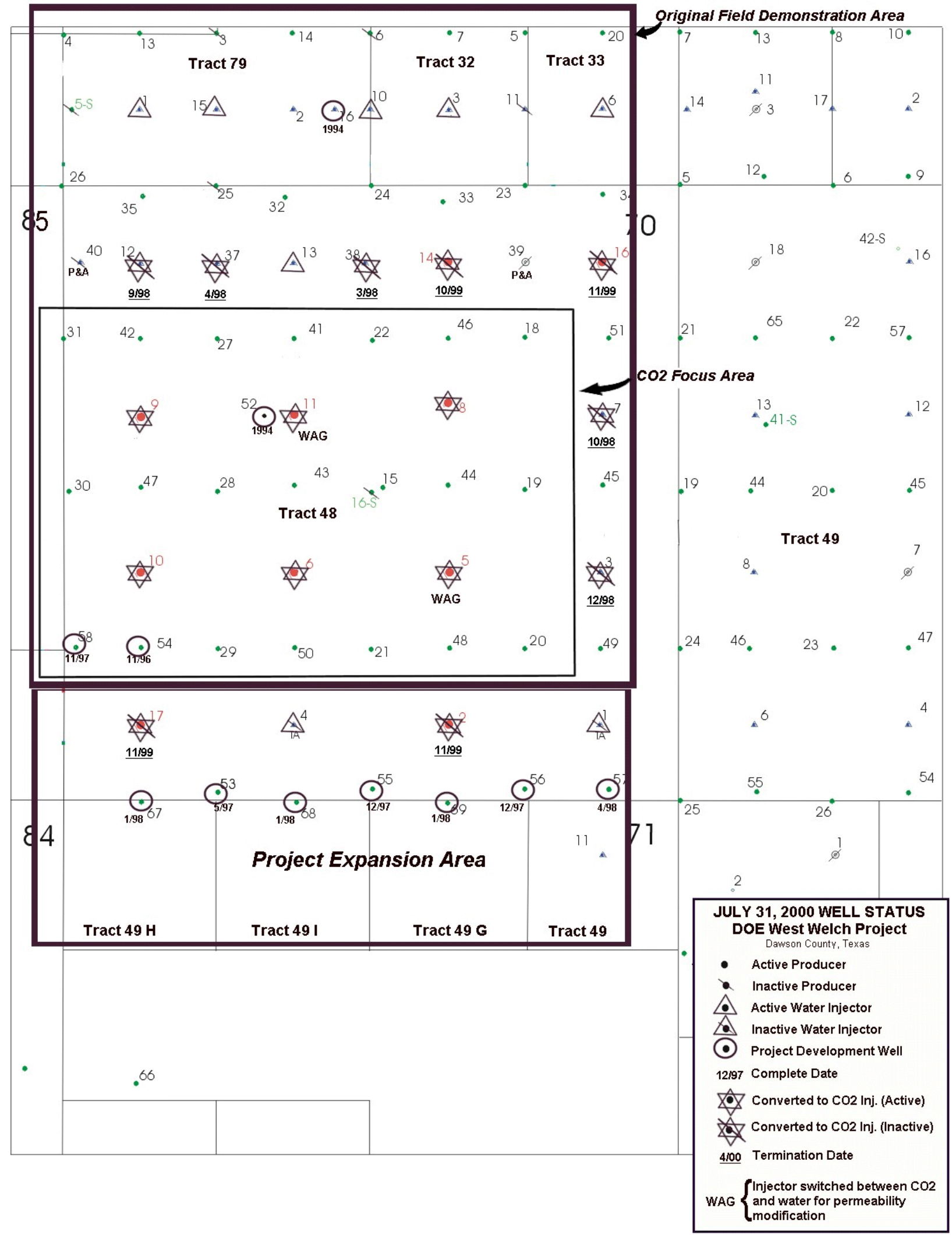

Fig. 15 - July 31, 2000 Well Status Plat 


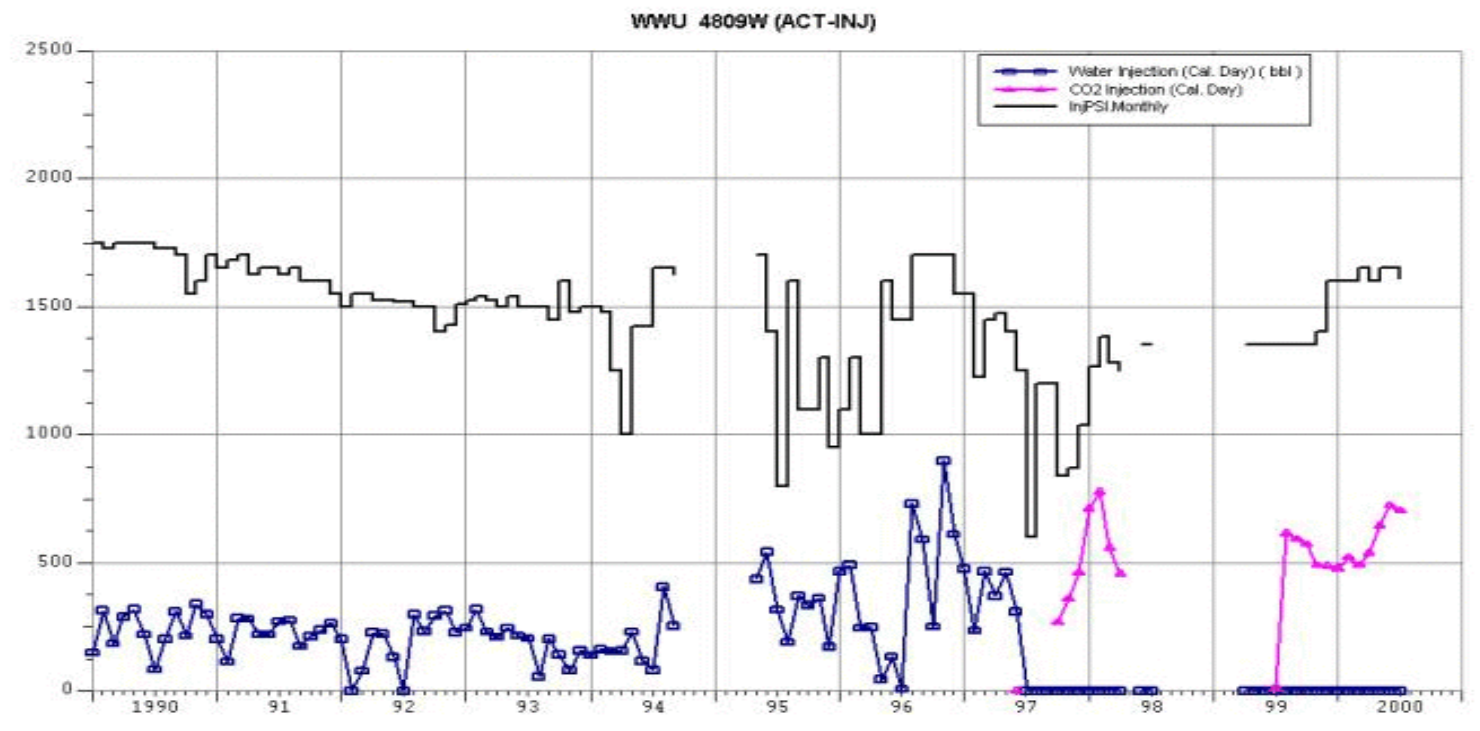

WWU \#4809 CO2 Injector

Fig. 16 - Rate v. Time Curve - Injector 4809

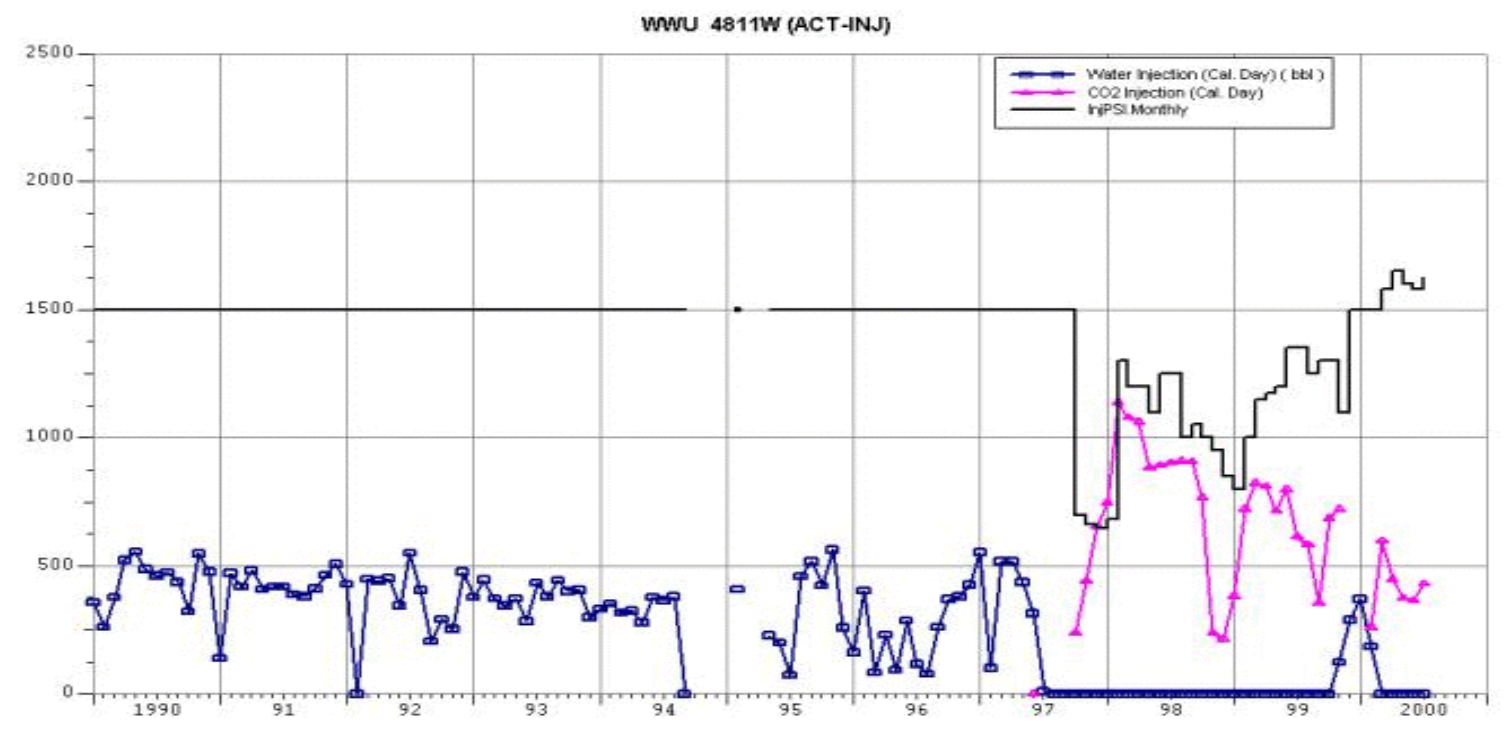

WWU \#4811 CO2 Injector

Fig. 17 - Rate v. Time Curve - Injector 4811 


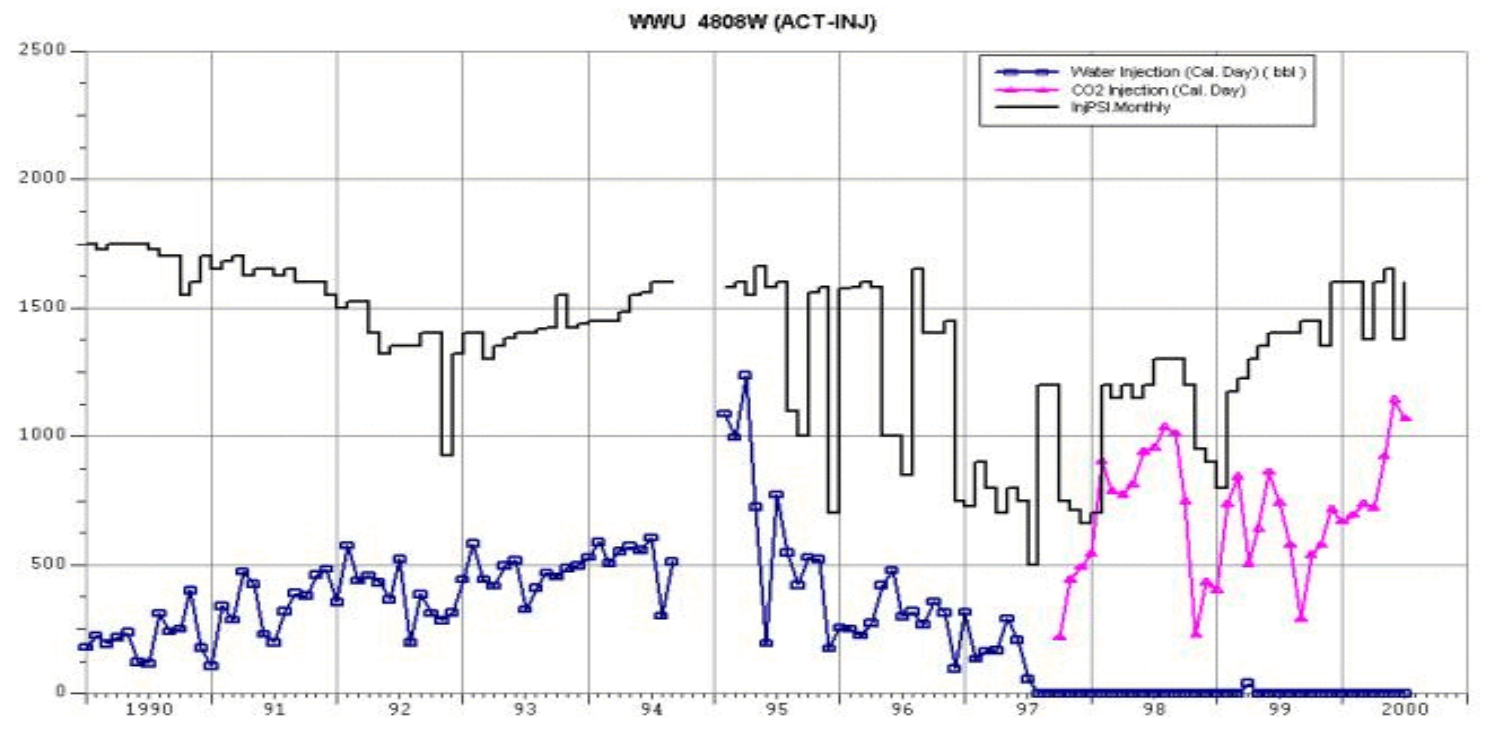

WWU \#4808 CO2 Injector

Fig. 18 - Rate v. Time Curve - Injector 4808

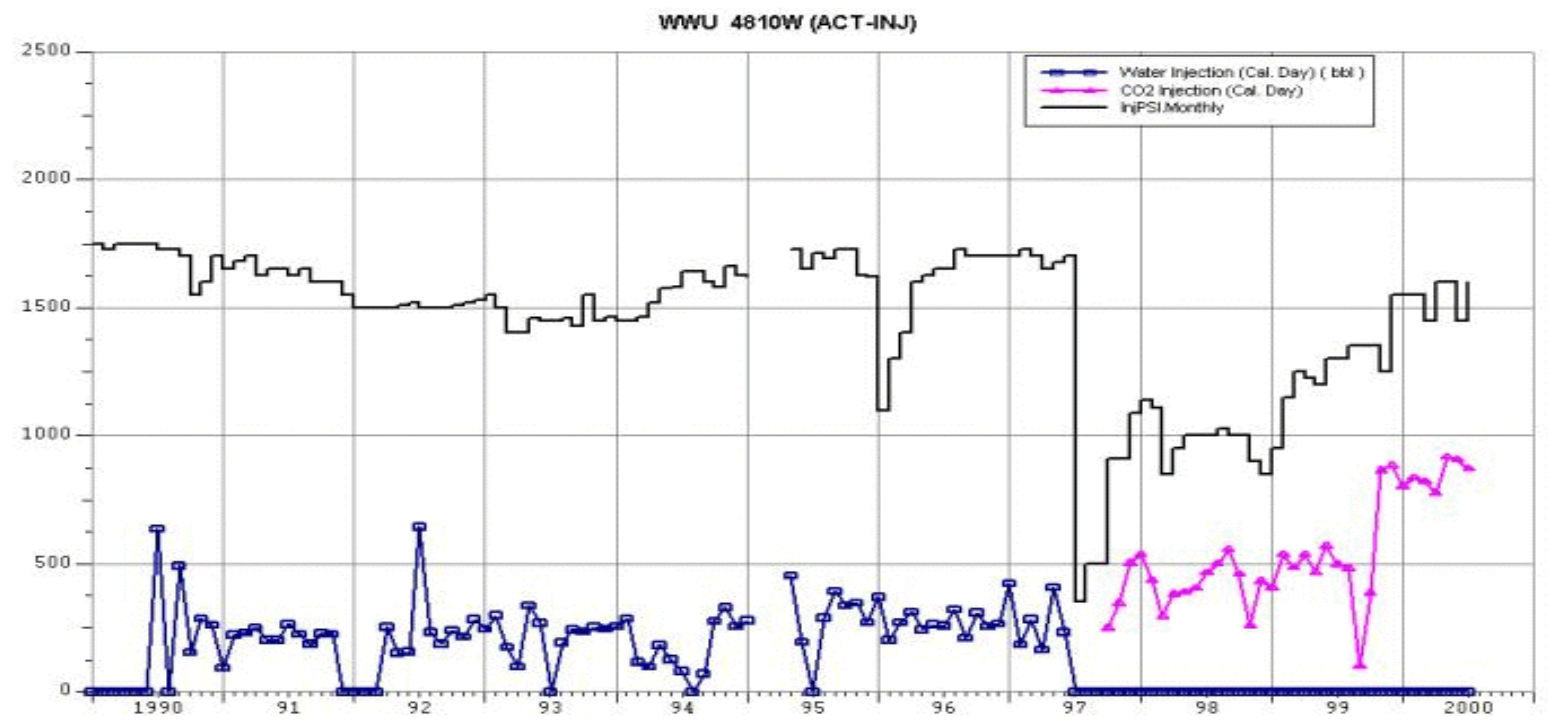

WWU \#4810 CO2 Injector

60

Fig. 19 - Rate v. Time Curve - Injector 4810 


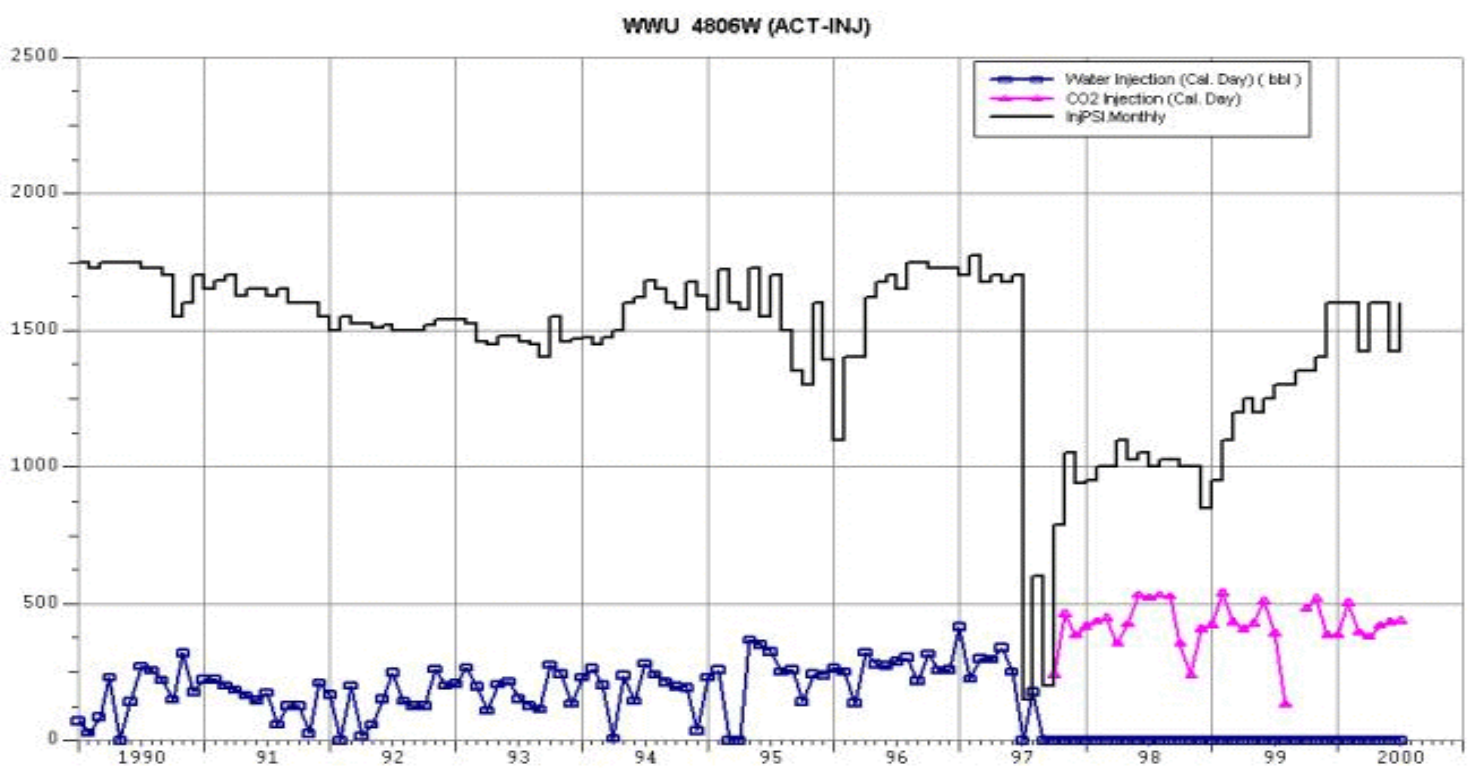

WWU \#4806 CO2 Injector

Fig. 20 - Rate v. Time Curve - Injector 4806

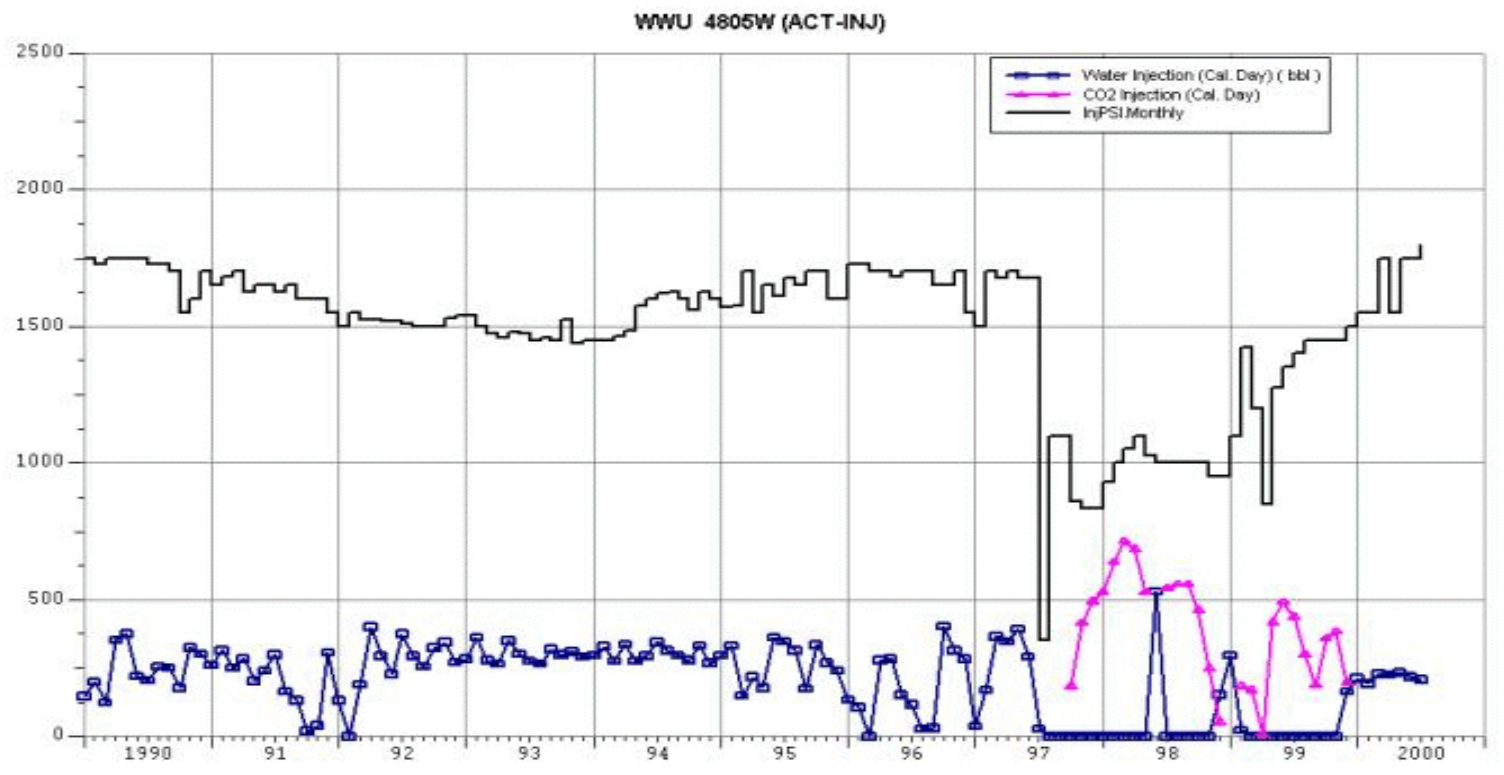

WWU \#4805 CO2 Injector

Fig. 21 - Rate v. Time Curve - Injector 4805 


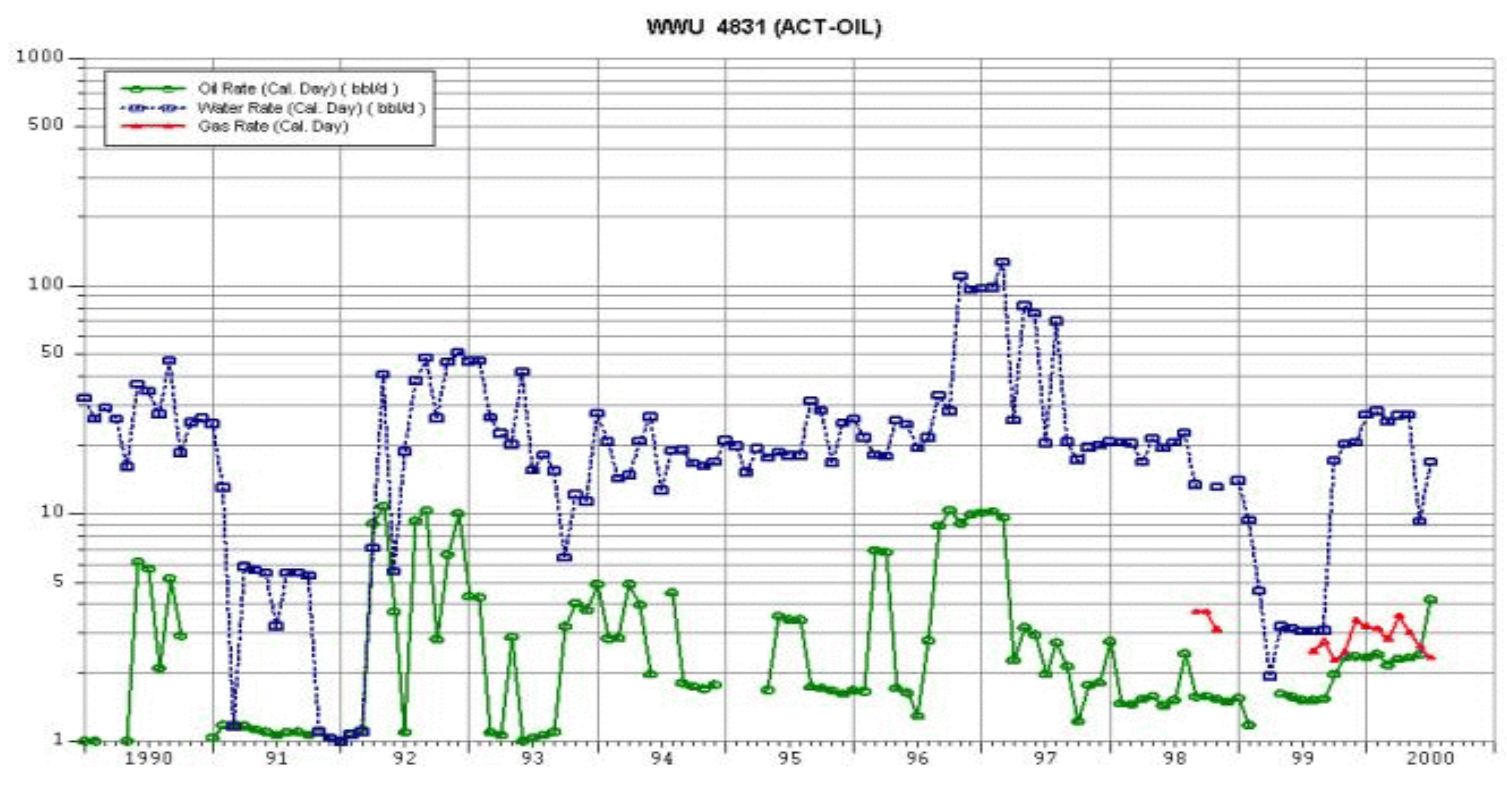

WWU \#4831

Fig. 22 - Rate v. Time Curve - Producer 4831 


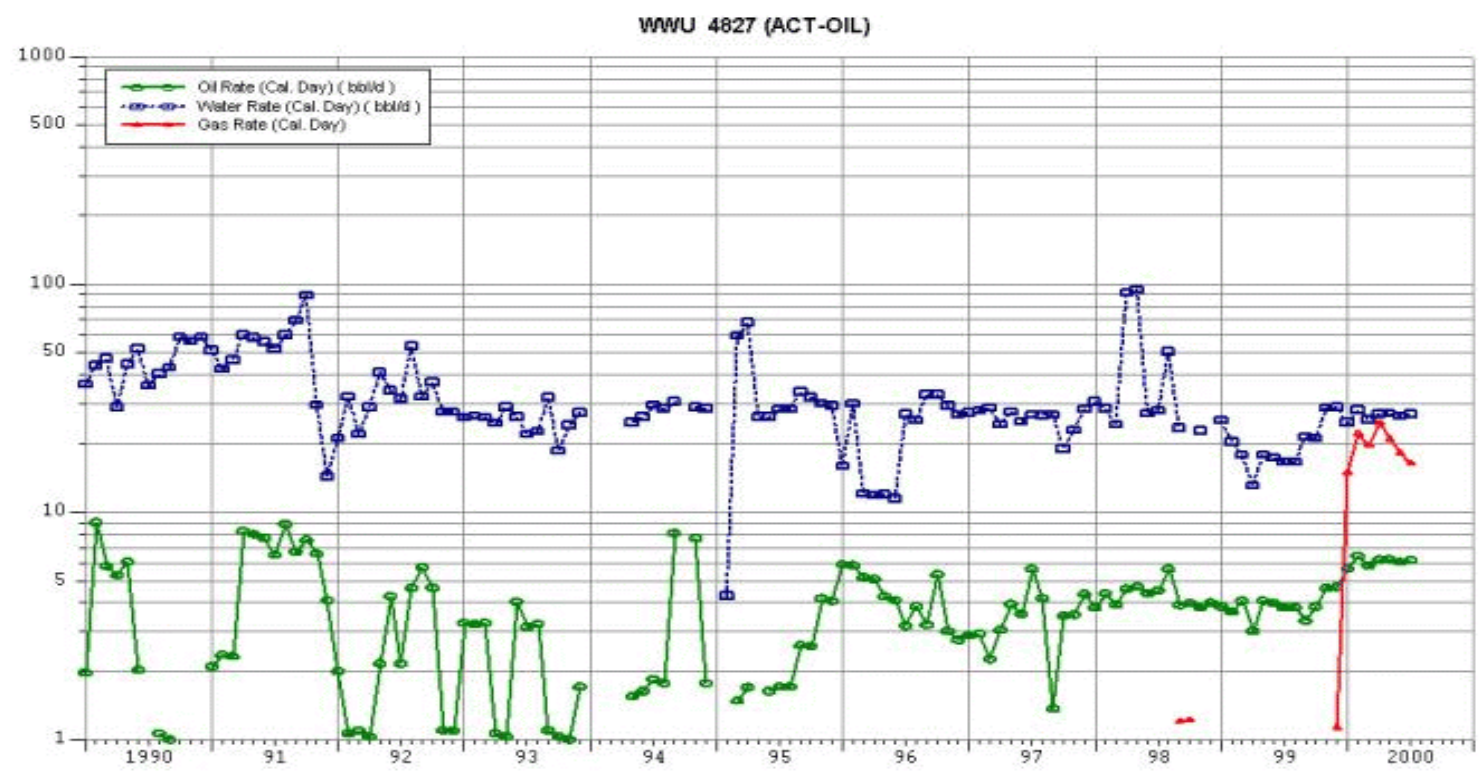

WWU \#4827

Fig. 24 - Rate v. Time Curve - Producer 4827

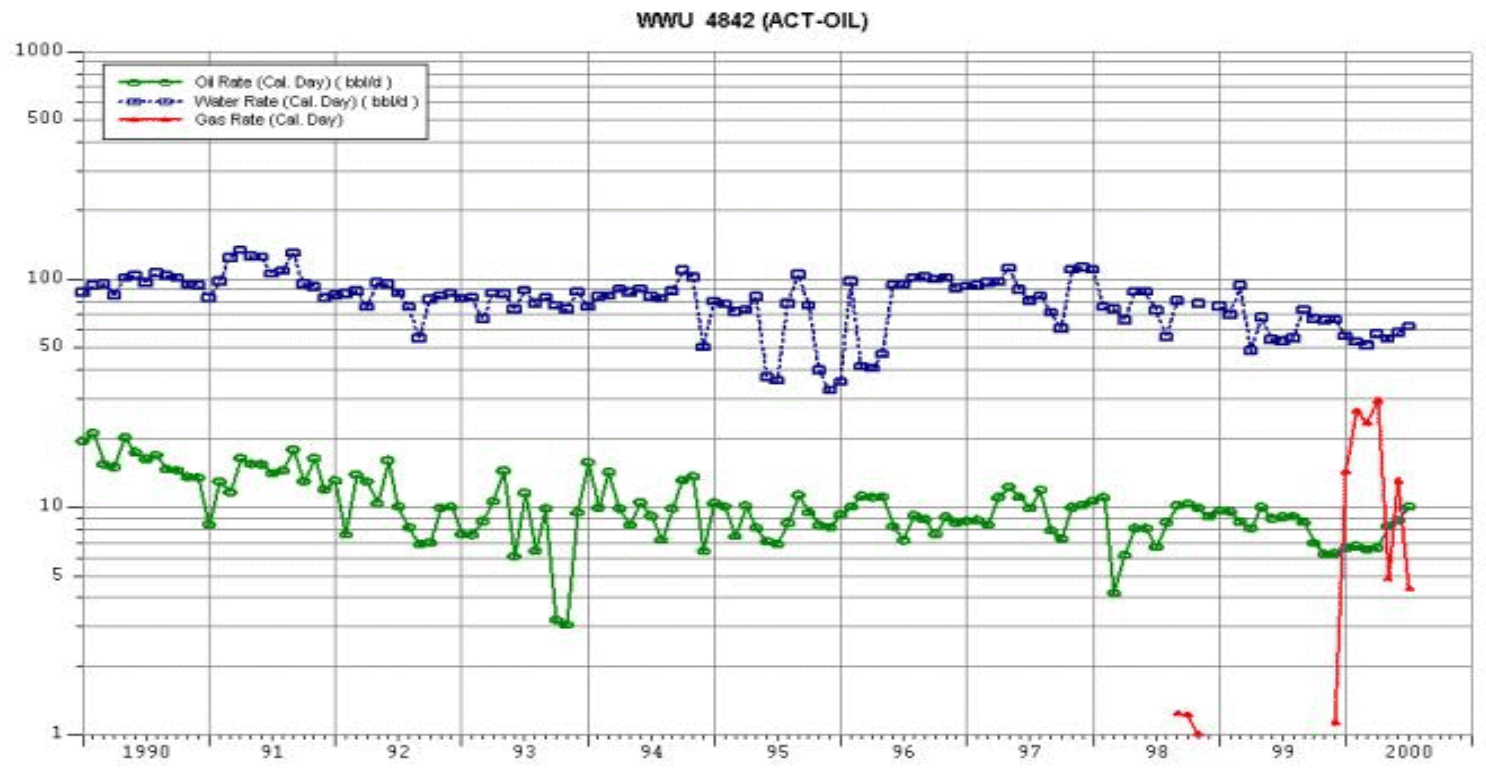

WWU \#4842

Fig. 23 - Rate v. Time Curve - Producer 4842 


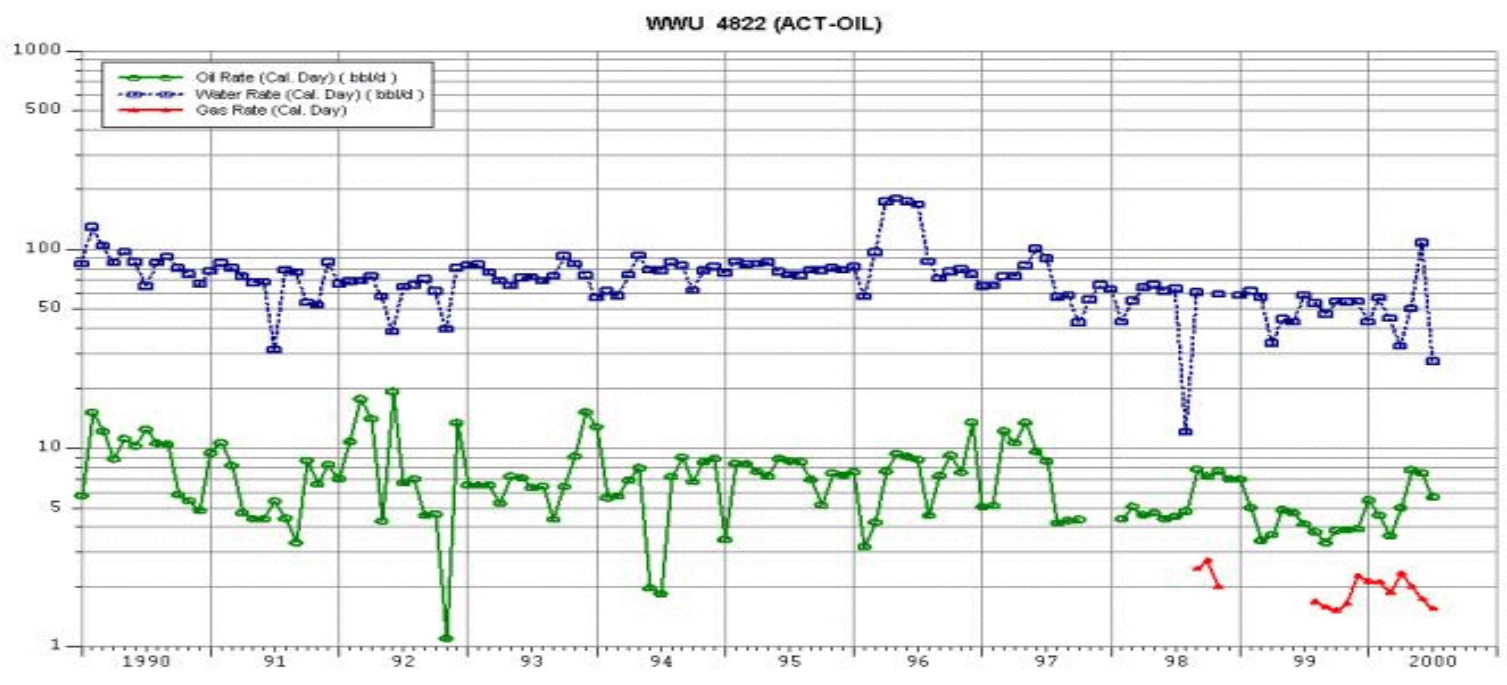

WWU $\# 4822$

Fig. 26 - Rate v. Time Curve - Producer 4822

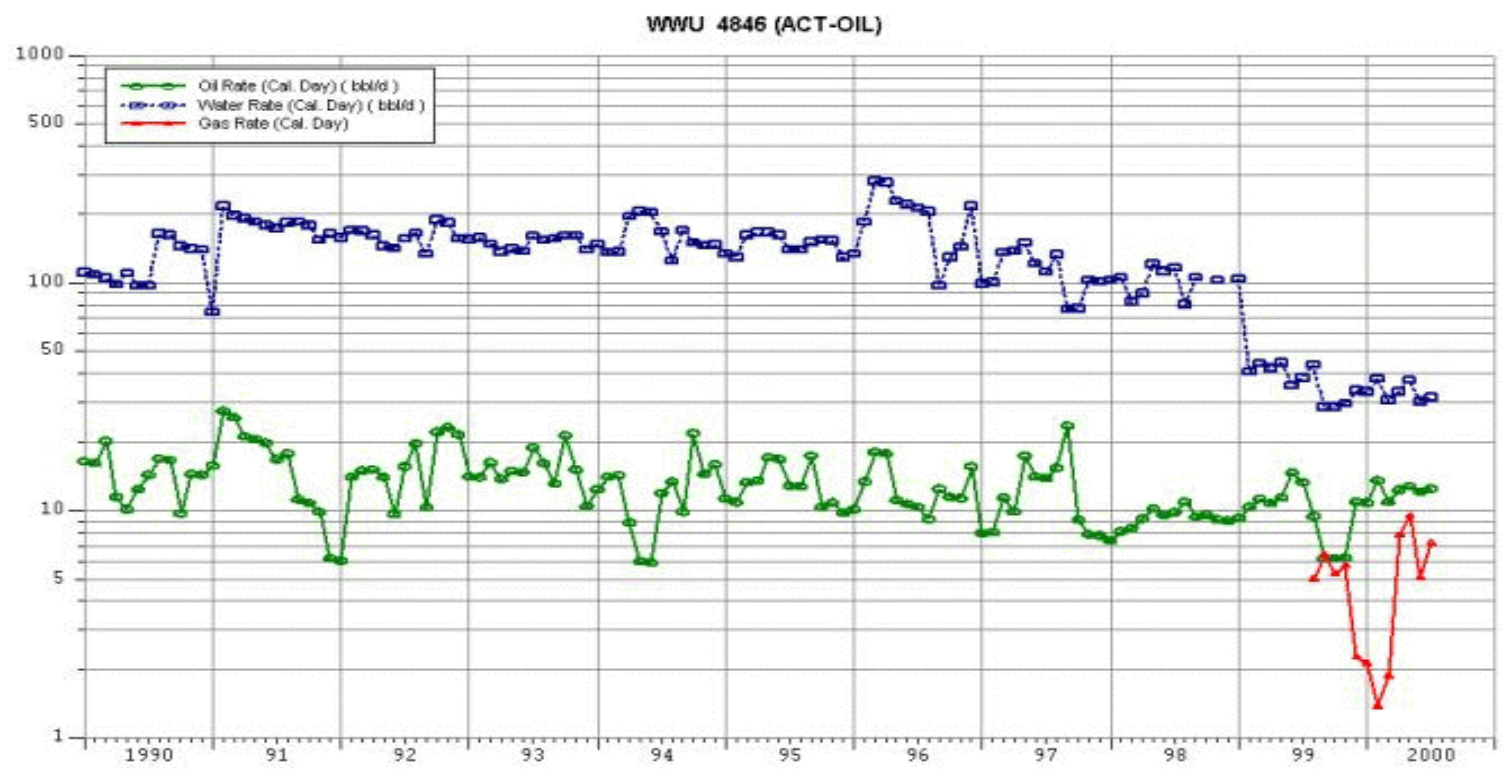

WWU \#4846

Fig. $2 \not$ - Rate v. Time Curve - Producer 4846 


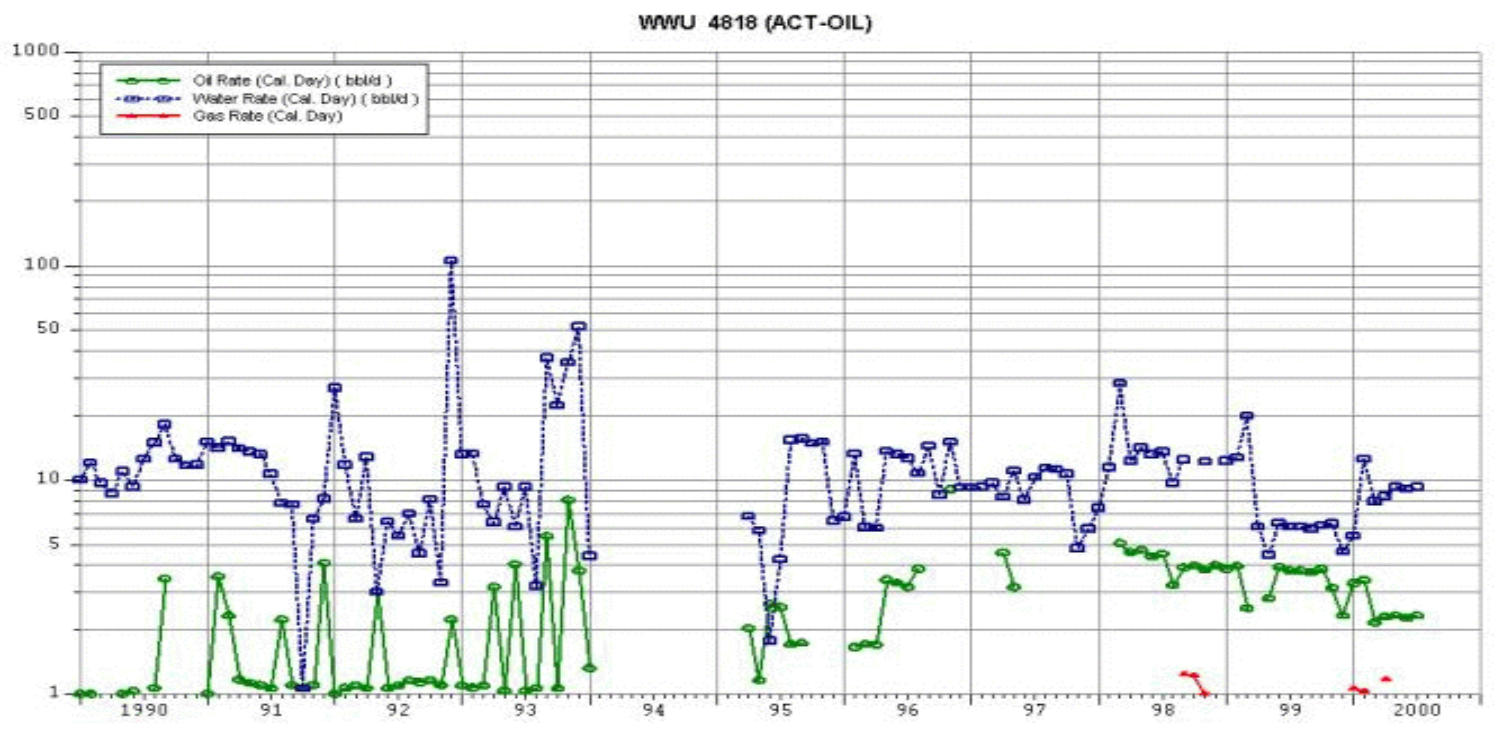

WWU \#4818

Fig. 28 - Rate v. Time Curve - Producer 4818

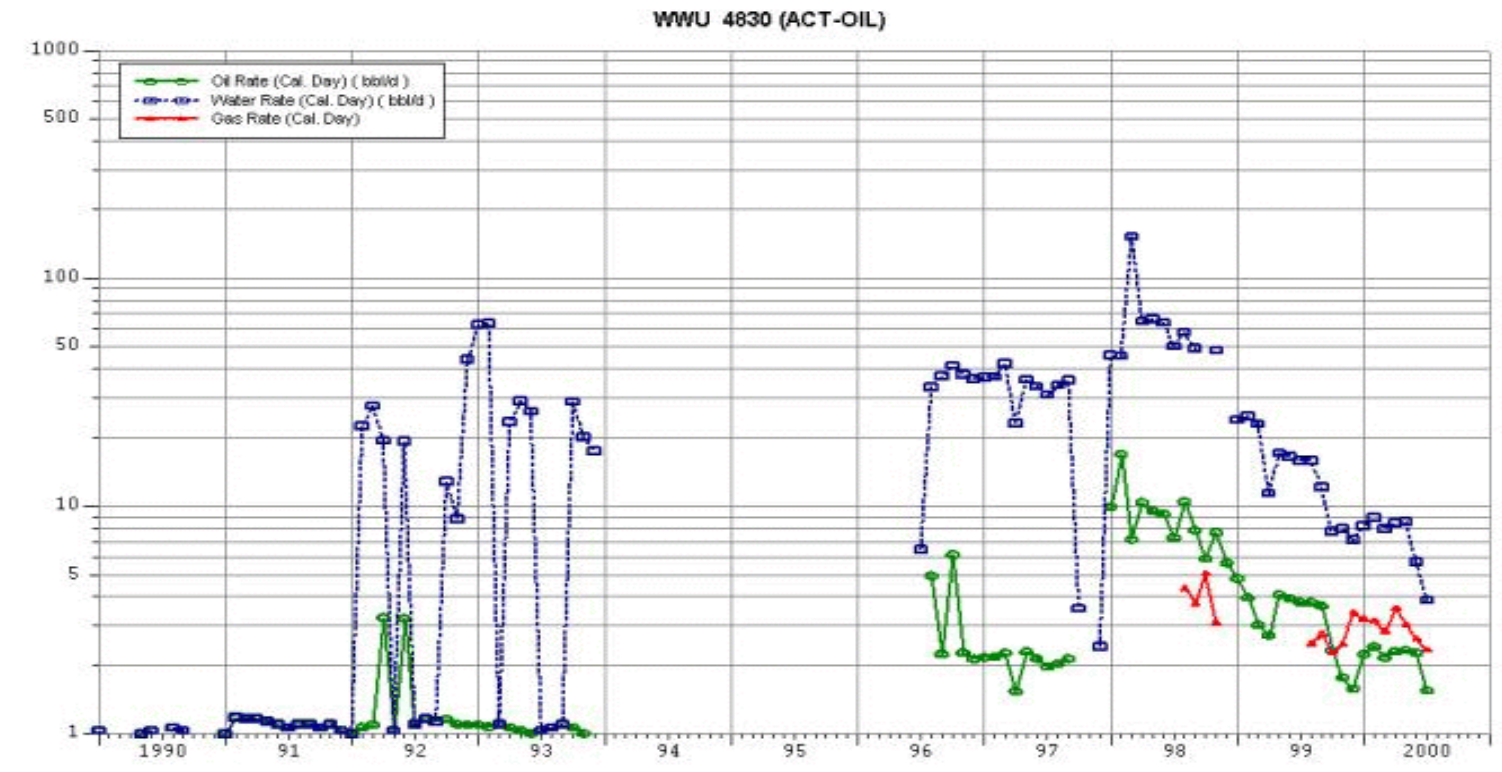

WWU \#4830

Fig. 29 - Rate v. Time Curve - Producer 4830 


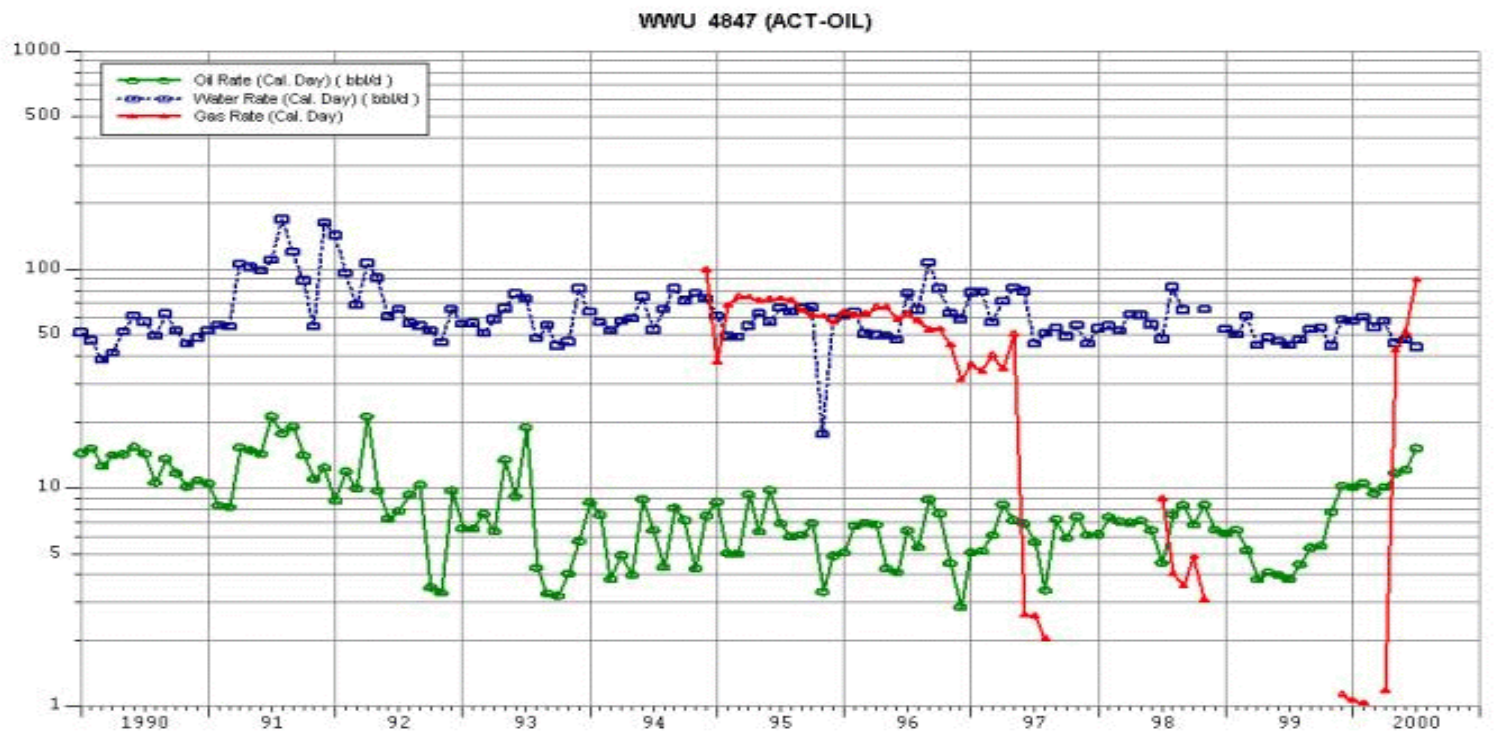

WWU \#4847

Fig. 30 - Rate v. Time Curve - Producer 4847

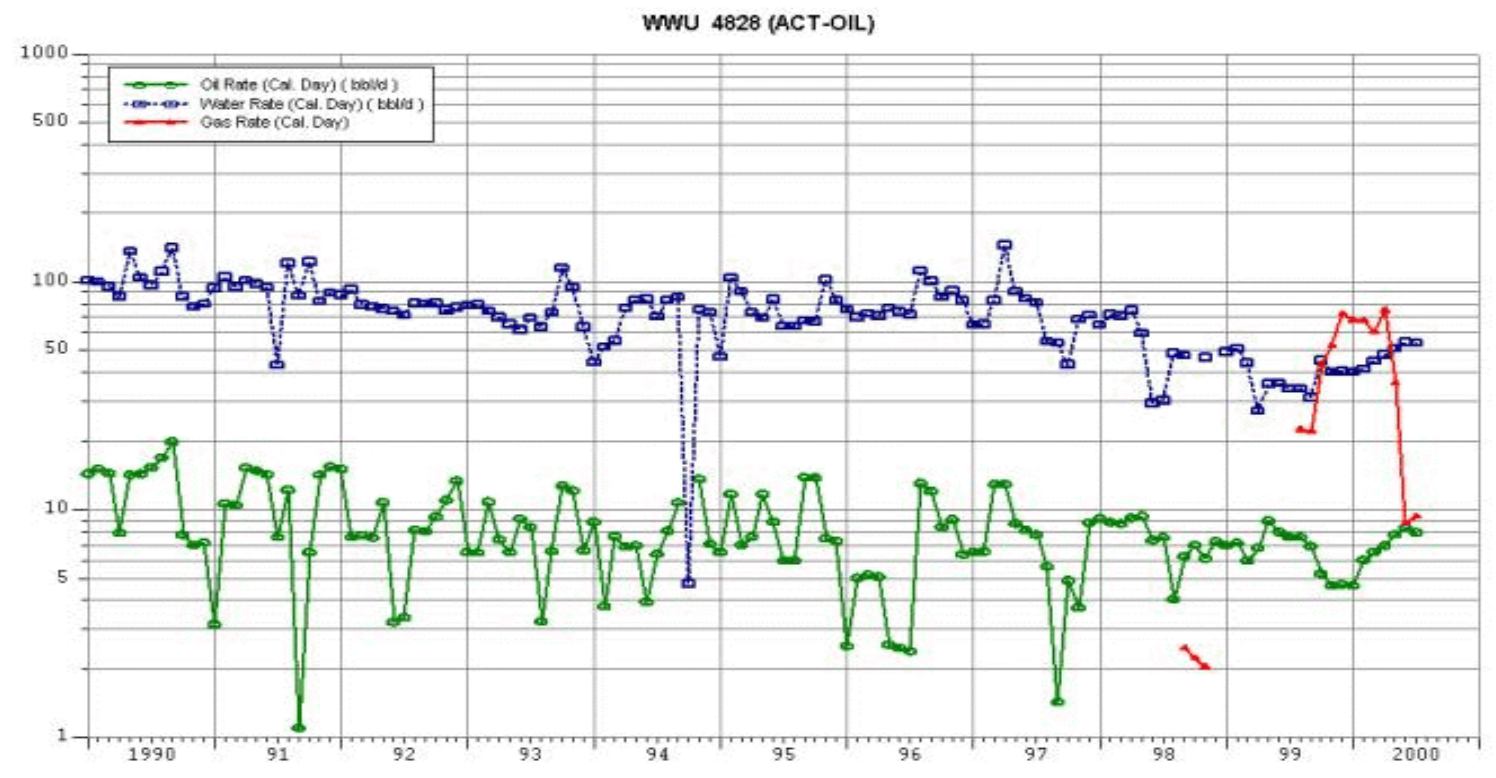

WWU \#4828

Fig. 31 - Rate v. Time Curve - Producer 4828 


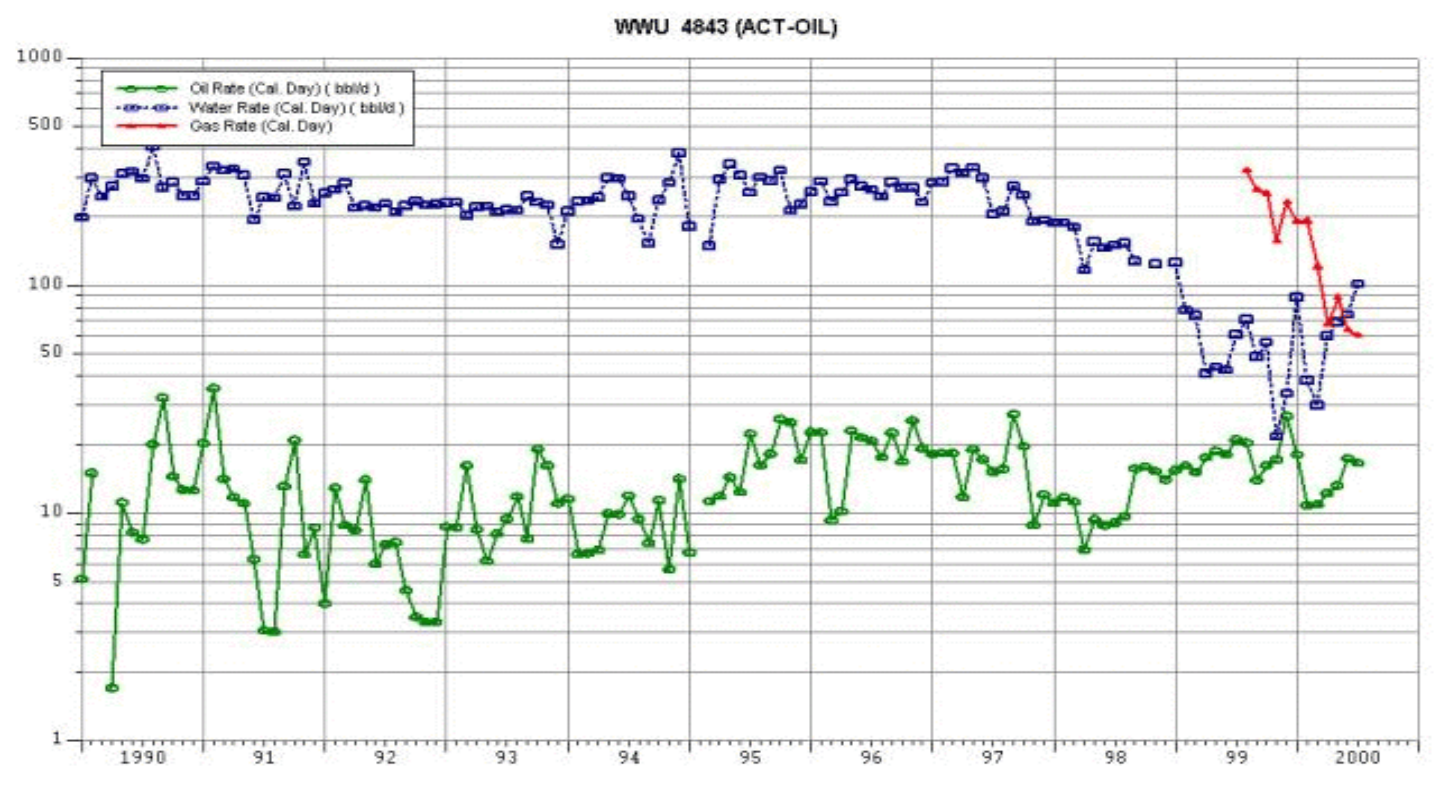

WWU \#4843

Fig. 32 - Rate v. Time Curve - Producer 4843

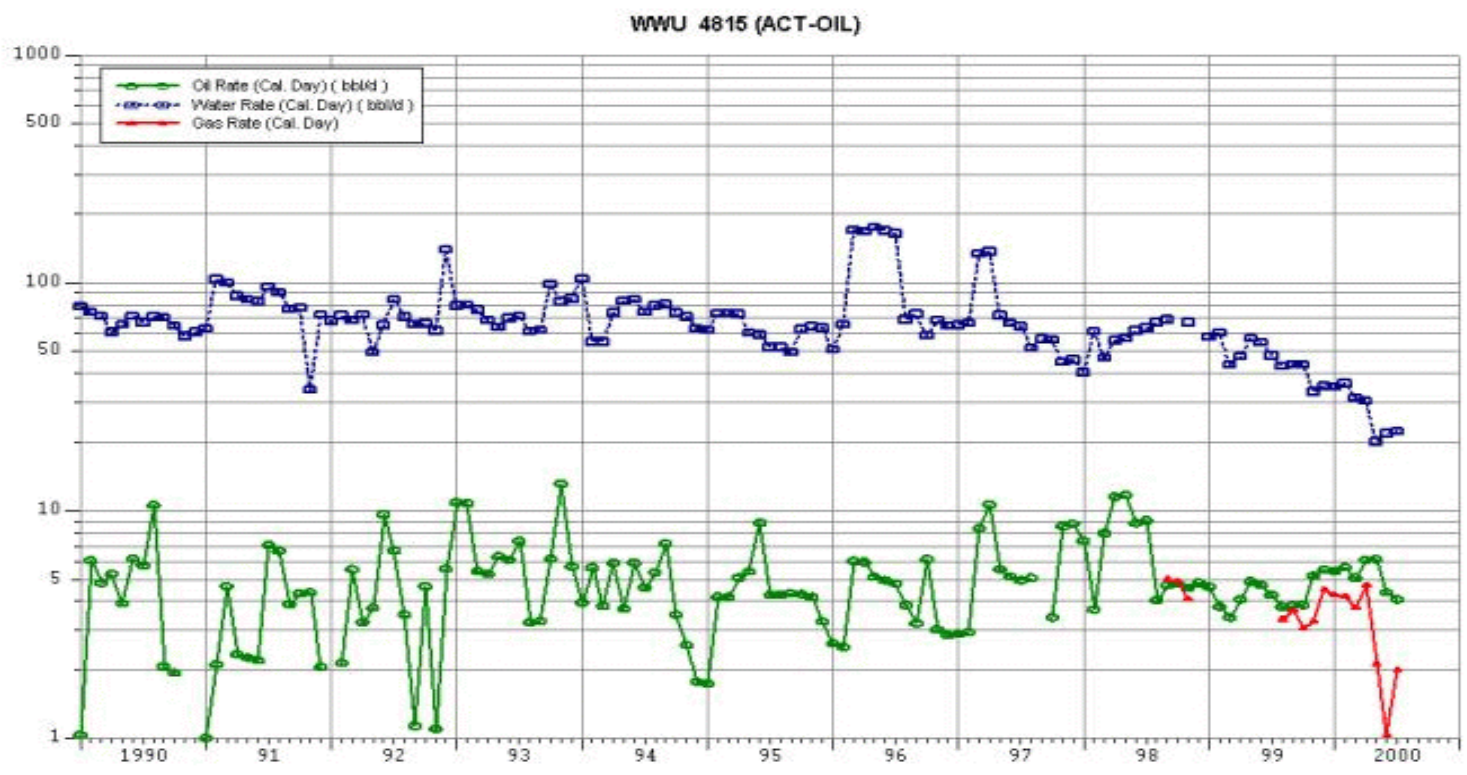

WWU \#4815

Fig. 33 - Rate v. Time Curve - Producer 4815 


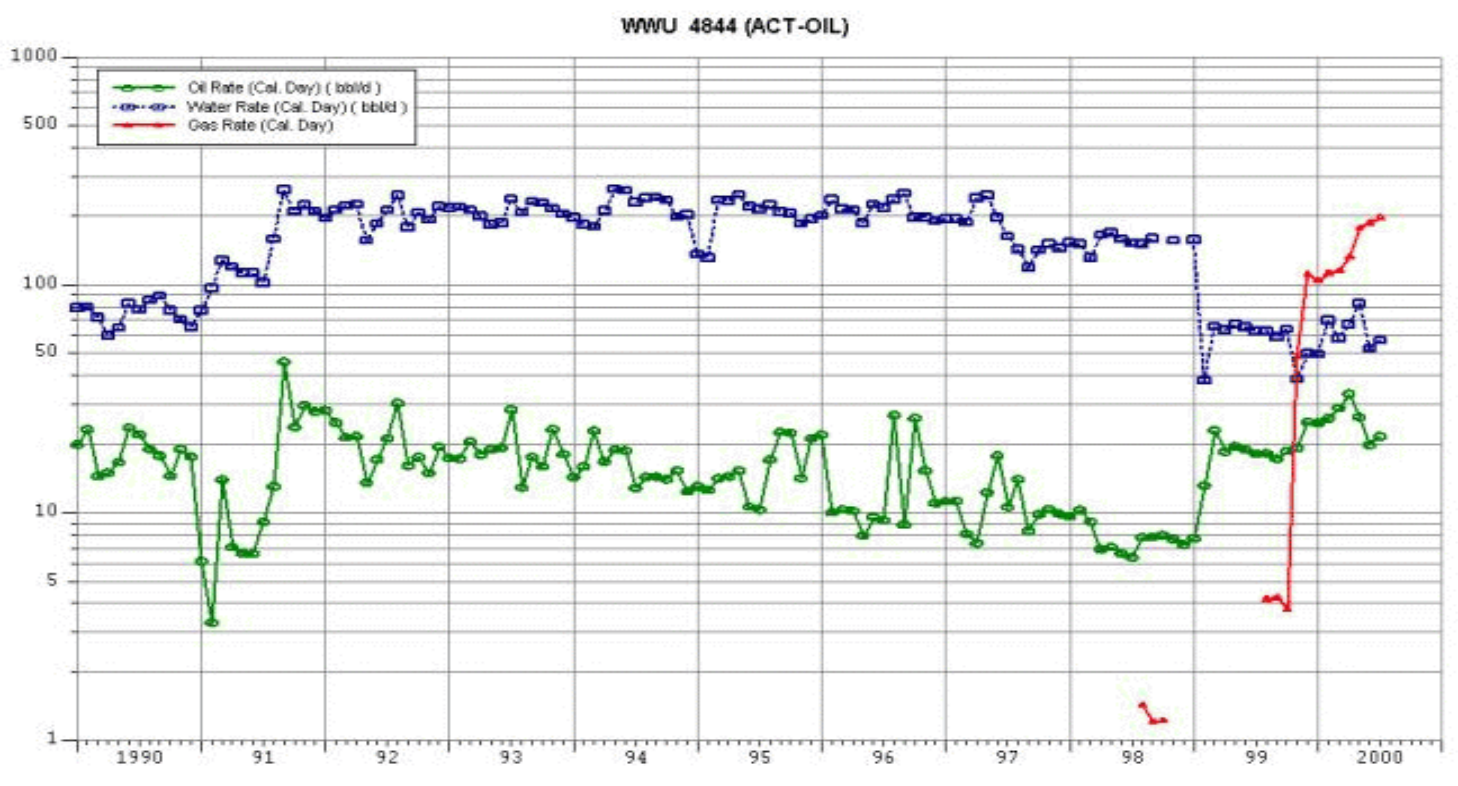

WWU \#4844

Fig. 34 - Rate v. Time Curve - Producer 4844

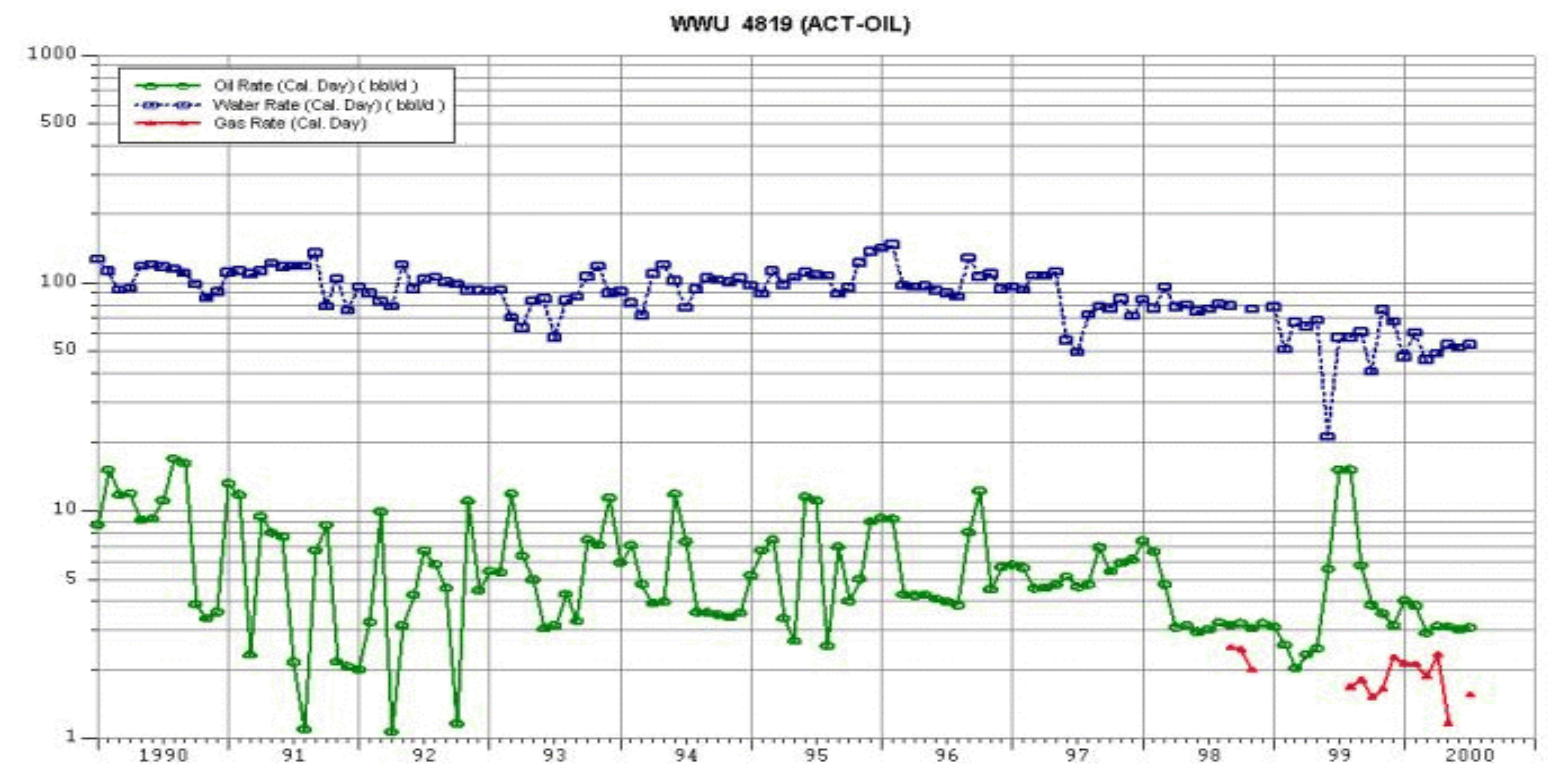

WWU\#4819

Fig. 35 - Rate v. Time Curve - Producer 4819 


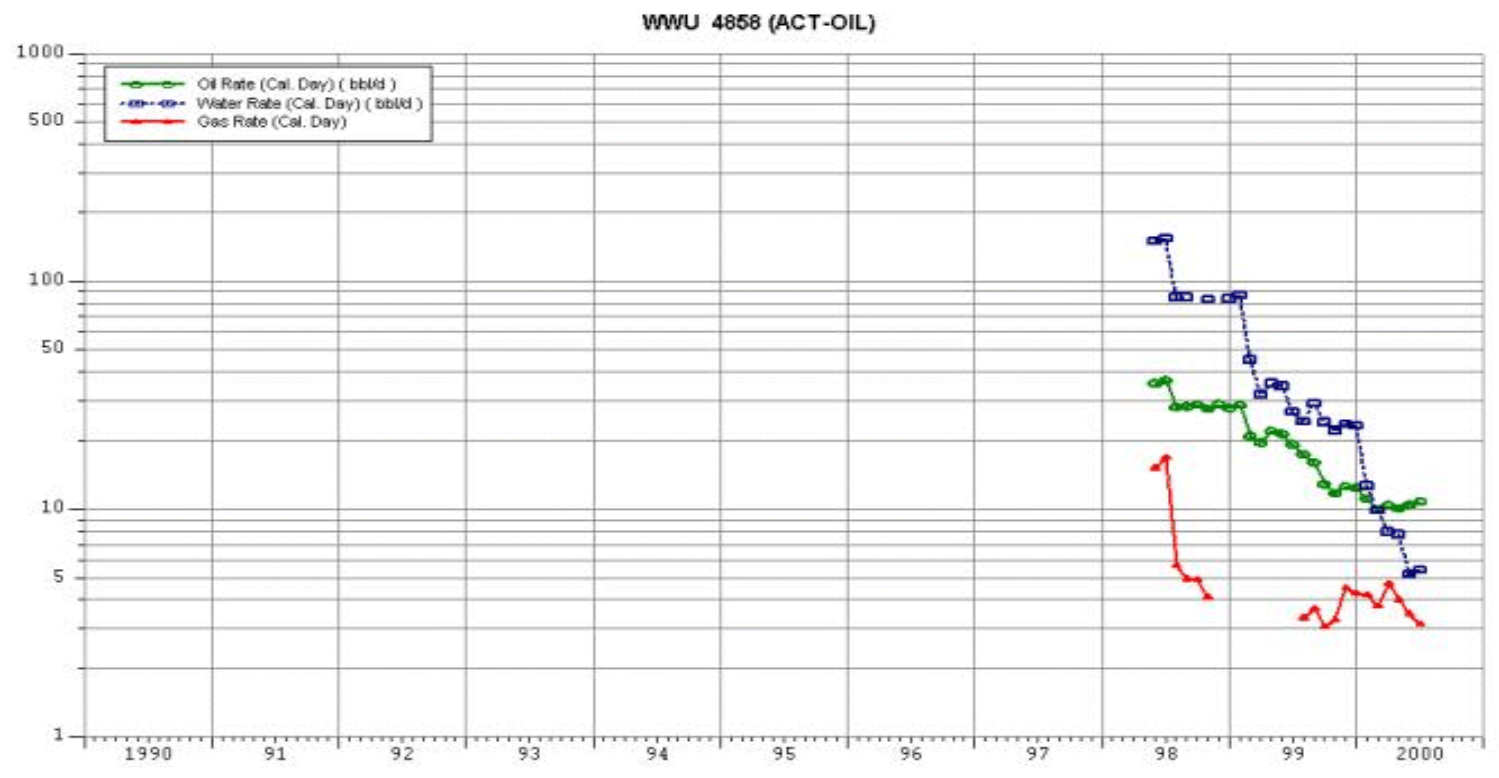

WWU \#4858

Fig. 36 - Rate v. Time Curve - Producer 4858

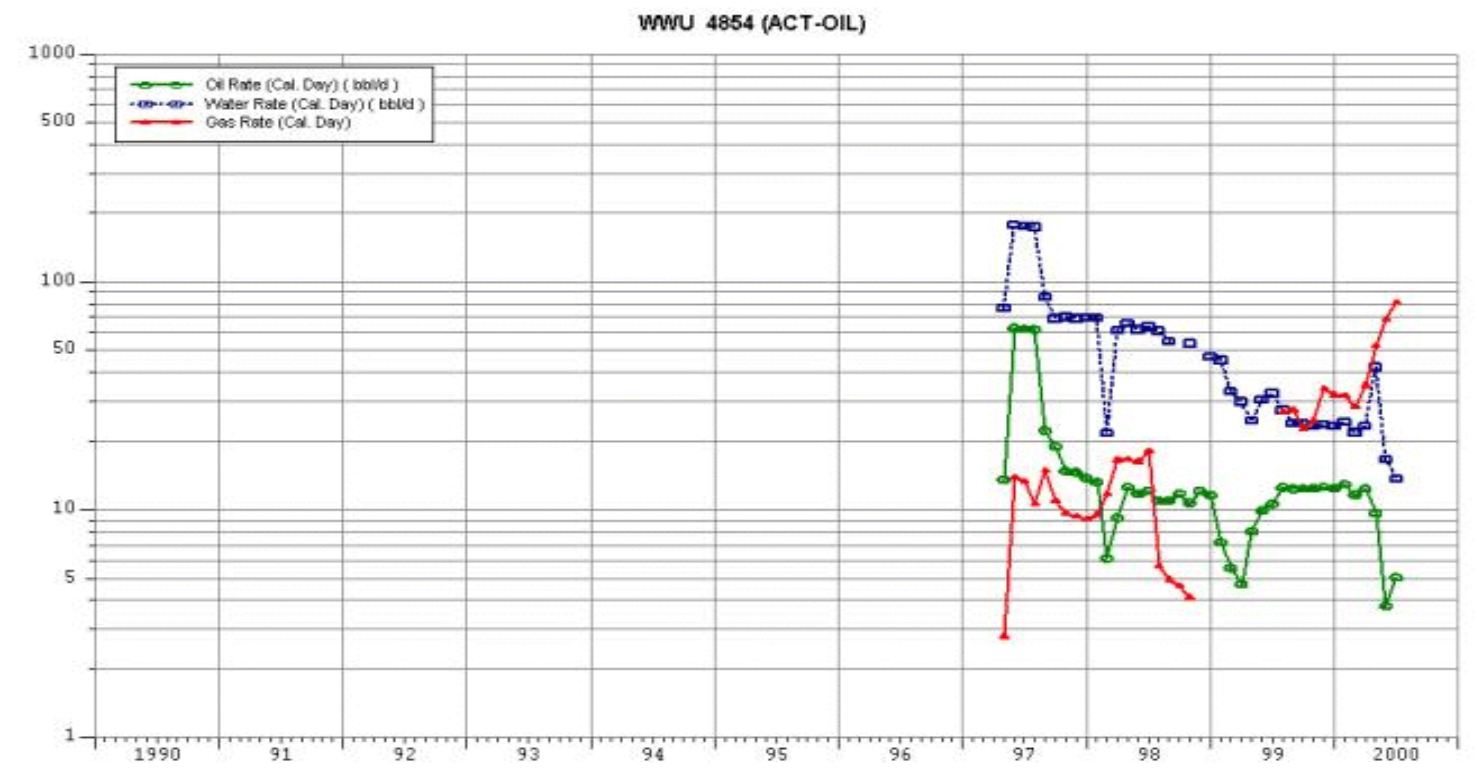

WWU \#4854

Fig. 37 - Rate v. Time Curve - Producer 4854 


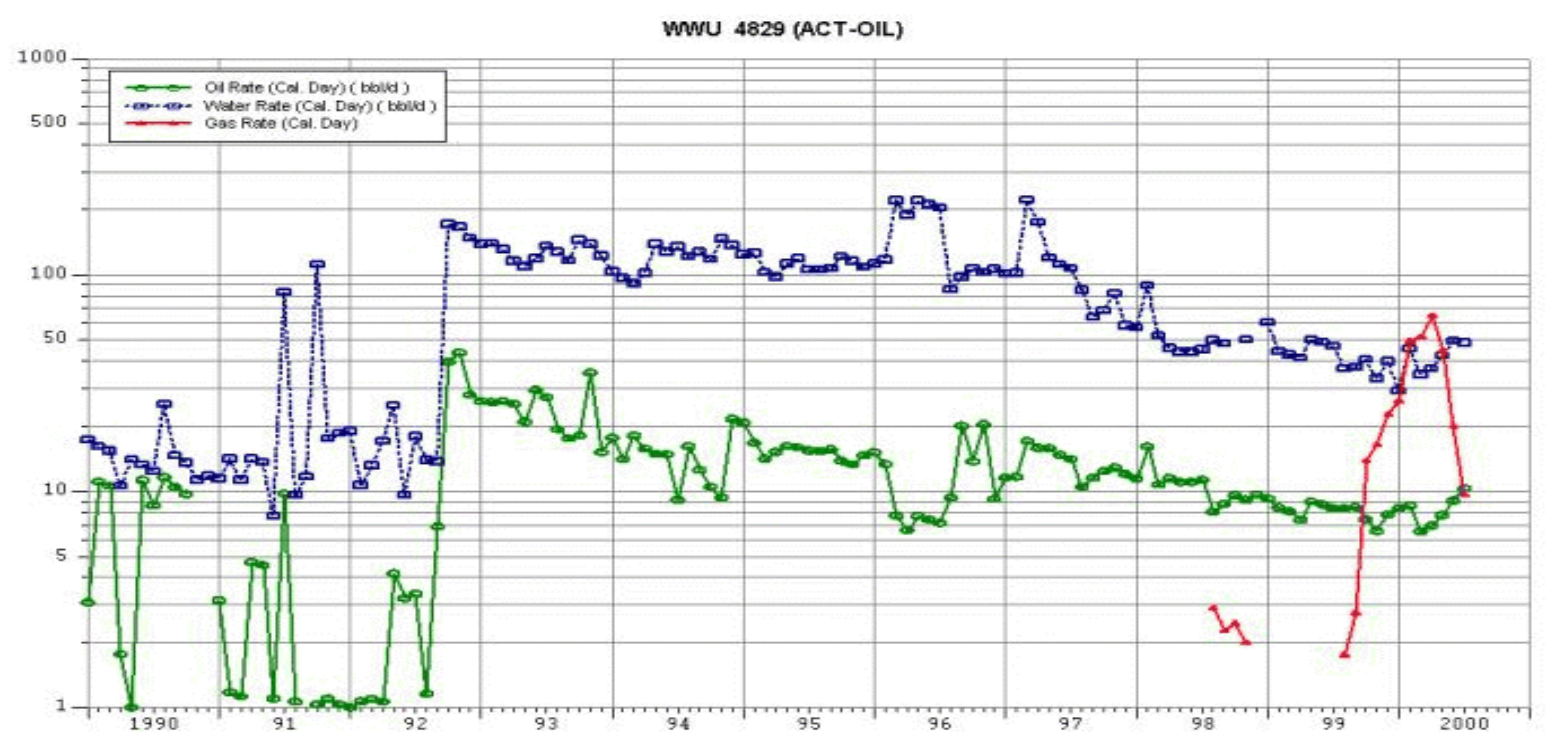

WWU \#4829

66

Fig. 38 - Rate v. Time Curve - Producer 4829

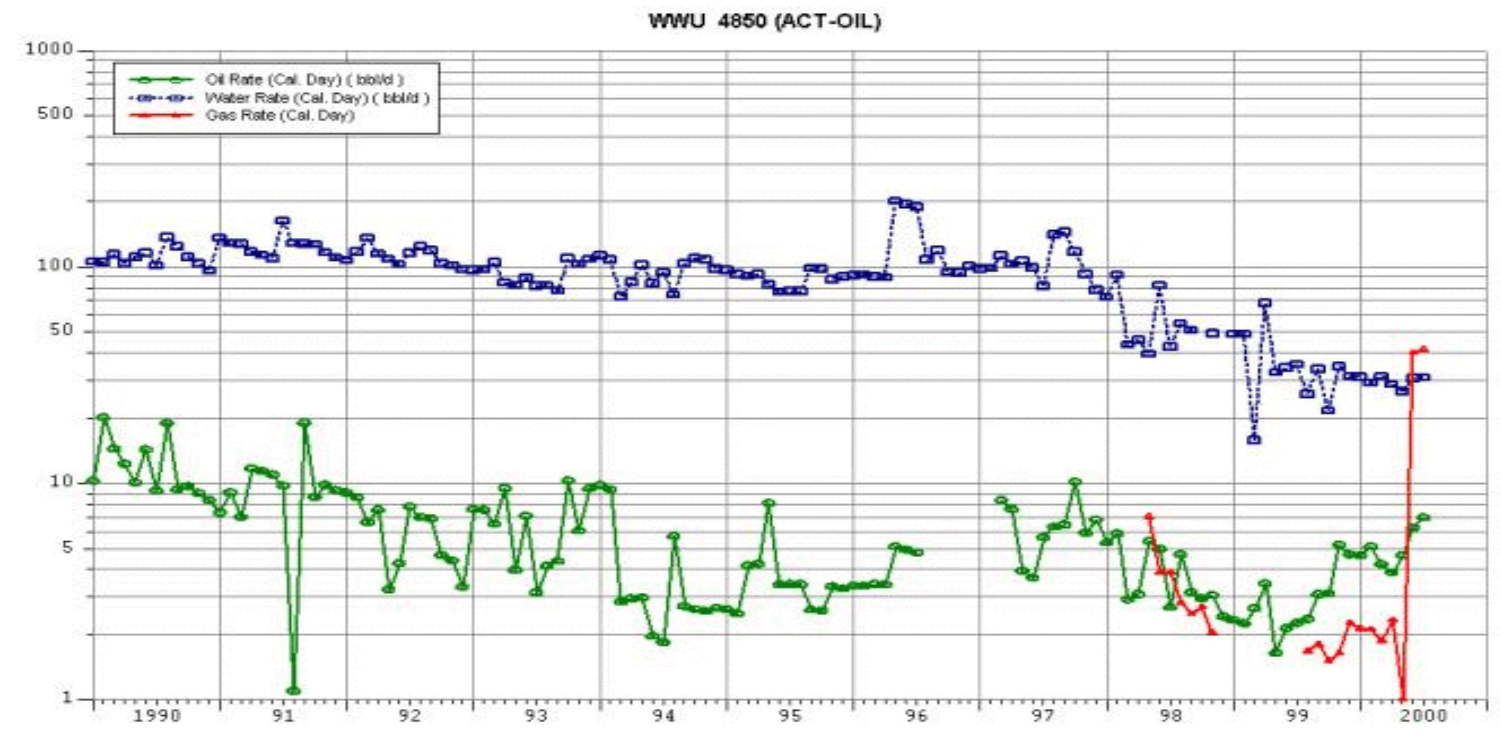

WWU \#4850

Fig. 39 - Rate v. Time Curve - Producer 4850 


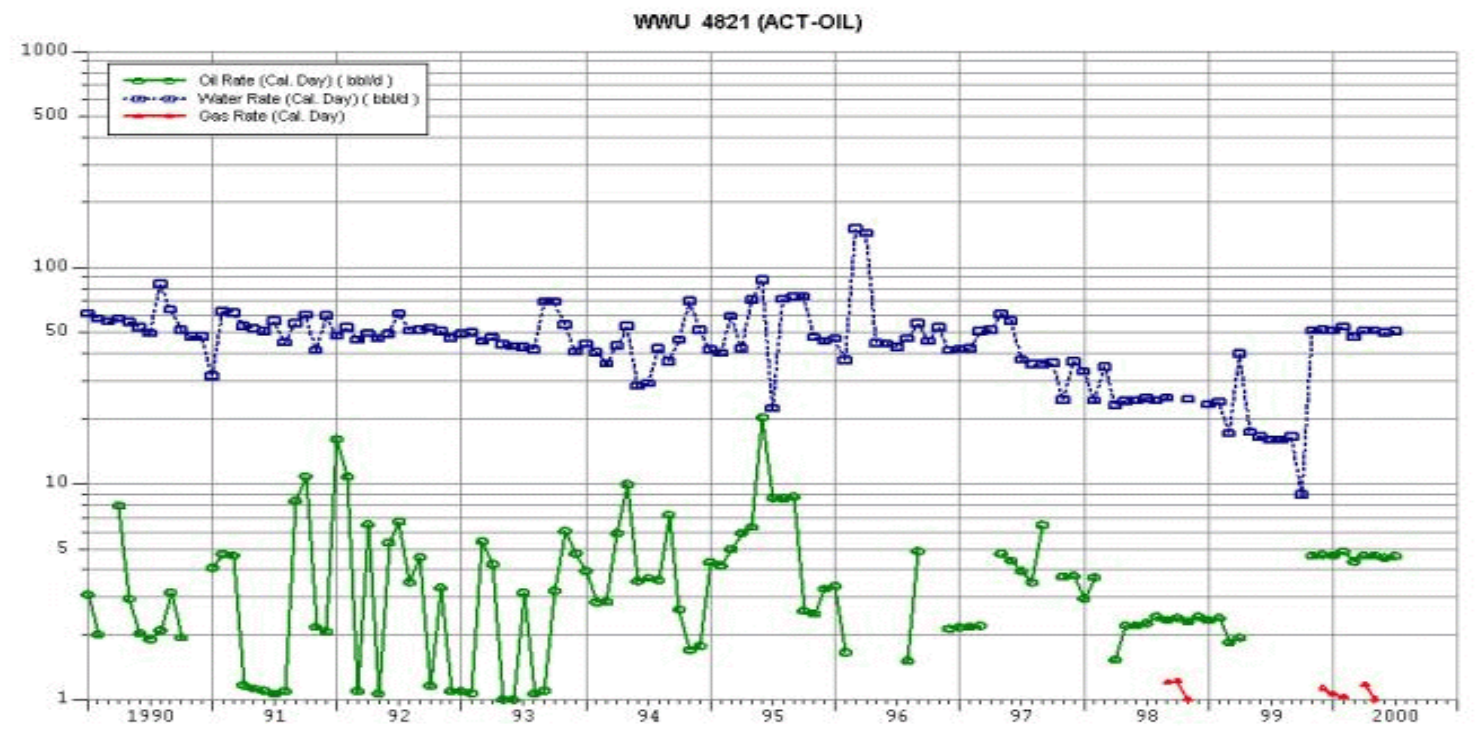

WWU \#4821

Fig. 40 - Rate v. Time Curve - Producer 4821

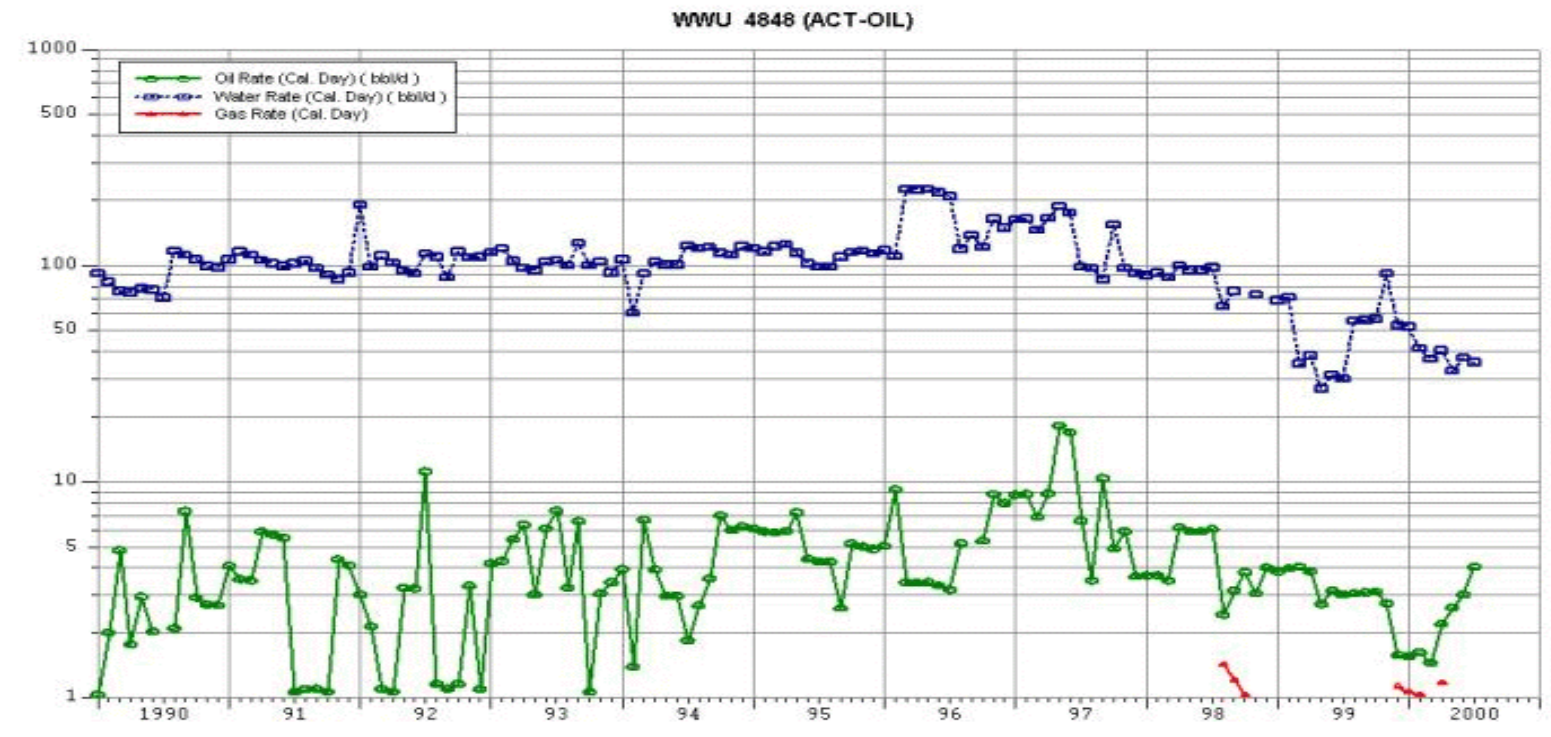

WWU \#4848

Fig. 41 - Rate v. Time Curve - Producer 4848 


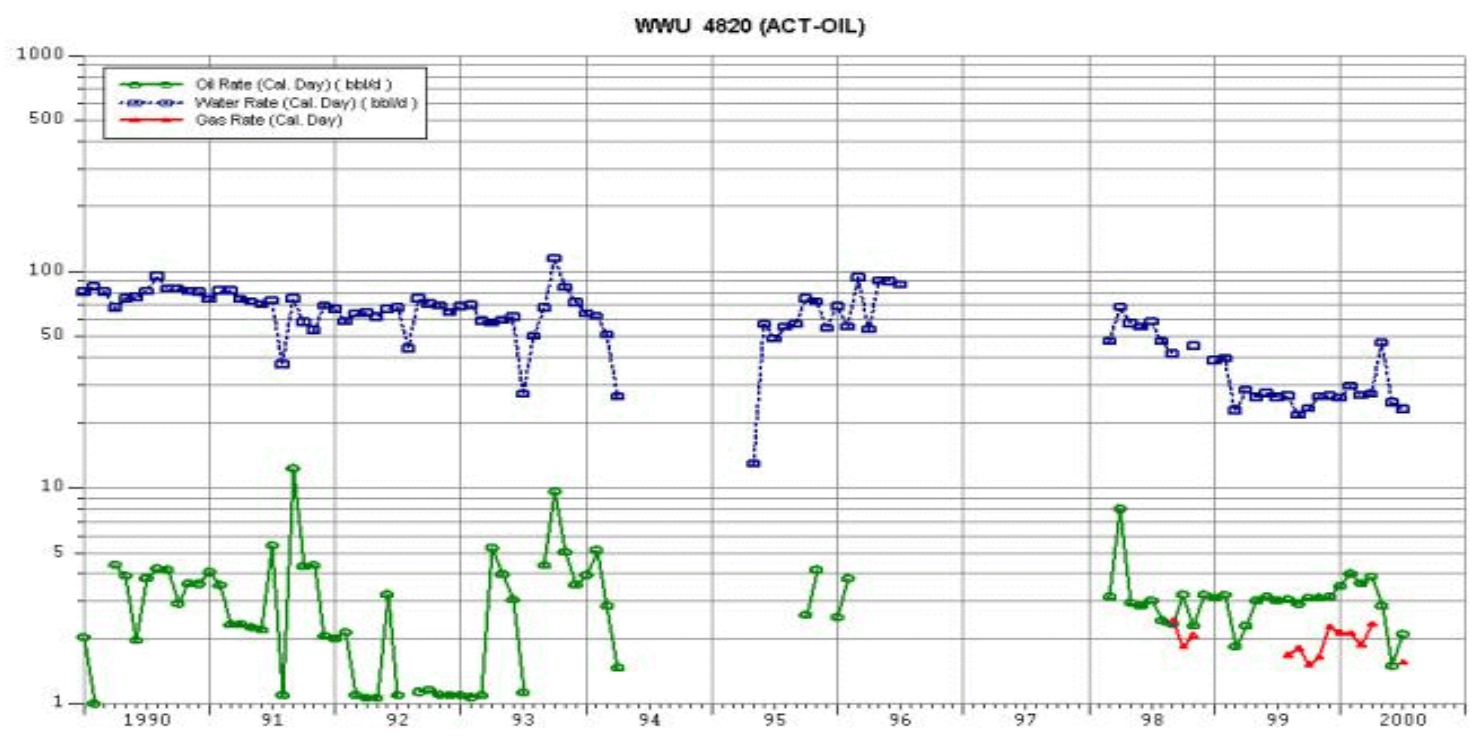

WWU \#4820

Fig. 42 - Rate v. Time Curve - Producer 4820 


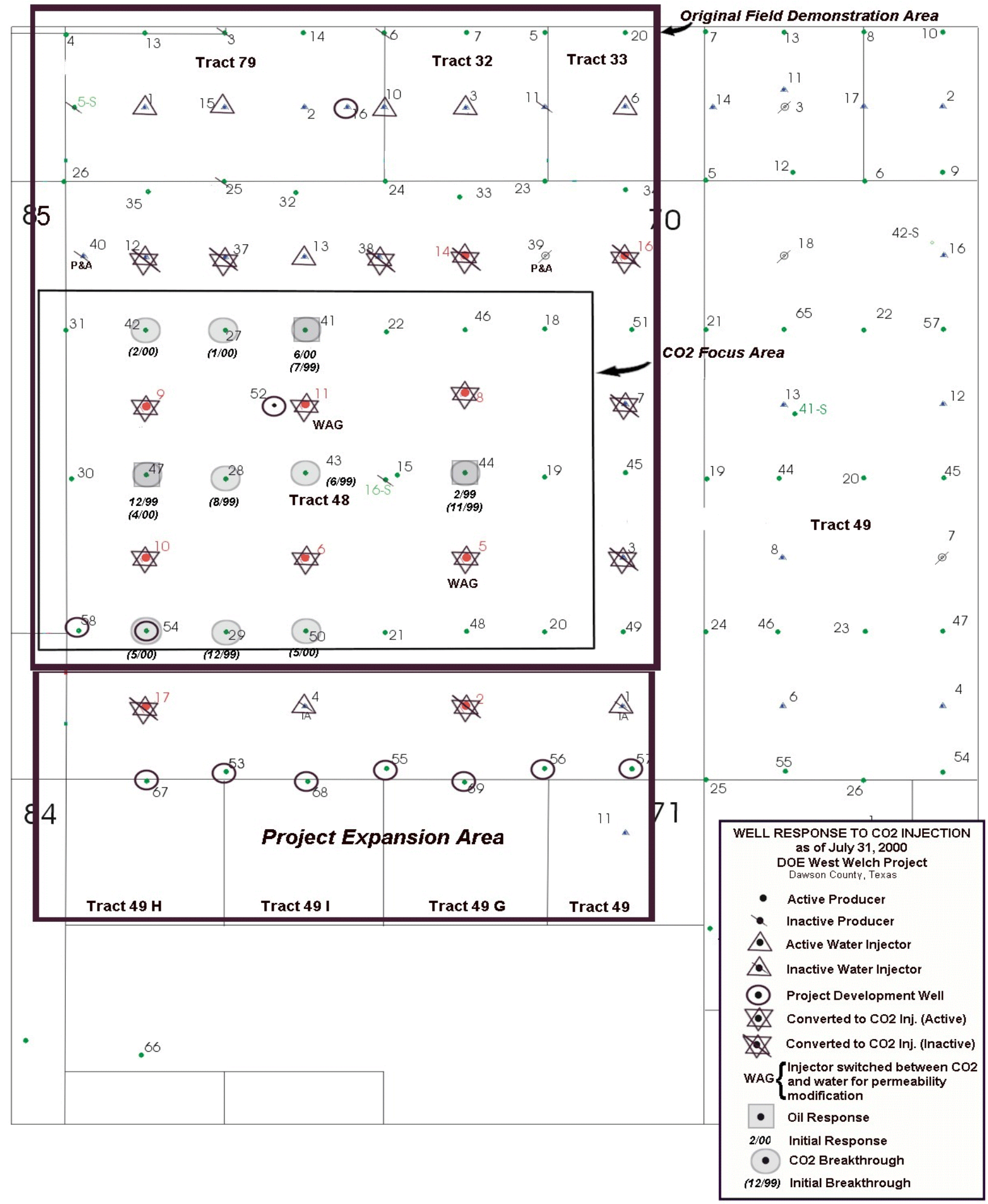

Fig. 43 


\title{
APPENDIX
}

\section{STATEMENT OF WORK}

OXY USA, INC.

\author{
APPLICATION OF RESERVOIR CHARACTERIZATION AND ADVANCED \\ TECHNOLOGY TO IMPROVE RECOVERY AND ECONOMICS IN A LOWER \\ QUALITY SHALLOW SHELF SAN ANDRES RESERVOIR
}

\section{Budget Period I}

In this Budget Period, geologic and geophysical reservoir characterization methods are combined with reservoir engineering and operations engineering methods to develop a reservoir management plan which will improve the economics of advanced secondary recovery and EOR processes.

\section{$\underline{\text { Task } 1.1 \text { - Project Management }}$}

This task will involve the management and administration of all Budget period I activities. The cooperative agreement requirements will be performed in conjunction with the administrative functions necessary to coordinate with producing partners, vendors, subcontractors, consultants and suppliers. A detailed project Management Plan encompassing both Budget Period I and II, including cost, labor and milestone plans will be prepared and submitted in accordance with the Reporting Requirements. All required reports will be prepared and submitted to the DOE in accordance with the Reporting Requirements.

\section{$\underline{\text { Task } 1.2 \text { - NEPA Requirements }}$}

It is anticipated that this project will qualify for a Categorical Exclusion (CX) under the National Environmental Policy Act (NEPA). If it does not, this task, which consists of all activities necessary to secure approval under this act, will be performed.

\section{$\underline{\text { Task } 1.3 \text { - Technology Transfer }}$}

This task will focus on technology transfer of information derived in this study through academic, technical and commercial channels.

\section{Subtask 1.3.1 - Local meetings and Study Groups}

Technical presentations on topics of interest related to this project will be offered to the appropriate forums of engineering, geological and geophysical societies located in the Permian Basin. Once the project is under way, at least one presentation per year will be offered to the various Permian Basin sections/chapters of these societies that meet on a regularly scheduled basis. In addition, at least two presentations per year will be offered to the appropriate technical interest groups such as the Permian Basin SPE Section's Reservoir Engineering Study Group and the Gulf Coast SPE Section's Permian Basin Study Group.

\section{Subtask 1.3.2 - Seminars}

Annual seminars will be held for interested individuals within industry and academia on topics such as reservoir simulation, $\mathrm{CO} 2$ project design, and improving $\mathrm{CO} 2$ economics. Efforts will be made annually to inform interested parties of the availability of these seminars through a mailing list of the targeted audience. With the approval of the DOE, a seminar may be canceled due to insufficient demand. 
Subtask 1.3.3 - Professional Meetings and Publications

Abstracts of papers describing various aspects of this project will be prepared for professional meetings and symposia. Upon acceptance, technical papers will be prepared, presented and offered for publication in appropriate journals as agreed upon with the DOE. Abstracts will be submitted yearly to at least two annual meetings held by the professional/technical societies. Technical papers, including abstracts, for presentation or publication, shall first be submitted to the DOE Document Control Center in draft form and stamped "Draft" or "Preliminary" and will be subject to the review/approval of the DOE TPO. Fifteen (15) calendar days shall be allowed for the DOE review and approval.

\section{Subtask 1.3.4 - Short Course}

A short course on the application of tomography and 3-D seismic to reservoir characterization will be held for interested parties. Efforts will be made to inform interested parties of the availability of this short course through a mailing list of the targeted audience. With approval of the DOE, this short course may be canceled due to insufficient demand.

\section{$\underline{\text { Task } 1.4 \text { - Reservoir Characterization }}$}

The objective of this task is to develop the most accurate reservoir characterization possible. Geologic and geophysical methods such as core analysis and descriptions combined with open hole well logging, and seismic techniques will be used. In addition, engineering methods such as computer simulation, production testing, and production/injection logs will be used. Selection of the methods to be used will be made by the Project Manager, as agreed upon by the DOE, based upon recommendations by the Technical Team.

\section{Subtask 1.4.1 - Update Existing Reservoir Characterization}

The existing reservoir characterization model will be refined and updated as necessary using available data. Particular attention will be paid to refining flow units and between well correlations.

Efforts will be made to develop depositional influences on rock properties.

\section{Subtask 1.4.2 - Observation Wells}

Design, drill and complete two observation wells at appropriate locations in the project area. The well programs will be designed to accomplish data gathering objectives. The wells will be cored within the San Andres Formation and routine core analysis performed with selected samples preserved for special core analysis. A full set of well logs will be run, including gamma ray, porosity, resistivity logs. This data will be incorporated into the existing data for the project area.

\section{Subtask 1.4.3 - Baseline Tomography Survey}

A baseline crosswell tomographic survey will be designed and conducted based on the updated reservoir characterization. This survey will provide equal coverage of both the infilled and non-infilled patterns in the project area and will establish parameters to be used in the tomographic surveys for cyclic huff-andpuff evaluation, as well as evaluation of the first WAG cycle in Budget Period II. The velocity tomograms and cross well reflection displays will be used to refine the interwell interpretation and make adjustments to the reservoir characterization model as necessary. The effectiveness of tomographic surveys in characterizing the geology of the reservoir will be assessed. 


\section{Subtask 1.4 .4 - Injection Survey Data}

Existing injection survey data from injection wells will be examined and compared to tomographic data. Reservoir characterization and flow units will be further refined. Additional injection surveys will be conducted as needed.

\section{Subtask 1.4.5 - 3D Seismic Interpretation}

The interwell reservoir characterization established by the tomography will be transformed to the 3D seismic data which will be extended throughout the field. The effectiveness of using the 3D seismic data for interwell reservoir characterization will be evaluated in the South Welch CO2 pilot area using computer simulation.

\section{Subtask 1.4.6 - Saturation Distributions}

The existing reservoir computer simulation model will be used to determine current saturation distribution and waterflood efficiency through history matching. If the Project Manager, as agreed upon by the DOE, deems it necessary, logs may be run on existing wells in the project area to aid in the determination.

\section{Subtask 1.4.7 - Fracture Geometry}

Techniques, such as pressure fall off, pulse and interference testing, and tiltmeter readings will be used to help determine induced fracture frequency and orientation in injection wells in the demonstration area. Efforts will be made to determine induced fracture properties and their effect on flood efficiencies.

\section{Subtask 1.4.8 - Laboratory Testing Requirements}

Any additional laboratory data, such as wettability, relative permeability, capillary pressures or CO2-oil phase characteristics, necessary to complete the reservoir characterization task will be identified. The appropriate laboratory tests as determined by the Project Manager and agreed upon by the DOE will be conducted on representative samples.

\section{$\underline{\text { Task } 1.5 \text { - Reservoir Management Plan Development }}$}

The objective of this task is to determine a comprehensive reservoir management plan that will maximize the economic recovery in the project area. The plan will address a broad scope of issues: $\mathrm{CO} 2$ flood design, cyclic stimulation, tomographic surveys, fracture treatments, etc. The plan will be approved by the Project Manager and agreed upon the DOE based on the recommendations of the Technical Team.

\section{Subtask 1.5.1 - CO2 Flood Design}

Computer simulation methods will be used to develop the most effective $\mathrm{CO} 2$ flood design and operating plan. Variables such as injection rates, volumes, compositions, and pressures will be studied. The use of propped fractures in injection wells to create a linear flood front will be considered.

\section{Subtask 1.5.2 - Cyclic CO2 Stimulation Evaluation}

Several producers will be selected and subjected to cyclic $\mathrm{CO} 2$ stimulation testing. The response from these wells will be used to develop cyclic $\mathrm{CO} 2$ simulation predictive methods and refine computer modeling of the process. The feasibility of using cyclic stimulation early in a WAG CO2 flood project life as a means of improving flood response time and project economics and as an alternative to a $\mathrm{CO} 2$ injection pilot will be studied. 
Subtask 1.5.3 - Fracture Treatment Design, Testing, and Optimization

Fracture treatments appropriate to creating a linear flood front will be designed. Fracture treatments based on these designs will be tested in two injection wells to determine implementation effectiveness and conformance. The fracture design will be optimized based on the results of these tests and the feasibility of creating a linear flood front will be determined.

\section{Subtask 1.5.4 - Reservoir Management Plan}

A comprehensive reservoir management plan will be developed. This plan shall include appropriate aspects of future operations - $\mathrm{CO} 2$ flood design, cyclic $\mathrm{CO} 2$ stimulation design and timing, tomographic imaging program, fracturing plans, etc. The economics of continued operations will be determined and compared to the expected value of the revised management plan. The enhanced project management requirements will be determined.

Task 1.6 - Facilities Assessment and Design

The suitability of the existing facilities to carry out the reservoir management plan will be assessed. Where inadequacies are determined, designs will be prepared for facility modifications or additions The gauging and tank system and the current artificial lift practices will be assessed to determine if they can handle expected fluid loads. A well producibility and scaling tendency assessment will be made. A CO2 distribution system and an improved gas gathering system will be designed, if needed.

\section{$\underline{\text { Task } 1.7 \text { - Project Continuation }}$}

A Project Evaluation Report describing the results of Budget period I of the project will be prepared. An economic evaluation of the future development of the reservoir, based on Budget period I results, will include a written recommendation whether or not to proceed with Budget period II. If appropriate, application for continuation of the project will be prepared and submitted.

\section{Task 1.8 - Preliminary Data Set}

The goal of this task is to provide a preliminary data set to the DOE at the conclusion of the project to form a project reservoir database for use by the DOE in disseminating information about the project.

The operator will provide the DOE with a preliminary project data set (Reference Attachment C - Report Requirements, Topical Report \#1) to the best of the operator's ability. The data will fall into several categories including: general information; reservoir description; field development history; field production constraints and design logic; evaluation of cost-share project results; environmental and supporting data. These data will be provided in a PC-compatible digital form (both numerical and descriptive text information) whenever practical. Some supporting data may have to be provided as hardcopy masters suitable for reproduction. The preliminary project data set will be limited to data from the defined project area, obtained within the stratigraphic interval of the San Andres Formation targeted for characterization under this project, and to those data obtained under the DOE funded portions of the negotiated agreement for this project. Additional data may be provided at the operator's discretion if the operator deems those data to be important to the interpretation of the project performance and applicability to other shallow shelf carbonate reservoirs.

\section{Budget Period II}

In this Budget Period, the reservoir management plan developed in Budget Period I will be implemented and the results evaluated. 


\section{Task 2.1 - Project Management}

This task is a continuation of activities of Task 1.1. this task will involve the management and administration of all Budget Period II activities, such as the administrative functions necessary for project continuation and coordination, the generation of required reports and statements, and the preparation of a final report.

\section{Task 2.2 - Technology Transfer}

This task, a continuation of a Budget Period I Task, will focus on technology transfer of information derived in this study through academic, technical and commercial channels.

\section{Subtask 2.2.1 - Local Meetings and Study Groups}

Technical presentations on topics of interest related to this project will be offered to the appropriate forums of engineering, geological and geophysical societies located in the Permian Basin. Once the project is under way, at least one presentation per year will be offered to the various Permian Basin sections/chapters of these societies that meet on a regularly scheduled basis. In addition, at least two presentations per year will be offered to the appropriate technical interest roups such as the Permian Basin SPE Section's Reservoir Engineering Study Group and the Gulf Coast SPE Section's Permian Basin Study Group.

\section{Subtask 2.2.2 - Seminars}

Annual seminars will be held for interested individuals within industry and academia on topics such as reservoir simulation, $\mathrm{CO} 2$ project design, and improving $\mathrm{CO} 2$ economics. Effort will be made annually to inform interested parties of the availability of these seminars through a mailing list of the targeted audience. With the approval of the DOE, a seminar may be canceled due to insufficient demand.

\section{Subtask 2.2.3 - Professional Meetings and Publications}

Abstracts of papers describing various aspects of this project will be prepared for professional meetings and symposia. Upon acceptance, technical papers will be prepared, presented and offered for publication in appropriate journals as agreed upon with the DOE. Abstracts will be submitted yearly to at least two annual meetings held by the professional/technical societies. Technical papers, including abstracts, for presentation or publication, shall first be submitted to the DOE Document Control Center in draft form and stamped "Draft" or "Preliminary" and will be subject to the review/approval of the DOE TPO. Fifteen (15) calendar days shall be allowed for the DOE review and approval.

\section{$\underline{\text { Task } 2.3 \text { - Project Area Preparation }}$}

this task consists of all activities necessary to prepare the project area for initiation and operation of the reservoir management plan developed in Budget Period I. The following subtasks are anticipated.

\section{Subtask 2.3.1 - Update Existing Reservoir Characterization}

The existing reservoir characterization model will be refined and updated as necessary using any new data that have become available.

\section{Subtask 2.3.2 - Well Workovers}

Remedial well work necessary to implement the reservoir management plan, such as recompletions and conversions, will be performed. 


\section{Subtask 2.3.3 - Fracture Stimulation}

Based on the design developed in Budget Period I, fracture stimulations will be performed on selected injection wells. Fracture treatments for producing wells will be identified and performed as necessary.

\section{Subtask 2.3.4 - Facilities Upgrade}

Facility modifications and upgrades identified in Budget Period I will be performed. A CO2 distribution system will be constructed.

Subtask 2.3.5 - Water Injection

Water injection will be adjusted to follow the reservoir management plan. Pressures and rates will be monitored.

Task 2.4 - Reservoir management Plan Initiation and Operations

Subtask 2.41 - CO2 Injection

The proposed $\mathrm{CO} 2$ flood design will be initiated and operated in the project area. Selected producers will be cyclically stimulated with $\mathrm{CO} 2$. Production response and associated expenses will be recorded.

\section{Subtask 2.42 - Tomography Surveys for Front Tracking}

A tomography survey will be performed near end of firstCO2 cycle of injection in baseline areas. The data from this survey will be used to assess the use of tomography in determining $\mathrm{CO} 2$ flood frond advancement and cyclic $\mathrm{CO} 2$ recoveries. If warranted, additional surveys will be designed and performed as needed during the project life.

\section{Subtask 2.4.3 - Project Evaluation}

Upon completion of Budget Period II, the project performance will be analyzed and a final report issued containing both technical and economical conclusions and recommendations for the application and enhancement of the processes tested by the project. Specific items to be reported on include an economic projection of project expansion and the effect of induced fractures in injection wells on floodfront shape and sweep efficiency in comparison to infill injection wells.

\section{$\underline{\text { Task } 2.5 \text { - Final Data Set }}$}

The goal of this task is to provide a final data set to the DOE at the conclusion of the project to form a project reservoir database for use by the DOE in disseminating information about the project.

The operator will provide the DOE with a final project data set (Reference Attachment C - Reporting Requirements, Topical Report \#2) to the best of the operator's ability. The data will fall into several categories including: general information; reservoir description; field development history; field production constraints and design logic; evaluation of cost-share project results; environmental and supporting data. These data will be provided in a PC-compatible digital form (both numerical and descriptive text information) wherever practical. Some supporting data may have to be provided as hardcopy masters suitable for reproduction. The final project data set will be limited to data from the defined project area, obtained within the stratigraphic interval of the San Andres Formation targeted for characterization under this project, and to those data obtained under the DOEfunded portions of the negotiated agreement for this project. Additional data may be provided at the operator's discretion if the operator deems those data to be important to the interpretation of the project performance and applicability to other shallow shelf carbonate reservoirs. 